\title{
Occupation-Based Volunteer Training Program to Increase Social Engagement for Residents with Dementia in Skilled Nursing Facilities
}

\author{
Nhat Hoang \\ Kiyomi Kuroda \\ Victoria Ramia \\ Kelsy Wallace
}

A culminating capstone project submitted to the faculty of Dominican University of California in partial fulfillment of the requirements for the degree of Master of Science in Occupational Therapy

Dominican University of California

San Rafael, CA

May 2021 
Copyright (C) Nhat Hoang, Kiyomi Kuroda, Victoria Ramia, Kelsy Wallace 2020. All rights reserved 


\begin{abstract}
The population of individuals with dementia (IwD) is increasing, and IwD are often admitted into skilled nursing facilities (SNFs) due to greater need for care (Alzheimer's Association, 2020b). Admittance leads to social isolation as a result of decreased engagement in co-occupations. Co-occupations are occupations, or meaningful activities necessary for wellbeing and survival, that are performed with others (American Occupational Therapy Association [AOTA], 2014). IwD exhibit behaviors and symptoms that create challenges for family caregivers to engage in co-occupations (Ono et al., 2014). Without guidance or support, family members or volunteers may be less likely to visit or facilitate quality visits, impacting the quality of life of the IwD. Current visitor programs lack occupational therapy consultation for person-centeredness and comprehensiveness in communication and activities-based training.
\end{abstract}

Heart to Heart volunteer program promotes engagement in social occupations for IwD in SNFs. Heart to Heart provides an occupational therapy perspective and resources for SNFs to implement a comprehensive occupation-based volunteer program. Heart to Heart includes a program implementation guide to outline the recruitment, education, and equipment of volunteers with knowledge and tools to effectively facilitate co-occupations. The program also provides digital and in-person training for communication strategies and activity adaptation appropriate for remaining abilities at various stages of dementia. Additionally, Heart to Heart supplies volunteers with a client profile and activity box to optimize meaningful and individualized visits. This program aims to increase quality and frequency of visits by enhancing volunteer knowledge and skills in dementia. With increased volunteer competency, confidence, and satisfaction, the Heart to Heart volunteer program will ultimately decrease social isolation for improved quality of life for SNF residents with dementia. 


\section{Acknowledgment}

We would like to thank Dr. Gina Tucker-Roghi, our thesis advisor, for her continuous guidance and insight throughout this process. We would also like to thank JB Chua, Cason Bush, and the staff at Summerfield Healthcare Center for collaborating with us in the Heart to Heart volunteer program. In addition, we would like to thank Dr. Susan Morris for being our second reader for our proposal, as well as Tina Hand with the California Association of Health Facilities, and Amanda Grace with Ensign Services for evaluating our program materials for feasibility.

We would like to thank the California Foundation of Occupational Therapy (CFOT) and Ensign Services, Inc. (a network of affiliated facilities that provide post-acute rehabilitation services) for the seed money that funded this program. The grant money covered the expenses of printing client profile, volunteer forms, volunteer handbook, and the implementation guide. The grants also fund an implementation guide template, and supplies for the activity boxes. The development of the Heart to Heart online training was supported by the Health Resources and Services Administration (HRSA) of the U.S. Department of Health and Human Services (HHS) as part of a four year Geriatric Academic Career Award for Dr. Tucker-Roghi, totaling \$300,000 with zero percent funding from non-governmental sources. The contents are those of the author(s) and do not necessarily represent the official views of, nor an endorsement, by HRSA, HHS, or the U.S. Government.

Lastly, we would like to thank our friends and family for their constant love and support throughout this academic journey. 
Table of Contents

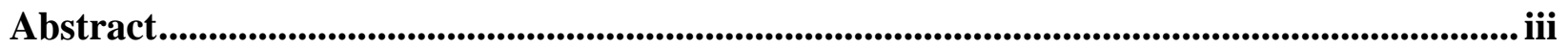

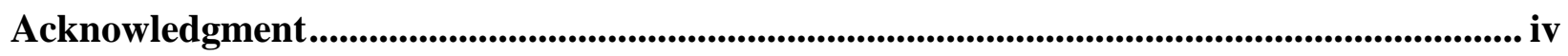

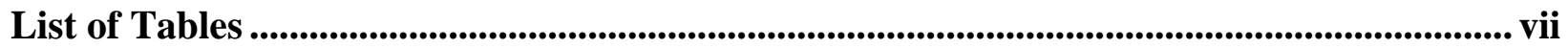

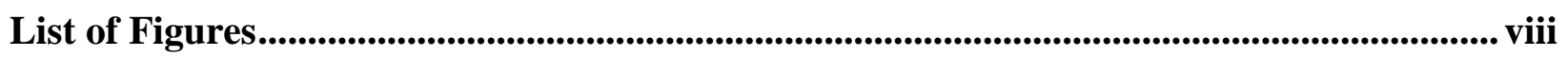

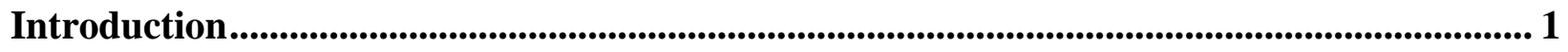

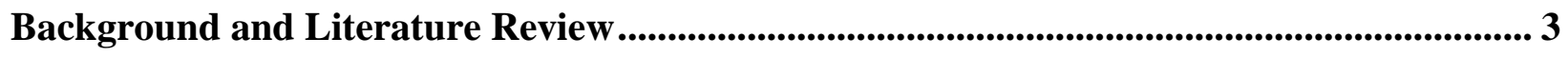

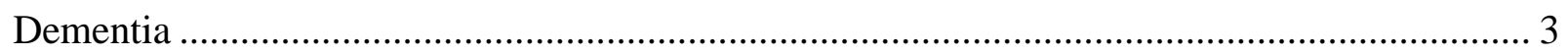

Behaviors and Symptoms of Dementia ......................................................................... 3

Occupational Therapy for Individuals with Dementia ......................................................... 4

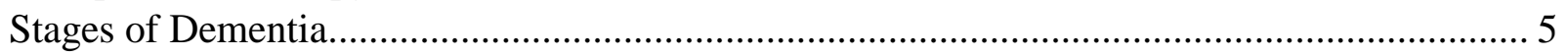

Stereotypes and Stigma About Dementia..................................................................... 8

Quality of Life of Residents with Dementia in Skilled Nursing Facilities ............................ 9

Person-Centered Care Practices and Environment in SNFs............................................ 12

Family Visits of Residents with Dementia in SNF .......................................................... 13

Purpose and Expectations of Volunteers......................................................................... 15

Current Visitor Training Programs for Dementia Residents in SNF .................................. 16

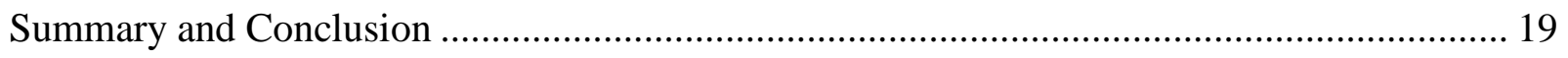

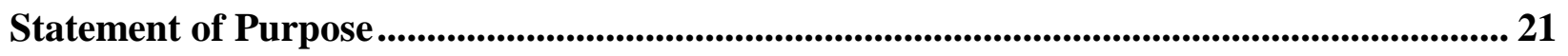

Theoretical Frameworks ...................................................................................................................... 22

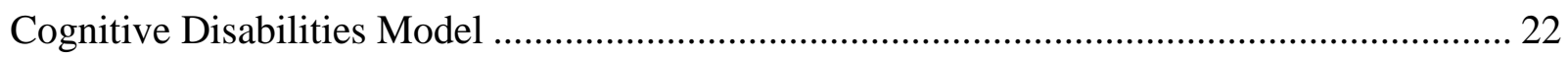

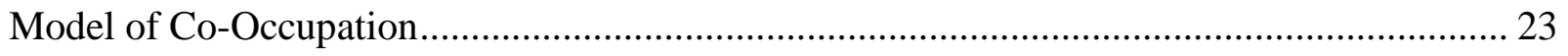

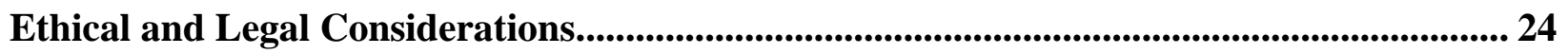

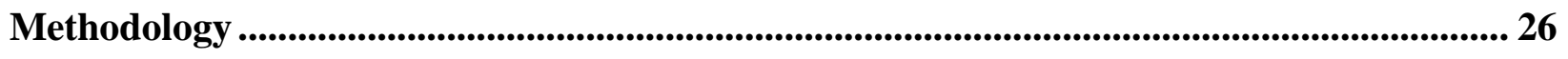

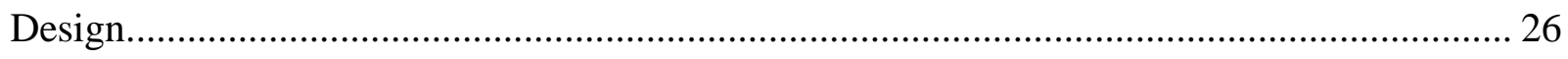

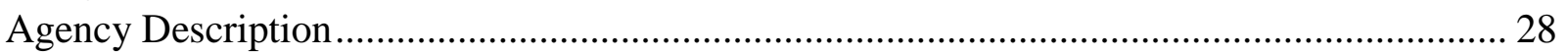

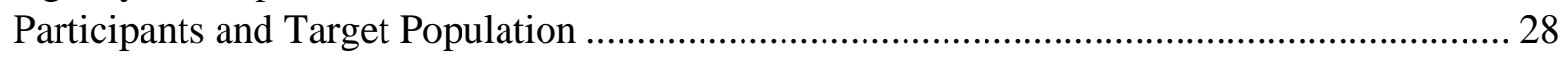

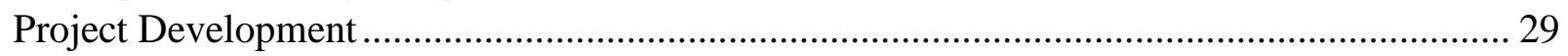

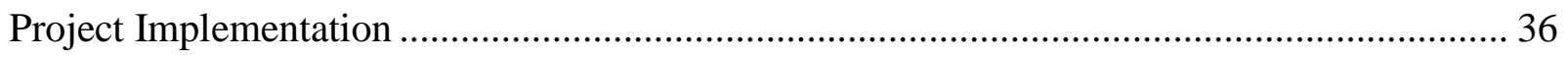

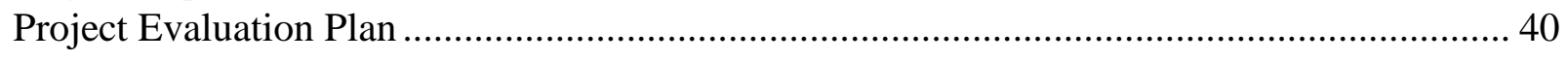

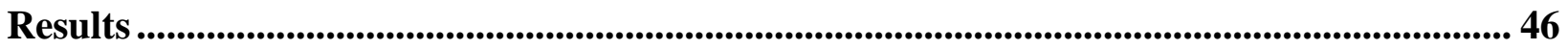

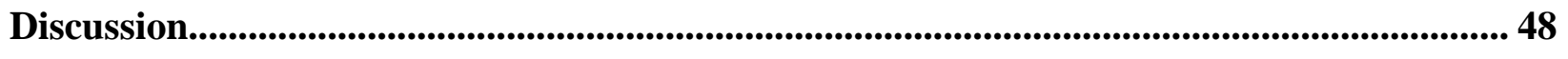

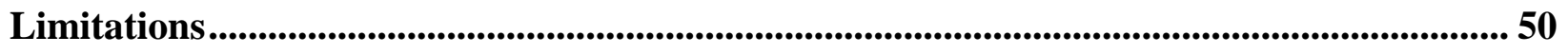

Implications for Occupational Therapy Practice............................................................................... 52

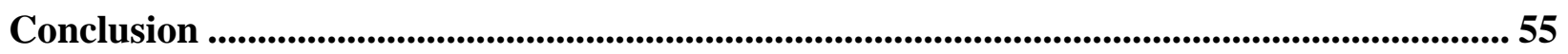




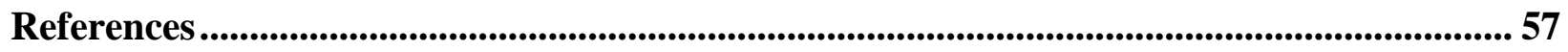

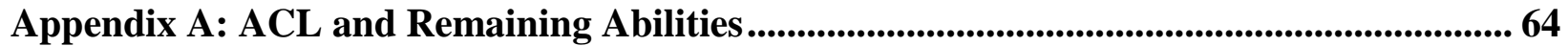

Appendix B: Online Module Knowledge Checks..................................................................... 66

Appendix C: Heart to Heart Dementia Volunteer Program Feasibility Evaluation ............. 71

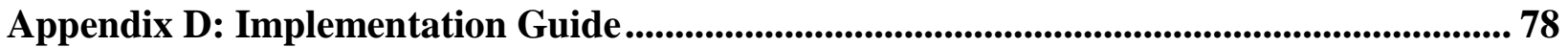




\section{List of Tables}

Table 1 Early, Middle and Late Stages of Dementia ............................................................ 6

Table 2 Learning Objectives for Online Training Course Modules ....................................... 33

Table 3 Schedule of Volunteer In-Person and Online Training ............................................ 34

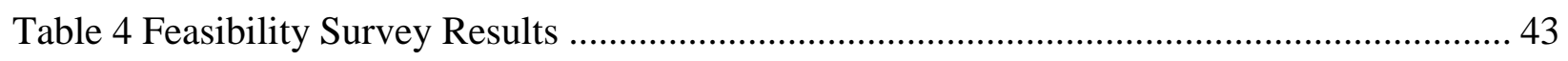

Table 5 OTAC 2020 Virtual Annual Conference Presentation Feedback ................................ 47 


\section{List of Figures}

Figure 1 Heart to Heart Volunteer Program Activity Box Items ............................................. 36

Figure 2 Steps for Heart to Heart volunteer program implementation ................................... 37 


\section{Introduction}

Social isolation is a major health risk for older adults. On a daily basis, 43 percent of older adults feel lonely, which increases the risk of mortality by 45 percent (Health Resources \& Services Administration, 2019). Furthermore, individuals with dementia (IwD) have a higher risk of social isolation (Alzheimer's Society, 2019b). IwD benefit from social connection, and the Heart to Heart volunteer program is designed to increase the frequency and quality of social interactions between IwD who live in skilled nursing facilities (SNFs) and volunteer visitors.

According to the Alzheimer's Association (2020), 5.8 million Americans currently live with Alzheimer's dementia and by 2050, the number is projected to increase to 13.8 million. Due to the progressive decline in memory, language, and cognition that affects IwD's ability to complete everyday activities, IwD require increased care, and they are often admitted to SNFs to receive care (Alzheimer's Association, 2020b). Admittance frequently results in IwD experiencing increased social isolation and loneliness. Public misconceptions of dementia, limited family availability, and lack of family support create barriers for social interactions with IwD upon an individual's admittance to a SNF (Alzheimer's Society, 2019b; Houser, 2007; Redfoot et al., 2013). The prevalence of loneliness in those with dementia indicates a need for social interaction.

Social interactions are a type of occupation. Occupations are defined as purposeful and everyday activities in which individuals participate because of the value, meaning, and importance to their well-being (AOTA, 2014). Occupations include social participation, work, education, play, leisure, and activities of daily living, which support health, quality of life (QOL), and human needs (AOTA, 2014). Occupations performed with others are cooccupations. Behavioral and psychological symptoms experienced by individuals with dementia 
create challenges for family caregivers to engage in co-occupations (Ono et al., 2014).

Occupational therapy utilizes a person-centered and strengths-based approach to promote engagement in meaningful occupations for all individuals, regardless of physical, cognitive, or emotional ability (AOTA, 2014). Person-centered occupational therapy services for SNF residents with dementia include providing opportunities for social interaction to decrease social isolation and improve quality of life (Fazio et al., 2018).

People with dementia benefit from engaging in interactions and activities with others in a social environment. Current visitor programs lack comprehensive training that includes education regarding strategies for communication with IwD and implementation of tailored, meaningful activities with IwD. Without guidance or support in interacting with IwD, family members or volunteers may be less likely to visit, impacting the health and well-being of IwD. Therefore, the Heart to Heart volunteer program aims to promote engagement in meaningful interactions by equipping volunteers with effective communication strategies and activities that are appropriate for the various stages of dementia. The Heart to Heart volunteer program will establish confidence in volunteers to facilitate frequent and quality visits, thus decreasing social isolation and enhancing the QOL for IwD in a SNF. 


\section{Background and Literature Review}

\section{Dementia}

According to the Alzheimer's Association (2020), dementia is a group of conditions characterized by symptoms, such as declines in memory, problem-solving, language, and other executive functioning skills. This chronic condition impacts the ability to live independently and perform activities of daily living (ADLs) (Alzheimer's Association, 2020e). As the condition progresses from early to late stages of dementia, IwD experience a decrease in functional abilities (Leland \& Wong, 2018). Irreversible and progressive dementia is most commonly caused by Alzheimer's disease (AD), vascular disease, Lewy Body disease, Frontotemporal degeneration, Huntington's disease, and Creutzfeldt-Jakob disease. Each type is characterized by a typical pattern of progression and associated functional decline. The various types of dementia share many similar challenges and areas of decline. Due to the decrease in the IwD's performance in self-care, communication, and response to their environment, IwD are at risk of experiencing sensory challenges and decreased engagement in meaningful occupations. Their participation in roles, routines and activities diminish significantly, impacting overall QOL, selfworth, and self-identity (Champagne, 2018). A decline in cognition and function results in a greater need for assistance in order to meet the social, physical, and emotional needs of the IwD.

\section{Behaviors and Symptoms of Dementia}

IwD may exhibit common neuropsychiatric behaviors related to dementia, such as resistance to care, verbal or physical aggression, anxiety, forgetfulness, confusion, shadowing, repetitive actions, and getting lost (Alzheimer's Association, 2020c). These challenging behaviors may occur as a result of a variety of factors, such as an overstimulating environment, a changing environment, physical discomfort, lack of understanding, or a deteriorating brain. IwD 
also struggle with reasoning, judgement, executive functioning skills, and sensory and perceptual skills beyond typical age-related degeneration (Centers for Disease Control and Prevention, 2019). Some examples of impairment include becoming lost in a familiar setting, using unusual words to refer to familiar items, forgetting the name of family and friends, and declining in overall independence. Common limitations also include mobility deficits, such as diminished balance and increased involuntary movements, which increase the risk of falling and incurring physical injuries (Champagne, 2018). Behaviors and symptoms related to dementia cause challenges in engagement in co-occupations, resulting in unmet needs, such as lack of social interactions and boredom (Cohen et al., 2015; Ono et al., 2014). Unmet needs can then lead to undesirable health outcomes. Knowledge of the progression of typical behaviors and symptoms of IwD allows for healthcare practitioners to identify the specific stages of dementia for individualized care. Understanding of the progression also benefits those interacting with IwD, such as caregivers, visitors, and volunteers, by providing guidance to enhance social interactions.

\section{Occupational Therapy for Individuals with Dementia}

Occupational therapists (OTs) apply knowledge about the progression of dementia to promote health for IwD directly or through consultation (AOTA, 2017). OTs evaluate strengths, challenges, and performance areas that require interventions. Interventions include engaging the remaining abilities for participation in preferred activities. In addition, OTs modify caregiving approaches, activities, and social supports for a supportive and safe environment. The occupational profile, a key tool used by OTs, guides intervention planning. The occupational profile requires understanding critical client information such as interests, values, needs, history, experiences, routines, strengths, limitations, and priorities (AOTA, 2014). A systematic review 
found that occupational therapy interventions involving the adaptation of activity demands for individuals with dementia enabled participation in self-care and leisure (Padilla, 2011). Modifications included matching of client interests and skills, environmental adaptations, and use of various cues.

OTs promote occupational engagement, and occupations completed with others are cooccupations (AOTA, 2014). While co-occupations have not been widely researched, social isolation has been shown to increase symptoms of suicide, alcoholism, and schizophrenia in individuals with mental health conditions, suggesting the importance of co-occupations to support wellbeing (Brown \& Stoffel, 2011). However, IwD may experience decreased participation in co-occupations. Family caregivers struggle with facilitating co-occupations due to behaviors and symptoms of their loved one with dementia (Ono et al., 2014). Caregivers also prioritize assisting IwD with completing activities of daily living, managing safety, coordinating supportive services, and making financial and healthcare decisions. Therefore, IwD require interventions targeting shared activities. A pilot study for person-centered care of residents in a dementia care unit found that co-occupations, such as singing, reading, or praying with other residents, family, or volunteers, can stimulate reminiscence (Du Toit \& Van Der Merwe, 2013). IwD may exhibit forgetfulness, and reminiscence can increase participation in self-care or leisure activities. These studies suggest the need for OT consultation in strengths-based activity modifications. IwD require tailored activities appropriate for their abilities and interests for enhanced engagement in co-occupations.

\section{Stages of Dementia}

The abilities of the IwD vary based on the stage of dementia. Dementia can be classified as early, middle, and late stage, which is determined by the severity of symptoms experienced by 
the IwD (Alzheimer's Association, 2020d). See Table 1 for a list of common challenges and remaining abilities of individuals in the early, middle, and late stage dementia.

Table 1 Early, Middle and Late Stages of Dementia

\begin{tabular}{|c|c|c|}
\hline $\begin{array}{l}\text { Stages of } \\
\text { dementia }\end{array}$ & Challenges & Remaining Abilities \\
\hline Early stage & $\begin{array}{ll}\text { - } & \text { difficulty finding words } \\
\text { difficulty remembering } \\
\text { newly learned information } \\
\text { or names of new people } \\
\text { - } & \text { difficulty performing } \\
\text { tasks in social or work } \\
\text { setting } \\
\text { difficulty planning and } \\
\text { organizing }\end{array}$ & $\begin{array}{l}\text { - maintains effective verbal skills } \\
\text { - participates in familiar ADLs }\end{array}$ \\
\hline Middle stage & $\begin{array}{ll}\text { - loss of memory of } \\
\text { personal events and } \\
\text { history } \\
\text { - } \text { mood swings } \\
\text { withdrawn in challenging } \\
\text { situations } \\
\text { disorientation to the day, } \\
\text { time, or location } \\
\text { changes in personality and } \\
\text { behaviors }\end{array}$ & $\begin{array}{l}\text { performs repetitive motor } \\
\text { actions } \\
\text { follows one step direction as } \\
\text { part of a familiar task } \\
\text { engages in meaningful } \\
\text { interaction through the use of } \\
\text { "memory book" or storyboards }\end{array}$ \\
\hline Late stage & $\begin{array}{l}\text { - need for around the clock } \\
\text { care } \\
\text { - fully dependent on a } \\
\text { caregiver } \\
\text { - loss of memory and lack } \\
\text { of awareness of recent } \\
\text { experience } \\
\text { - decrease in mobility } \\
\text { - decrease in oral motor }\end{array}$ & $\begin{array}{l}\text { - } \begin{array}{l}\text { responds to proprioceptive cues } \\
\text { maintains visual attention to } \\
\text { stimuli directly in front of them }\end{array}\end{array}$ \\
\hline
\end{tabular}

During early stage dementia, individuals may not experience significant impacts on their quality of life (Alzheimer's Association, 2020d) (see Table 1). Individuals in the early stage are likely to manage their health and wellness, make decisions, and participate in meaningful 
activities with support. Challenges may include recalling memories and performing complex tasks in social and work settings.

Middle stage dementia can last for many years and is typically the longest stage (Alzheimer's Association, 2020d). Individuals in middle stage dementia may require more care and can engage in familiar everyday activities with assistance or simplification (see Table 1). Assistance may include task set-up or step-by-step cues.

Late stage dementia is characterized by the most severe symptoms (Alzheimer's Association, 2020d) (see Table 1). Individuals in late stage dementia may not possess the ability to initiate and actively participate in activities. However, they may benefit from sensory stimulation, such as music and gentle touch.

\section{Allen Cognitive Level}

In addition to the classification of dementia by three stages, cognitive function can also be classified by Allen Cognitive Level (ACL) (Allen Cognitive Group, n.d.). The Cognitive Disabilities Model (CDM) includes a battery of assessments for the identification of key remaining cognitive abilities in IwD, which often guide occupational therapy interventions for IwD (Champagne, 2006). The CDM focuses on functional cognition, or the cognitive skills required to complete everyday activities and occupations (Allen Cognitive Group, n.d.). The CDM includes the ACLs, which provide six levels of cognition on a hierarchical and ordinal scale (see Appendix A). OTs benefit from utilization of the ACLs, as it distinguishes the various levels of cognition and identifies the primary remaining abilities for IwD at each level. Identification of remaining abilities allows for strengths-based facilitation of tasks and communication necessary for IwD to engage in meaningful activities. 


\section{Stereotypes and Stigma About Dementia}

IwD retain remaining abilities at every level of dementia that enable them to participate in social co-occupations. However, 40 percent of IwD feel socially excluded due to stigma and experiences of family and friends avoiding them and treating them differently, which can decrease QOL for IwD (Alzheimer's Association, 2012; Stites et al., 2018). A secondary analysis was completed for an experimental study surveying a random sample of adults in the U.S. regarding knowledge of dementia causes and prognosis (Stites et al., 2016). The analysis found that participants who believed dementia is a mental illness often rated symptoms of individuals with mild dementia more severely than those who did not believe that dementia is a mental illness, suggesting an underestimation of remaining abilities (Stites et al., 2016). In addition, over half of the public living without dementia feel that they would lose their identities and that their lives would be over if they had dementia (Alzheimer's Society, 2019). The belief that IwD can no longer live quality lives may be caused by the media's tendency to depict challenges of IwD in the later stages of the condition. To gain attention for financial donations, the media often emphasizes negative aspects of dementia, such as IwD's dependence, lack of autonomy, and caretaker's burden (Stites et al., 2018).

In addition, the general public holds misconceptions about the causes of dementia, including the belief that a decline in memory and cognition is a natural part of typical aging (Cahill et al., 2015). Age-associated memory impairment is considered part of normal aging, but memory loss in IwD interferes with daily functioning and social occupations. While dementia can lead to challenges in occupational performance, IwD at all stages of dementia can still participate in meaningful interactions, from activities to sensory stimulation, with assistance and 
adaptation. Thus, adequate education regarding dementia can reduce stigma and increase opportunities for IwD to engage in meaningful co-occupations.

\section{Quality of Life of Residents with Dementia in Skilled Nursing Facilities}

SNFs shelter a unique community of diverse people, needs, joys, and challenges. Although SNFs are not traditionally considered a setting where community-based interventions would be the service delivery model, an article by McColl (1998) describes OTs providing community-based intervention as "a catalyst to community development." OTs increase "community awareness of the needs of its members with disabilities" and assist "communities to marshall resources and evolve solutions" (McColl, 1998). According to Meyers (2009), communities can be defined as the settings where people reside, build relationships, and engage in health practices. Another important aspect of a community is that the members of the community may be engaged in a collective occupation (Meyers, 2009). OTs provide community-based interventions to promote health for populations for a larger scale and must address community barriers to engagement.

IwD often live between four to eight years after receiving a diagnosis, but can live up to twenty years, creating a need for maintenance and promotion of their QOL as their dementia progresses (Alzheimer's Association, 2020d; Piechniczek-Buczek et al., 2007). A variety of factors determine IwD's QOL, including life satisfaction, health, and functioning (AOTA, 2014). However, as dementia progresses, an individual's ability to initiate participation in meaningful activity diminishes, increasing their reliance on external support in order to engage in meaningful occupations (Smit et al., 2016). IwD require occupational engagement regardless of their stage of dementia, through activities that consider their unique needs and abilities, as well as their preferences and interests (Smit et al., 2016). 
A study observing 1,144 residents across 144 Dutch long-term facilities providing nursing home care evaluated activity involvement on QOL (Smit et. al., 2016). Registered nurses and certified nursing assistants most involved with the residents completed questionnaires regarding resident characteristics, involvement in activities, and quality of life. The study found that the residents spent the most time watching television or listening to the radio, which were considered passive activities. On average, residents actively participated in activities, such as playing games, exercising, reading, creating art, and walking, for 2.5 hours over three days. The study also concluded that participation in activities improved relationships with care staff and other residents, positive affect, and restlessness. However, high engagement in activities was associated with lower positive self-image, likely due to activities that were not suitable for the resident's abilities, leading residents to be confronted with their inabilities. These results suggest that activities must be modified to residents' abilities.

Similarly, unmet needs of 89 residents with dementia exhibiting verbal agitation or physical non-aggressive agitation were evaluated in six Maryland nursing homes through observations by research assistants (RAs) and nursing assistants (NAs) (Cohen et. al., 2015). Researchers measured agitation using the Agitated Behaviors Mapping Instrument, which identified frequency of verbal or vocal agitation, such as groaning, or physical agitation, such as pacing. The authors developed the Type of Unmet Need Assessment (TUNA) to assess unmet needs, which included discomfort, pain, anxiety, sensory deprivation, boredom, and loneliness. Unmet needs also included needs for social interaction, meaningful activity, relaxation, control, other, or no need. The study found that each participant had at least one unmet need (Cohen et. al., 2015). Two thirds of RAs and half of NAs identified that residents most commonly needed meaningful activities and social interactions. Verbal agitation was significantly higher in 
residents with loneliness, and physical nonaggressive behaviors were somewhat higher in residents with boredom or sensory deprivation.

Residents with dementia in SNFs need OTs to provide activity programs specifically tailored for various stages of dementia. Activity adaptation to IwD's remaining abilities will enhance satisfaction and engagement in meaningful occupations. OTs consider the IwD's previous interests and personal history, allowing for more person-centered interactions. Without the person-centered care and individualized activity programs that OTs can provide, IwD are likely to experience increased agitation and decreased QOL due to unmet needs.

The study by Cohen-Mansfield, Dakheel-Ali, Marx, Thein, and Regier (2015) was a continuation of a previous randomized, placebo-controlled clinical trial of nonpharmacologic interventions residents with dementia experiencing agitation (Cohen-Mansfield et al., 2015). Agitation was also measured using the Agitation Behavior Mapping Instrument. The intervention group received treatment matching their needs, preferences, abilities, and past identity, such as one-on-one interactions, music, arts and crafts, sensory stimulation, and puzzles and games. Results indicated that the intervention group significantly decreased total, physical nonaggressive, and verbal agitation. Decreased agitation was also observed in residents with frequent family visits (Piechniczek et al., 2007). Residents with dementia in SNFs lack social interaction, sensory stimulation, and meaningful activities. OTs have the expertise to create individualized, nonpharmacologic programs that enhance occupational engagement for increased QOL through tailoring activities to the interests and remaining abilities of residents at various stages of dementia to enhance overall satisfaction and QOL. 


\section{Person-Centered Care Practices and Environment in SNFs}

The Centers for Medicare and Medicaid Services launched a National Partnership in 2011 to improve dementia care in SNFs through reduction of antipsychotic drugs and promotion of nonpharmacological approaches and person-centered care practices (Centers for Medicare and Medicaid Services [CMS], 2019). The Partnership included research, training, public reporting, state-based coalitions, and revised surveyor guidance. The Partnership led to a decrease in the use of antipsychotic medication, from 23.9 percent in 2011, to 14.3 percent in 2019. A study evaluated the effects of physical restraints and antipsychotic drugs on physical and cognitive function in 532 nursing home residents with dementia, and found an increase in physical and cognitive decline, including ADL deficits, cognitive impairment, and negative behaviors (Foebel et al., 2016). There is little support for restraints and antipsychotic drugs, as they often do more harm than good. Hence, The Partnership advocated for the use of person-centered care in SNFs.

The CMS recommends person-centered care to promote resident safety and QOL, and replace the use of antipsychotic drugs and restraints (CMS, 2019). Practice recommendations for person-centered care by Alzheimer's Association includes knowing the person, providing opportunities for engagement in meaningful occupations, and building authentic and caring relationships (Fazio et al., 2018). Through coding of video observations of interactions between 12 Wisconsin nursing home residents with dementia and eight certified nursing assistants, behavioral symptoms such as aggression, agitation, or resisting care, were found to be significantly more likely to occur after a task-centered caregiver action, rather than a personcentered action (Gilmore-Bykovskyi et al., 2015). Task-centered actions include negative statements and infantilizing speech, whereas person-centered actions are individualized and resident-directed. 
Person-centered care can include consideration of the physical environment for SNF residents with dementia. In a controlled longitudinal study, residents with dementia in a Spanish nursing home participated in either multisensory sessions, one-to-one activity sessions, or no sessions (Maseda et al., 2014). Multisensory sessions included environmental stimulation, such as music, aroma, and a tactile board. One-to-one activity sessions incorporated activities such as playing cards, or quizzes that placed intellectual and/or physical demands on the resident. The study found that the multisensory group demonstrated improvement in physical nonaggressive behavior, verbally agitated behavior, and neuropsychiatric symptoms included in the Neuropsychiatric Inventory - Nursing Home (NPI-NH). Although there may be cultural differences for dementia care between the United States and Spain, benefits of a sensory rich environment have been observed across nursing homes globally. A volunteer training program supports person-centered care by understanding the IwD's strengths, providing opportunities for IwD to engage in social interactions, promoting volunteer and resident relationships, and creating sensory rich environments.

\section{Family Visits of Residents with Dementia in SNF}

Person-centered care involves providing opportunities for IwD to engage in meaningful and social activities, which can occur during family visits. However, family visits for IwD often do not involve socialization, and many residents do not have family support. In an analysis of family involvement for residents with dementia in nursing and assisted living facilities, families of residents with dementia reported spending less time on social activities and more time on care tasks than families of residents without dementia (Cohen et al., 2014). Care tasks included discussing resident care with staff, or helping the resident eat, walk, move, or maintain their appearance. 
In addition, frequency of visits positively relates to having a spouse, living close to the facility, and a previously close relationship (Yamamoto-Mitani et al., 2002). In a 5-year longitudinal study of family visiting patterns in the San Francisco Bay Area or Greater Los Angeles, researchers found that spouses are typically older and have greater flexibility in their schedules, whereas adult children often have commitments to work and family (YamamotoMitani et al., 2002; Lindman, 2004). Thus, spouses more frequently visit loved ones with dementia, compared to adult children. Those with "good" relationships with the IwD, such as a close family relationship with the resident, would also visit more often than those who will not (Lindman, 2004).

However, the declining availability of family members to visit IwD creates barriers for residents to receive visits. Due to declining fertility in the U.S., there are an estimated 1.2 million individuals 65 years or older without living siblings or children in 2020 (Redfoot et al., 2013). The average number of children is expected to decrease from 3.1 in 2010 to 2.0 in 2030 among women aged 80-84, and the number of older women without children will increase from 11.6 percent in 2010 to 16.0 in 2030 . Women are more likely to require nursing home care due to their longer life expectancy, and over half of nursing home residents will be widowed (Houser, 2007). Studies regarding family visitation exclude residents without involved spouses or children, and results regarding positive visiting frequency or quality do not reflect experiences of all residents with dementia (Cohen et al, 2014; Yamamoto-Mitani et al., 2002). Lack of social activities during family visits, and the increasing prevalence of residents without spouses or children create a need for social interaction for residents with dementia. 


\section{Purpose and Expectations of Volunteers}

In addition to visits from family, IwD in SNFs also receive visits from volunteers. Volunteering is defined as helping those in need within one's community by connecting to individuals and creating a lasting impact (Segal \& Robinson, 2019). Volunteering offers benefits for the people in need of receiving volunteer services, as well as for the volunteers themselves. Altruistic behavior can reduce stress and provide a sense of purpose when volunteers give their time and care to another individual or cause. The motivation to volunteer may be different based on factors including age, opportunities, and previous experiences. A literature review evaluated the motives and benefits of student volunteering, comparing occasional, regular, and nonvolunteers (Smith et al., 2010). Student volunteers' motivation included enhancement in academics, personal development, and career development. In addition, students aim to seek self-growth, increase skills, and extend their assistance within a community in need.

In a meta-analysis of volunteers in dementia care across numerous countries, researchers found three themes: volunteer motivation, volunteer involvement, and understanding roles.

\section{Volunteer Motivation}

Adequately trained and valued volunteers felt satisfied and found meaning in the program (Hurst et. al., 2019). Volunteers working in healthcare settings were motivated to help others, self-develop, and increase opportunities for socialization with the residents.

\section{Volunteer Involvement}

Meeting with family members and other volunteers to discuss care for the specific IwD allowed volunteers to feel more motivated and involved (Hurst et al., 2019). 


\section{Volunteer Understanding of Roles}

Programs should provide adequate training and role description pertaining to the performance of required activities or skills (Hurst et. al., 2019). Not only did a clear role description help those in volunteer programs, but also reduced confusion among the staff and family members. Additionally, opportunities for volunteers to receive feedback and express their feelings promoted satisfaction, as volunteers left programs due to lack of support (Hurst et al., 2019). Volunteer dropout rates decreased as volunteers felt valued and programs implemented improvements, including sufficient training, appropriate workload, and support for the volunteers. Volunteers provided benefits for residents with dementia by ensuring safety as a ‘human alarm system' for residents. Volunteers also sat with residents with high fall risk and alerted staff of potential falls or risk of falls, while promoting participation in meaningful occupations, such as reading, card games, and singing (Hurst et al., 2019). Volunteering opportunities benefit both volunteers and residents with dementia, and well-planned and supportive programs promote volunteer retention with adequate training and communication.

\section{Current Visitor Training Programs for Dementia Residents in SNF}

Previously implemented visitor training programs for volunteers working with SNF residents with dementia have focused on communication training or activities-based training (Eggenberger et al., 2012; Hurst et. al., 2019; McCallion et al., 1999; Särkämö et al, 2014; Van der Ploeg et al., 2014). Programs focusing on communication training involved familial visitors of residents and lacked the inclusion of volunteer visitors and education regarding the facilitation of activities. Programs that focused on the volunteer as the facilitator of meaningful activities lacked communication training, which led to challenges during interactions between the volunteer and resident. The training was tailored to the resident's level of dementia, cognitive 
abilities, physical abilities, and interests; however, the programs did not provide a personcentered client profile to allow for a quick and comprehensive snapshot of resident strengths, weaknesses, and values.

\section{Communication Training for Visitors}

Visitors of IwD require support, training, and tools in order to maintain a safe and engaging environment. IwD need an environment where everyone feels safe and comfortable (Champagne, 2018). The Family Visit Education Program (FVEP) focused on improving the interaction between families and nursing home residents with dementia (McCallion et al., 1999). The program addressed three major areas including verbal communication, nonverbal communication, and effective structures for family visits over 8 weekly sessions. Education covered the stages of dementia, common challenges when interacting with people with dementia, and benefits for the resident resulting from appropriate communication strategies. Families also received training tailored to the resident's level of dementia. FVEP found significant positive improvements in preventing worsening of depressive symptoms, but did not reduce or eliminate depressive symptoms altogether. Additionally, residents demonstrated significantly decreased verbally agitated behavior, including yelling, and decreased physically nonaggressive behavior, including pacing. Family members also reported that FVEP benefited both residents and family. FVEP focused on communication strategies for $\mathrm{IwD}$, but did not facilitate participation in activities.

A systematic review of communication skills training in residential and home dementia care in the USA, the UK, and Germany also found improvements in QOL and wellbeing for IwD (Eggenberger et al., 2012). QOL and wellbeing were defined as increased satisfying interactions and positive behavior. Volunteers also desire to expand their skills and methods for interactions 
with residents with dementia (Hurst et. al., 2019). However, current communication training focuses on educating professional and informal family caregivers, and lacks the inclusion of SNF family visitors or volunteers (Eggenberger et al., 2012; Van der Ploeg et al., , 2014).

\section{Activities-Based Training for Visitors}

In addition to utilization of communication strategies tailored to an IwD's stage of dementia, activities should also be tailored to enhance IwD's participation, which is significant for their overall well-being (Alzheimer's Association, 2019d). In a meta-analysis of dementia care, several sources found that reading, reminiscing, and singing activities calmed and distracted IwD (Hurst et al., 2019). Engagement in these activities provided stimulation that reduced depression and increased QOL for IwD. Visitor programs also included musical interventions (Särkämö et al., 2014). It was found that novel music intervention had a positive impact for some, but not all IwD; however, listening and singing improved orientation, mood, and episodic memory. Along with positive impacts for IwD, caregivers' well-being was also enhanced through musical activities.

Another volunteer program utilized meaningful activities for residents with dementia. 16 nursing home volunteers in Australia were trained to implement individualized one-on-one activities that matched each resident's cognitive abilities, physical capacities, former interests, and culture, such as reading, craft work, music, and arranging flowers (Van der Ploeg et al., 2014). Volunteers received training on application of the activities. Volunteers participated in an interview after their final visit and all described the activities as feasible and helpful. However, some volunteers recalled difficulty pacing the activity, responding sensitively to the resident's mood and interest, and witnessing resident distress. This program facilitated individualized activities for residents with dementia, but did not provide education regarding dementia, stages 
of dementia, or stage-appropriate communication strategies. Had these topics been included in the education, they would have addressed potential stigma, volunteer challenges with facilitation techniques, and behaviors and symptoms of dementia. Incorporating both communication training and activities-based interventions would benefit both the volunteers and residents with dementia, but current programs lack incorporation of both.

\section{Summary and Conclusion}

Participation in social co-occupations enhances the QOL and overall well-being for IwD. As the prevalence of dementia increases, admittance of IwD into SNFs increases as well. Relocating to a SNF increases the IwD's risk of experiencing social isolation due to lack of family support. Visitors of residents are often family members, particularly spouses (YamamotoMitani et al., 2002). However, over half of residents in SNFs are surviving spouses, having lost their partners prior to residing in a SNF. Additionally, there is an increasing population of older adults without children (Houser, 2007; Redfoot et al., 2013). Stigma about dementia also creates barriers for IwD to participate in social occupations, as the general public often believe that IwD are unable or do not want to engage in activities. Existing visitor programs, such as FVEP, music interventions, and individualized one-on-one activities, have positive impacts on IwD in SNF. These programs provide training regarding communication techniques or facilitation of individualized activities in isolation, but do not combine both. These programs also tailor communication strategies and activities to the resident's abilities and interests, but lack an accessible client profile for visitors. A visitor training program increases visiting frequency through recruitment of volunteers motivated to give their time and care. Stigma will also be reduced through education addressing stages of dementia, stage-specific behaviors, and remaining abilities. Additionally, an effective volunteer training program includes training of 
communication and activity adaptation for the various stages of dementia, in order to enhance volunteer confidence in facilitating co-occupations for IwD. A client profile developed through OT consultation provides a quick and comprehensive understanding of the client's strengths, weaknesses, and interests for multiple visitors. If volunteers feel successful in their visits with IwD, they will likely return for more frequent visits, resulting in positive impacts for the resident with dementia (Piechniczek-Buczek et al., 2007). 


\section{Statement of Purpose}

Residents with dementia in SNFs will increase engagement in co-occupations through the Heart to Heart volunteer program. Heart to Heart provides a person-centered and strengthsbased perspective, as well as resources for SNFs to implement a comprehensive occupationbased volunteer program. The program provides volunteers with training and tools in dementia stages, communication strategies and activity adaptations for successful facilitation of meaningful visits. The purpose of this project is to decrease social isolation and increase QOL of IwD through improved quality and frequency of volunteer visits to enhance engagement in meaningful and supported social occupations for IwD. Existing visitor programs focus on communication strategies, or individualized activities at a SNF, but not both in combination. The primary objective of this project is to create a volunteer training program with a partnering SNF that equips visitors with knowledge of the common symptoms and behavioral responses of IwD. The program will also provide resources to guide the volunteers in effectively communicating and facilitating stage-appropriate activities in order to improve their interactions with IwD. Resources include OT consultation in the form of a client profile highlighting client strengths, challenges, and interests, as well as recommended communication strategies. Training resources also consist of an online training module, a live interactive training, and a printed resource booklet. Additionally, an implementation guide will outline methods for successful program implementation (see Appendix D and will be attached as a separate document). Volunteer visitors participating in this program will gain foundational knowledge of dementia to reduce stigma, utilize effective communication strategies, and facilitate activity adaptation for IwD. Heart to Heart aims to increase volunteer's skills and confidence in facilitating visits for residents with dementia. Ultimately, increased social interactions will enhance the IwD's QOL. 


\section{Theoretical Frameworks}

\section{Cognitive Disabilities Model}

The Cognitive Disabilities Model (CDM) focuses on functional cognition, which refers to the cognitive skills required to complete everyday tasks (Allen Cognitive Group, n.d.). The CDM identifies typical functional cognition at each stage of dementia using six Allen Cognitive Levels (ACLs). The six ACLs are further categorized into modes to describe verbal behaviors and motor actions commonly observed during occupational engagement at each stage of dementia. The levels and modes allow OT practitioners to identify an individual's strengths and remaining abilities, thereby facilitating their best ability to function. Thus, practitioners can match cognitive demands of activities with an IwD's remaining abilities for success and safety (Allen Cognitive Group, n.d.). Understanding an individual's best ability to function includes identification of what the individual "Can Do," "Will Do," and "May Do." "Can Do" refers to an IwD's capabilities, which is guided by their ACL. "Will Do" refers to preferred activities of an IwD as informed by their occupational profile. Lastly, "May Do" refers to the support for engagement, which is affected by the social and physical environment.

The CDM has guided the Abilities Care Approach (ACA®), an Ensign trademarked program, developed by Dr. Gina Tucker-Roghi OTD, OTR/L for evidence-based, nonpharmacologic, stage-specific and person-centered care for IwD (Ensign Therapy, n.d.). Interventions supported by the ACA ${ }^{\circledR}$ modify caregiving approaches, the environment, and task demands to match an IwD's needs. The ACA® outlines four strategies to care for an IwD: identify remaining abilities, learn the IwD's personal story and history, modify the environment and activities to match the remaining abilities, and share successful techniques with other caregivers. 


\section{Model of Co-Occupation}

The Model of Co-Occupation (MoCO) focuses on interactive and responsive occupations involving other individuals (Pickens \& Pizur-Barnekow, 2009). Co-occupations are characterized by shared emotionality, physicality, and intentionality. Emotionality refers to enjoyment, physicality refers to physical support, and intentionality refers to completion of the co-occupation. The participating individuals perceive meaning depending on the overall experience. In addition, engagement can be influenced by disabilities or impairments. The target co-occupation is social interaction, which will be achieved through interactions between volunteers and SNF residents with dementia. Emotionality will be promoted through engagement in activities meaningful for the volunteer and resident. Additionally, residents experiencing social isolation in SNFs will increase their social participation in activities that match their abilities and needs. The volunteer's use of effective communication strategies will also ensure more satisfying interactions for both the volunteers and residents. Physicality will be supported through the use of effective non-verbal communication. While volunteers will not physically assist residents with ambulation due to safety risks, volunteers can physically support residents during activities by providing physical cues and a sensory-stimulating environment. Intentionality will be ensured by educating volunteers with adequate knowledge and skills regarding dementia to facilitate occupations that the resident can complete successfully. 


\section{Ethical and Legal Considerations}

The American Occupational Therapy Association Code of Ethics informed this project (AOTA, 2020). The team followed all principles of the Code of Ethics, with careful consideration to beneficence, nonmaleficence, autonomy, and fidelity.

The principle of beneficence required the team to consider the safety and well-being of participants (AOTA, 2020). Participants in this project include Summerfield Healthcare Center residents with dementia and volunteer high school students, both of whom are vulnerable populations. To promote beneficence for both populations, a collaborating OT at Summerfield Healthcare Center will evaluate and refer residents fit for the program. Volunteers will not be permitted to transfer residents, protecting the physical safety of both resident and volunteer. Additionally, a referral will ensure participating residents can safely remain seated during activities. In addition, volunteers will be appropriately trained with respect to dementia, including techniques to facilitate meaningful activities with effective communication strategies. Training will promote the mental well-being of both residents and volunteers during satisfying and quality interactions.

The principle of nonmaleficence describes the prevention of harm (AOTA, 2020). The team will prevent physical harm of volunteers and residents by prohibiting volunteers from physically assisting residents with ambulation, which may result in falls and injuries. Volunteers may provide physical prompts during activities. However, facility staff will be present to assist with resident mobility needs. Additionally, psychological harm of volunteers and residents will be prevented with adequate training of volunteers to ensure volunteer confidence in facilitating interactions with techniques to avoid agitation in the residents with dementia. Volunteers will also receive education regarding techniques for approaching challenging behaviors and 
symptoms. Additionally, support and debrief opportunities will be provided by the Activity Director or Director of Rehabilitation throughout the volunteer experience to ensure that volunteer needs are being met, and volunteer concerns are addressed.

The principle of autonomy refers to the participant's right to consent, self-determination, privacy, and confidentiality (AOTA, 2020). Volunteers will provide written consent and may withdraw from the project at any time (see Appendix D). Due to the residents' decreased cognition and ability to make decisions due to the progression of dementia, their consent may be assessed on a day-to-day basis, by a family member or power of attorney, or the volunteer or Activity Director's best judgement. The resident may also withdraw from the project at any time. In addition, volunteer confidentiality will be respected as their information and participation will not be revealed. Though volunteers will have access to the resident's name and condition, resident confidentiality will also be protected as volunteers participate in HIPAA (Health Insurance Portability and Accountability Act) training, as well as abuse prevention training.

The principle of fidelity ensures the team will provide accurate, objective, and comprehensive information when representing the profession (AOTA, 2020). Throughout all forms of communication for the project proposal and implementation, the team has adhered to evidence-based occupational therapy practices. The team has cited credit when using the work or ideas of others, including the ACA®. The team has also emailed each of the authors to request permissions for use and modification of the Dementia Knowledge Assessment Tool Version Two, and Dementia Attitude Scale that will be used for program evaluation (see Appendix D). 


\section{Methodology}

\section{Design}

The Heart to Heart volunteer program aims to increase QOL for residents with dementia at Summerfield Healthcare Center, and other Ensign-affiliated SNFs. Currently, IwD are at risk for social isolation and a decline in overall well-being. Heart to Heart utilizes a train-the-trainer design to provide SNFs the resources to implement a volunteer program to increase opportunities for social co-occupations for residents with dementia. An implementation guide outlines the process of program execution for the facility's Activity Director (see Appendix D and will be attached as a separate document). Heart to Heart also includes virtual and in-person volunteer training, which provides an accessible delivery of knowledge, supports a variety of learning styles, and allows for effective evaluation of the learners' understanding of the material. In addition, the program incorporates a client profile card and activity box to include OT consultation and resources for effective volunteer facilitation of visits. Heart to Heart comprehensively addresses the needs of the SNF organization, as well as dementia and volunteer populations. Ultimately, the program aims to improve the quality and frequency of visits for the volunteer and the resident, which may increase social engagement and QOL for residents.

Heart to Heart includes a referral process for residents with dementia from the licensed OT to the activities department. Once the residents are identified as participants in the program, the licensed OT creates a client profile with information about the resident's preferred activities and the best strategies and approaches to facilitate meaningful interaction considering their ACL. The project focuses on individuals in ACL 3 and 4, otherwise referred to as early and middle stage dementia. The referral excludes individuals in ACL 1 and 2, or end and late stage dementia, due to the severity of symptoms that impact the safety of the volunteers and the 
residents. The referral also excludes individuals in ACL 5 and 6, as they are often high functioning individuals who can initiate meaningful interactions and occupational participation autonomously, and without significant challenge.

Heart to Heart provides a guide for the Activity Director at Summerfield Healthcare Center to implement the program. The Activity Director will recruit volunteers and facilitate training with an introduction session, online training modules, and an in-person volunteer session. Heart to Heart utilizes a train-the-trainer model to provide an occupational perspective for program development in SNFs and maximize the effectiveness of the training when the Activity Director trains future volunteers.

- The Activity Director first connects with career counselors at local high schools to recruit students at the junior and senior grade levels.

- The Activity Director then facilitates an introductory session with a facility orientation and explanation of the program and roles of the volunteer.

- The volunteers complete an online training module focusing on dementia, stages of dementia, remaining abilities of each stage, stage-appropriate communication strategies, and stage-appropriate activities.

- Once the volunteers complete the online module, the Activity Director facilitates an inperson training session that includes case-based learning using simulations of communication and activity facilitation by the volunteers with the IwD.

Heart to Heart includes replicable resources, including a consent form, contact form, time $\log$, client profile, sample activity box for volunteer use during visits, volunteer handbook for additional support, and a volunteer pre- and post-training survey to evaluate effectiveness of the project (see Appendix D). 


\section{Agency Description}

Heart to Heart will be implemented at an Ensign-affiliated SNF, Summerfield Healthcare Center in Santa Rosa, California. This SNF offers support for about 50 long-term and short-term residents through therapy programs customized for each individual. The current rehabilitation team consists of OTs, certified occupational therapist assistants (COTA), physical therapists, physical therapy assistants, speech-language pathologists, and a rehabilitation aide/technician.

Currently, the facility implements an activity program throughout the month for the residents. Each day, residents can participate in different types of activities in the activities room, which can include ice cream socials, arts and crafts classes, bingo, music appreciation, current events, and pet therapy. However, according to the Director of Rehabilitation, there is a lack of volunteers, and therefore, a lack of individualized one-on-one interactions. Upon successful implementation of the volunteer training program, Heart to Heart has the potential to be scaled to over 200 other Ensign-affiliated SNF throughout the country.

\section{Participants and Target Population}

The target population of Heart to Heart are residents with dementia at ACL 3 and 4 at Summerfield Healthcare Center, as well as volunteers who work with these individuals. The volunteers visiting and engaging with the residents will be from Elsie Allen High School. Elsie Allen High School is located in Santa Rosa, California, with roughly 1,050 students. Demographically, the school is Hispanic dominant, with other ethnic groups including White, Asian, African American, and American Indian. A minimum of five juniors and seniors will be chosen to pilot the program. 


\section{Project Development}

Heart to Heart volunteer program aims to improve social interaction and decrease isolation of IwD through the development of a comprehensive training program. The project development process included a thorough literature review, needs assessment, and the creation of resources.

\section{Literature Review}

The team conducted a literature review to analyze the need for project development supporting social occupations for IwD. The literature review was completed using databases related to health sciences, public health, and OT. Databases are offered from the Dominican University of California Archbishop Alemany Library, including Google Scholar, CINAHL, Cochrane, PubMed, ScienceDirect, as well as AJOT accessed through AOTA student membership. The topics searched included remaining abilities of dementia, current dementia focused programs, quality of life of residents with dementia in SNFs, safety and policies of SNFs, and activities that IwD have the ability to do.

\section{Needs Assessment}

To better understand the facility's needs, the team completed a needs assessment with the facility's Director of Rehabilitation, JB Chua, via on-site interview. During the interview, JB expressed that the facility did not currently have volunteers and had few individualized one-onone activities, as well as the fact that there had been a high turnover of volunteers in the past. Typically visitors engaged in the group activities in the activities room, or aided other staff members to provide additional support. Therefore, the facility needed a volunteer program that promoted ongoing engagement of volunteers to facilitate individualized activities for the residents, and appropriate communication skills that would aid social interaction with IwD. The 
goal was to facilitate increased one-on-one activities as volunteers became more comfortable interacting with the residents. Ongoing support for the volunteers, and opportunities for debriefing would assist in retaining volunteers at the facility and increase opportunities for residents to interact with volunteers at the site. JB Chua initially suggested recruiting older adults in the local community as volunteers due to the likelihood of increased availability and long-term commitment. However, he ultimately requested recruitment of high school students to encourage intergenerational interaction. Intergenerational interaction would benefit the younger volunteers and the older IwD through the sharing of meaningful activities and interactions.

\section{Project Deliverables}

Training materials and volunteer resources increase knowledge and awareness of dementia to prevent stigmatization, promote volunteer skill and confidence, and improve interactions between volunteers and residents. Digital program resources were created using Articulate 360:Rise, Canva, Google Docs, and Microsoft Word. Program materials include an implementation guide, volunteer forms, in-person training presentations, an online training course, a volunteer handbook, a client profile, and an activity box (see Appendix D). The implementation guide was created using the website Canva, a free graphic design platform, with the intent to provide as much information and visuals to create a smooth process of preparing the activity director to implement the program. The team also created resources to support training volunteers. The volunteer forms and client profile, in-person training presentations, and volunteer handbook were created on Google Docs, Google Slides, and Microsoft Word, respectively. Additionally, the online training course was created on the program Articulate 360:Rise, providing education about dementia through interactive modules. Accessible and replicable materials support a lasting program to be sustained by the facility's Activity Director. 


\section{Program Implementation Guide}

The team developed a guide to outline the implementation schedule and methods for the Heart to Heart volunteer program (see Appendix D). The Activity Director will coordinate the training for the volunteers. Volunteer training consists of two sessions for in-person training and an online training (see Table 3). The program implementation guide includes a digital copy of volunteer forms, training presentations, volunteer handbook, client profile, and activity box instructions. It also provides instructions for utilization of program materials.

\section{Volunteer Forms}

Heart to Heart forms include a consent form, contact form, and timesheet for volunteer use (see Appendix D). The consent form emphasizes acknowledgment of confidentiality and voluntary engagement with a vulnerable population. It also provides a space for acknowledgment by a guardian for volunteers under 18 years of age. The participant contact form asks for basic information of the volunteer and two emergency contacts, such as names and phone numbers. Additionally, the timesheet provides space for volunteers to track the date of visitation, as well as the time they arrive and depart.

\section{Day 1 In-Person Training Presentation}

The PowerPoint presentation for the first day of in-person training includes a detailed introduction of the Heart to Heart volunteer program. The trainer will then introduce the Summerfield Healthcare staff, including the Director of Rehabilitation, Administrator, Activity Director, and OT on-site, as these team members are the volunteers' designated contact persons, and have specific roles in implementing the volunteer program. The first in-person training day also includes a tour of the facility for volunteers to become familiar and more comfortable with the environment. The trainer will explain the expectations and requirements of the volunteers in 
the program. The trainer will then provide an opportunity for volunteers to reflect on any previous experiences with individuals with dementia, as well as what they wish to take away upon completion of the program. An explanation and overview of the resources provided by Heart to Heart, including the activity box and the client profile, concludes the first in-person training session.

\section{Online Training Course}

An online course using Articulate 360:Rise software offers a variety of applications for the creation of customizable lessons. The team specifically used Rise, one of the many applications in Articulate 360 that is easy and intuitive to use, with numerous templates, royaltyfree images, and interactive components to create an engaging training course. The modules include photos, audio, and videos to provide a variety of learning experiences to enhance overall engagement. The course offers text for people who learn best by reading, pictures and videos for visual learners, voiceovers for auditory learners, and interactive activities for kinesthetic learners.

Before starting the online course, volunteers must complete a pre-volunteer survey with questions regarding their current knowledge and attitudes about dementia. Volunteers will complete the same survey with additional questions about their experience after completing eight weeks of visitation. The online portion of the volunteer training includes multiple modules that focus on understanding the basics about dementia, the specific stages of dementia, the remaining abilities associated with each stage, stage-appropriate strategies for meaningful communication, stage-appropriate activities to enhance resident participation, and a brief introduction to the activity box. See Table 2 for the learning objectives for each module. Each module includes a variety of interactive knowledge assessments, such as quizzes, matching, flashcards, and case studies. 
Table 2 Learning Objectives for Online Training Course Modules

\begin{tabular}{|c|c|}
\hline Module & Objectives \\
\hline What is Dementia? & $\begin{array}{l}\text { - Define dementia } \\
\text { - Understand the brain changes in individuals with } \\
\text { dementia } \\
\text { - Identify common behaviors and symptoms } \\
\text { - Discontinue stigma and misconceptions about dementia }\end{array}$ \\
\hline Behaviors and Symptoms & $\begin{array}{l}\text { - Identify general behaviors and symptoms of dementia } \\
\text { - Apply strategies when approaching dementia behaviors }\end{array}$ \\
\hline Stages of Dementia & $\begin{array}{l}\text { - Learn about stages of dementia } \\
\text { Identify common strengths and weaknesses at each } \\
\text { stage }\end{array}$ \\
\hline $\begin{array}{l}\text { Communication Skills and } \\
\text { Strategies }\end{array}$ & $\begin{array}{l}\text { - Identify strategies to communicate with individuals } \\
\text { with dementia } \\
\text { - Adapt communication strategies based on dementia } \\
\text { stages }\end{array}$ \\
\hline $\begin{array}{l}\text { Caring for Residents and } \\
\text { Yourself }\end{array}$ & $\begin{array}{l}\text { Value person-centered care for residents with dementia } \\
\text { - Identify problem-solving strategies for challenging } \\
\text { situations during visits }\end{array}$ \\
\hline Heart to Heart Activity Box & - Identify the purpose of the activity box \\
\hline Quiz & $\begin{array}{l}\text { - Apply strategies and knowledge learned throughout the } \\
\text { modules }\end{array}$ \\
\hline
\end{tabular}

\section{Volunteer Handbook}

A volunteer handbook summarizing key concepts from the online training course provides a supplemental resource for volunteers to study or utilize during visits. The handbook includes information about early and middle stage dementia, such as strengths, challenges, recommended activities, and tips for activity facilitation. It also outlines best practices for effective communication with residents including verbal, visual, physical, and contextual communication strategies. 


\section{Day 2 In-Person Training Presentation}

The second in-person training begins with a discussion and reflection of the online modules, and proceeds into further explanation and practice with the activity box and client profile. A PowerPoint presentation supports the session, which includes hands-on practical with role-play interactions between volunteers and residents. Volunteers also practice modifications of activities based on the specific stages of dementia. After the role-play activity, the trainers demonstrate the process of logging hours for each volunteer session on their timesheets. Lastly, the final training day ends with a reflection and opportunities for questions before the dismissal. See Table 3 for the overall schedule for the Heart to Heart volunteer program.

\section{Table 3 Schedule of Volunteer In-Person and Online Training}

\begin{tabular}{|c|c|}
\hline $\begin{array}{l}\text { Stages of } \\
\text { Volunteer } \\
\text { Training }\end{array}$ & Description of Training \\
\hline $\begin{array}{l}\text { In-Person Training } \\
\text { Day } 1\end{array}$ & $\begin{array}{l}\text { - Introduction of the Heart to Heart volunteer program } \\
\text { - } \\
\text { - } \text { Tour of the facility } \\
\text { - } \\
\text { - } \text { Reflectin requirements on previous experiences } \\
\text { Overview of the activity box and client profile }\end{array}$ \\
\hline $\begin{array}{l}\text { Online Training: } \\
\text { Articulate - Rise }\end{array}$ & $\begin{array}{l}\text { - Interactive items: videos, audios, matching, fill-in-the-blanks, } \\
\text { multiple choice, flashcards, quizzes, and case studies } \\
\text { Multiple modules with the following topics (See Table } 2 \text { for } \\
\text { learning objectives for each module): } \\
\text { - What is Dementia? } \\
\text { - Behaviors and Symptoms } \\
\text { - Stages of Dementia } \\
\text { - Communication Skills and Strategies } \\
\text { - Caring for Residents and Yourself } \\
\text { - Heart to Heart Activity Box }\end{array}$ \\
\hline $\begin{array}{l}\text { In-Person Training } \\
\text { Day } 2\end{array}$ & $\begin{array}{l}\text { - Discussion and reflection of the online modules } \\
\text { - Further explanation and hands-on practice with the activity box } \\
\text { and client profile } \\
\text { Role-playing using the activities in the box }\end{array}$ \\
\hline
\end{tabular}




\section{Client Profile}

In collaboration with the project advisor, the team created a client profile that will be used by the OT to identify the residents' stage of dementia, sensory likes and dislikes, supportive strategies, strengths, challenges, recommended conversation topics, recommended activities, and favorite songs (see Appendix D). OTs at the facility are trained in the ACA®, created by Dr. Gina Tucker-Roghi, OTD, OTR/L. The ACA ${ }^{\circledR}$ is based on Claudia Allen's Cognitive Disability Model and focuses on using client-centered approaches, retaining remaining abilities, and using client reminiscences to engage IwD in meaningful activities. As part of the ACA® process, OTs create a resident occupational profile and identify the resident's stage of dementia through assessments. OTs may use this information to complete the client profile based on the client's occupational profile and remaining abilities. The client profile aids the interdisciplinary healthcare team and volunteers in facilitating meaningful activities and optimizing communication with the residents.

The OT or the Activity Director provides this information to the volunteers once the volunteers have completed their training and matched with a resident. This information allows the volunteer to understand the resident on a more personal level and facilitate more favorable activities, enhancing the experience for both the volunteer and resident. By indicating the residents' ACLs, volunteers can identify the appropriate communication techniques and activities for effective interactions.

\section{Activity Box}

Activity boxes provide volunteers with items and instructions to facilitate and adapt familiar objects and social activities according to typical remaining abilities of residents in early and middle stage dementia. Each activity box includes sensory enhancing objects (flameless 
candles and an essential oil diffuser), artificial flowers to make bouquets, a deck of cards, puzzles, balloons for a balloon toss activity, wooden beads and string, and a water painting activity (see Figure 1). Each box also includes a tips sheet to adapt the activity based on the remaining abilities of individuals in early or middle stage dementia to enhance the IwD's ability to engage with the materials and volunteer.

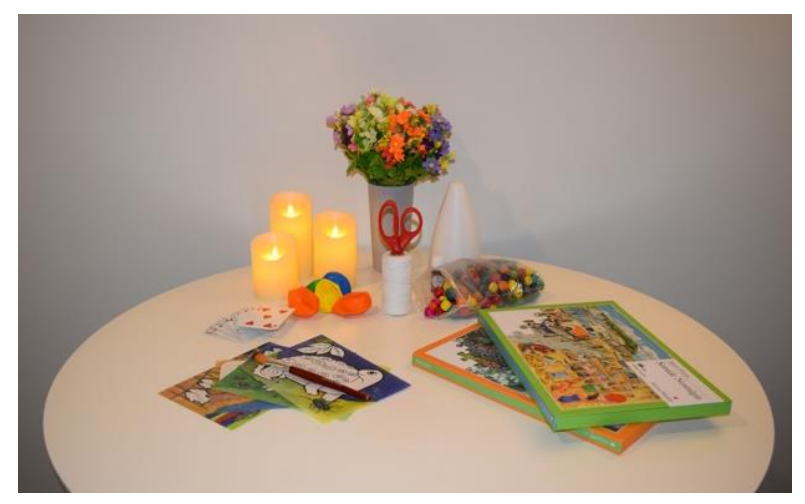

Figure 1 Heart to Heart Volunteer Program Activity Box Items

\section{Project Implementation}

Initially, the project's start date was March 23, 2020 and was projected to end on May 19, 2020. The team collaborated with the Summerfield Healthcare Center's Director of Rehabilitation and Elsie Allen High School's career counselor to recruit the target residents and volunteers. However, due to the COVID-19 pandemic and the resulting limitations, the team ceased recruitment. The implementation guide and accessible resources will allow program execution by the facility Activity Director following the project implementation plan in Figure 2 . All program resources are available on Dominican University's Occupational Therapy Department Healthy Aging website. 


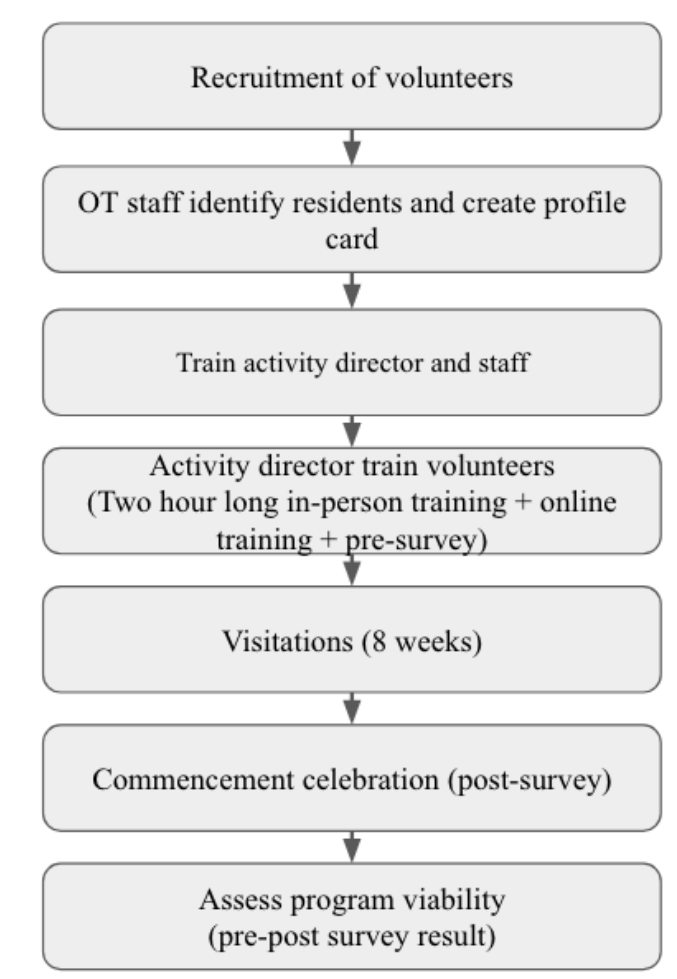

Figure 2 Steps for Heart to Heart volunteer program implementation

\section{Implementation Limitations}

The Heart to Heart volunteer program comprises many important components to promote the function and success of the program. However, significant limitations have hindered the implementation of this program, such as limited availability of the Summerfield Healthcare Center staff, lack of an activity director at the SNF, and visitation restrictions resulting from COVID-19.

Due to scheduling conflicts with Summerfield Healthcare Center's staff, the team was only able to meet staff during resident lunch hours. Therefore, the team was unable to visit with the residents, resulting in the inability to observe the resident's engagement and interests, and the inability to note strengths and weaknesses of the facility's current resident activity programs. In light of this limitation, the team attempted to provide a variety of activities to meet the 
resident population's diverse interests. Had the team been able to observe the activity programs and interact with the residents, the activities chosen for the activity box would have been more individualized, tailoring the activities more specifically for the residents who intended to participate in the Heart to Heart volunteer program.

At the time of the needs assessment with the Director of Rehabilitation, there was no Activity Director on staff at the facility. This limited interdisciplinary collaboration, which would have added another professional's perspective and increased the value of the program.

Lastly, the COVID-19 pandemic limited implementation of the Heart to Heart volunteer program, as Summerfield Healthcare Center restricted non-essential visitors and high schools transitioned to virtual learning. These limitations resulted in the inability to recruit volunteers and residents, facilitate visitations, obtain program evaluation data, and determine the effectiveness of the program. The implementation guide will outline the process for future implementation and evaluation by the Activity Director.

\section{Recruitment of Volunteers}

The program implementation team will first identify their target volunteer population. The team will contact a local high school to coordinate an informational session to recruit student volunteers. During the informational session, the SNF program implementation team will present a 15-minute PowerPoint presentation to provide an overview of the Heart to Heart volunteer program. Additionally, students will receive a flyer about the program (see Appendix D). Interested students will then sign up and obtain a consent form and student contact form, which will be collected during the first in-person introduction session (see Appendix D). 


\section{Recruitment of Residents}

Residents in early and middle stage dementia will be referred to Heart to Heart by Summerfield Healthcare Center's Director of Rehabilitation and licensed OT. Participating residents will receive information about the Heart to Heart volunteer program and sign a consent form (see Appendix D). If residents are unable to sign for themselves, a family member or power of attorney may complete the form on the resident's behalf. The OT will complete a client profile to guide the volunteers in the facilitation of meaningful activities and utilization of optimal communication skills.

\section{Training of Skilled Nursing Facility Staff}

The Activity Director, OTs, and COTAs will be trained to implement the program at the facility using the implementation guide. Training will occur over one day to review the inperson training, online modules, forms, and activity box materials. Each staff will familiarize themselves with the resources and tools to increase their knowledge and competency for volunteer training. The Activity Director will receive access to a variety of learning mediums, including PowerPoint presentations, role-play scenarios, and case studies.

\section{Volunteer Training and Visitation}

Once the Activity Director is trained, they will train the volunteers according to the schedule outlined in Table 3 . Then, volunteers will be matched with residents for eight weeks of visits. Throughout the visitations, the Activity Director will offer debriefing sessions with the volunteers to discuss successes, challenges, and/or concerns. Additionally, a staff member will be present and available for immediate support during the visits. 


\section{Commencement Celebration}

After eight weeks of visits, volunteers, residents, and staff will celebrate with a commencement event at the facility. Participants will have the opportunity to share their experiences in the Heart to Heart volunteer program. Volunteers will also complete the postvolunteer survey, which includes the same questions as the pre-volunteer survey with additional qualitative questions to evaluate the impact of the program. Volunteers may continue participation in the program if they wish.

\section{Project Evaluation Plan}

The Heart to Heart volunteer program includes methods to evaluate volunteer improvements in satisfaction, knowledge, and visiting frequency, which will be completed after the implementation of the program. To obtain feasibility data, content experts in dementia and skilled nursing facility practice completed a 24-question survey on Google Forms to provide feedback of Heart to Heart volunteer program. In addition, Heart to Heart was evaluated by OT students and practitioners at a state-wide virtual occupational therapy conference.

\section{Volunteer Pre-Test and Post-Test}

Heart to Heart volunteers will complete a questionnaire before the training and after the eight weeks of visitation to evaluate volunteer satisfaction, comfort, and confidence. In addition to satisfaction with the program, the questionnaire also addresses knowledge of dementia and attitudes towards dementia. Nine questions in a Likert Scale will determine the volunteer's knowledge of dementia. This section was adapted from Dementia Knowledge Assessment Tool Version Two (DKAT2) created by Toye, Lester, Popescu, Mcinerney, Andrews, \& Robinson (2013) to measure family member's and caregiver's understanding of the IwD's perspective (stigma), dementia's trajectory, and appropriate care for IwD. Adaptations included omission of 
questions irrelevant to high school volunteers, and inclusion of questions relevant to high school volunteers. Questions regarding attitudes towards dementia were adapted from Dementia Attitude Scale (DAS), which is a 20 item 5-point Likert scale measure. DAS scores are based on participants' dementia knowledge and social comfort. Adaptation of the questions included changing the language to fit the education level of our volunteers and eliminating irrelevant questions. Lastly, to understand volunteer satisfaction and quality of the Heart to Heart volunteer program, two open-ended questions were added in the post questionnaire (see Appendix D). The two questions allow volunteers to state aspects they enjoyed about the program and suggestions for improvement. Scores from pre- and post-volunteer surveys will be compared to determine the program's effects on volunteer knowledge, ease, and competency in engaging with residents with dementia.

\section{Volunteer Online Training Knowledge Checks}

Knowledge checks within the Heart to Heart online modules will measure participants' learning experiences (see Appendix B). Throughout the course, volunteers will be tested on identifying remaining abilities at various stages of dementia, and applying appropriate communication skills through multiple choice, fill-in-the-blank, matching, sorting, and case study activities. The course progress of the participant will be recorded for review of completion and competency.

\section{Volunteer Visiting Frequency and Satisfaction}

The SNF implementation team will use volunteer sign-in and sign-out records from the facility to compare the frequency and duration of visits with residents before and after implementation of the program. Volunteers will also journal their visit to document what they did, how they felt, and any arising concerns. The journal will provide opportunities for student 
volunteers to share their experiences, connect with other volunteers, and receive feedback from staff. The reflection may be implemented by the school as an additional learning activity if they so wish.

\section{Content Expert Feasibility Survey}

The Heart to Heart volunteer program was reviewed by content experts with knowledge of program development and the dementia population, Tina Hand and Amanda Grace. Tina Hand is the Volunteer Engagement Project Manager at California Association of Health Facilities (CAHF). Her work in CAHF Volunteer Engagement Project supports the implementation of an intensive pilot volunteer program in 20 SNFs that is successful and sustainable in the community. Amanda Grace is a Dominican University of California faculty member. She also works with Ensign Services as an Abilities Care Approach instructor for interdisciplinary practitioners in rehabilitation for IwD. After reviewing the Heart to Heart program materials, including the online training course, volunteer handbook, activity box instructions, and program implementation guide, they completed the Heart to Heart Dementia Volunteer Program Feasibility Evaluation. The survey included 5-point Likert scale and openended questions about the overall program and about each program item (see Appendix C). The Likert scale ranged from 1 (strongly disagree) to 5 (strongly agree). Questions focused on assessing the effect on the target population, factors influencing implementation, and ability of participants to facilitate program activities, as well as recommendations for improvement. Results are summarized in Table 4. 
Table 4 Feasibility Survey Results

\begin{tabular}{|c|c|c|}
\hline Area of Focus & Question & Average Response \\
\hline \multirow[t]{2}{*}{$\begin{array}{l}\text { Effect on target } \\
\text { population }\end{array}$} & $\begin{array}{l}\text { Do the materials support the } \\
\text { program's purpose? }\end{array}$ & $5 / 5$ \\
\hline & $\begin{array}{l}\text { Does Heart to Heart positively } \\
\text { impact social isolation in } \\
\text { individuals with dementia? }\end{array}$ & $4.5 / 5$ \\
\hline \multirow[t]{4}{*}{$\begin{array}{l}\text { Factors affecting } \\
\text { implementation ease } \\
\text { or difficulty }\end{array}$} & $\begin{array}{l}\text { What were some strengths you } \\
\text { observed from reviewing the Heart } \\
\text { to Heart Dementia Volunteer } \\
\text { Program? }\end{array}$ & $\begin{array}{l}\text { - Variety of learning } \\
\text { formats } \\
\text { - Ability to learn a lot about } \\
\text { dementia in a short } \\
\text { amount of time } \\
\text { - Interactive quiz at the end } \\
\text { of the online course } \\
\text { - Stage specific suggestions } \\
\text { - Collaboration with } \\
\text { activities programming }\end{array}$ \\
\hline & $\begin{array}{l}\text { Online Course, Volunteer } \\
\text { Handbook, Activity Box } \\
\text { Instructions, Program } \\
\text { Implementation Guide: Is the } \\
\text { content delivered effectively } \\
\text { through various mediums, such as } \\
\text { visuals, or text? }\end{array}$ & $\begin{array}{l}4.38 / 5 \text { (average across all } \\
\text { items) }\end{array}$ \\
\hline & $\begin{array}{l}\text { Online Course, Volunteer } \\
\text { Handbook, Activity Box } \\
\text { Instructions, Program } \\
\text { Implementation Guide: Is the } \\
\text { language appropriate for the } \\
\text { intended population? }\end{array}$ & $\begin{array}{l}4.63 / 5 \text { (average across all } \\
\text { items) }\end{array}$ \\
\hline & $\begin{array}{l}\text { Program Implementation Guide: } \\
\text { Do you understand how to run the } \\
\text { program? }\end{array}$ & $4 / 5$ \\
\hline \multirow{2}{*}{$\begin{array}{l}\text { Ability of participants } \\
\text { to carry out } \\
\text { intervention activities }\end{array}$} & $\begin{array}{l}\text { Activity Box Instructions: Do you } \\
\text { understand what the activities are? }\end{array}$ & $5 / 5$ \\
\hline & $\begin{array}{l}\text { Activity Box Instructions: Do you } \\
\text { understand how to adapt activities } \\
\text { to various stages of dementia? }\end{array}$ & $4 / 5$ \\
\hline
\end{tabular}


Area of Focus

Question

Average Response

Recommendations Overall: Do you have any overall suggestions for the Heart to Heart Dementia Volunteer Program?

- Develop easy to use materials for overview of facility responsibility and readiness, such as a checklist

Online Course: Do you have any suggestions for improvement?

- Provide context related to student/volunteer experience

- Consider comparison to developmental stages with children

- - Improve audio quality of videos in the online module

Volunteer Handbook: Do you have any suggestions for improvement?
- Add tips to adapt activities presented by level

- Add supplemental information and explanation for one activity per stage

Activity Box Instructions: Do you have any suggestions for improvement?

Program Implementation Guide: Do you have any suggestions for improvement?
- Consider adding desired outcomes and indications for active participation

- Consider a separate guide for volunteers and staff

- Indicate expectations and responsibilities of staff and caregivers

\section{Program Presentation at the Occupational Therapy Association of California Conference}

Despite significant implementation limitations, the Heart to Heart volunteer program provides a meaningful resource enabling SNFs to promote social co-occupations and a sense of community through intergenerational relationships, and ultimately enhance the QOL of residents with dementia. The team disseminated the Heart to Heart volunteer program in a 75-minute workshop at the Occupational Therapy Association of California (OTAC) 2020 Virtual Annual 
Conference. The OTAC conference provides opportunities for professional development and continuing education for OT students and practitioners. The Heart to Heart workshop included an explanation of the Heart to Heart program, a demonstration of our program resources, and a discussion of the program value in OT practice for the dementia population. Attendees completed a survey with 5-point Likert scale questions ranging from 1 (poor) to 5 (excellent). Questions related to quality in objectives, content, presentation style, organization, and evidencebased references. 


\section{Results}

Heart to Heart volunteer program is designed to promote engagement in social occupations for IwD in SNFs through volunteer training. The program aims to train volunteers on the use of effective communication strategies and appropriate activities that are optimal for the remaining abilities of individuals at the various stages of dementia. This program also aims to increase visiting frequency and IwD's QOL as a result of the volunteers' increased competency and confidence in engaging with the residents with dementia. This program was evaluated by content experts with a feasibility survey that used a 5-point Likert scale format. The results from the program feasibility survey indicate strong feasibility of the program through the inclusion of program materials that positively support the program's purpose. The results also reflect the potential for positive impacts on social isolation in $\operatorname{IwD}$ (see Table 3).

Results from the 5-point Likert scale questions from the survey regarding effects on the target population, factors influencing implementation, and ability of participants to facilitate program activities averaged 4.6 , indicating very good program feasibility. The team updated the program materials according to the evaluators' recommendations, increasing the program's potential effectiveness. Upon implementation of Heart to Heart, the program will undergo further evaluation for efficacy on volunteer knowledge, satisfaction, and visiting frequency.

In the survey, an evaluator reported, "I think this program is excellent and very important." Additionally, the same evaluator felt that she "learned a lot about dementia in a short amount of time" and "enjoyed the variety of formats through which [she] was learning." Another evaluator noted strengths of the program were the "stage specific suggestions for enhancing interaction and social engagement with individuals with dementia, and collaboration with facility-wide activities programming." She also noted "This is an excellent description of 
expectations for volunteers, the training and overview of the activity box."

In addition to the feasibility survey, the team presented the Heart to Heart program in a workshop at the OTAC 2020 Virtual Conference. The conference attendees included students, practitioners, and experts in occupational therapy. One attendee stated, "Once the COVID-19 sanctions are lifted, your program will be very successful in SNF/MCUs." The overall rating of the presentation was 4.78 , indicating strong interest and value of the Heart to Heart volunteer program in OT practice (see Table 5).

Table 5 OTAC 2020 Virtual Annual Conference Presentation Feedback

\begin{tabular}{ll}
\hline \multicolumn{1}{c}{ Presentation Features } & Average Response \\
\hline Objectives of the Session Were Met & 4.78 \\
\hline Content Provided Application to Practice & 4.78 \\
\hline Presentation Style & 4.56 \\
\hline Organization of Presentation & 4.78 \\
\hline Evidence-based References & 4.45 \\
\hline Overall Evaluation & 4.78 \\
\hline
\end{tabular}




\section{Discussion}

The current literature indicates that the existing programs, such as FVEP, music interventions, and individualized one-on-one activities do not include education for volunteers, in combination with individualized activities for the IwD (McCallion, Toseland \& Freeman, 1999; Särkämö, T., et al, 2014; Van der Ploeg, Walker \& O’Connor, 2014). The Heart to Heart volunteer program addresses the gap in the existing programs with a sustainable and comprehensive volunteer program. Heart to Heart provides SNFs with resources to recruit volunteers, and provide volunteers with sufficient knowledge and tools to promote frequent and quality visits for residents with dementia. The program ultimately aims to improve QOL for residents. All program materials are user-friendly, accessible and replicable for utilization by any SNF.

Evaluation of the Heart to Heart program included review by content experts, OT students, and OT practitioners. High average rating on program feasibility and its applicability to practice indicates the effectiveness of Heart to Heart in addressing the needs of the dementia population living in SNFs. Additionally the program adds value to the occupational therapy field by providing an organization-level intervention to improve the QOL of IwD. The team addressed necessary modifications to increase the value and feasibility of the program.

Further evaluation upon implementation is necessary to identify effectiveness of the program. Heart to Heart includes proposed methods for future evaluation, including volunteer visit frequency and duration data, as well as pre- and post-volunteer survey results to observe changes in knowledge and satisfaction. However, the program focused on short-term volunteer outcomes, and does not include methods to measure long-term resident outcomes. Established SNF data tracking processes address this gap in evaluation. SNFs regularly track residents' use 
of psychotropic medication, engagement in activities, and mental health. This data could be used to track program outcome measures. The Activity Director can utilize methods provided by Heart to Heart, along with data tracked by the SNF, to further evaluate the effectiveness of the program in improving social engagement and QOL of SNF residents with dementia. 


\section{Limitations}

Limitations for this program include the exclusion of individuals with late stage and end stage dementia. Individuals at these stages of dementia were excluded because the volunteer population included high school volunteers. Late and end stage dementia are both complex, and require thorough training for the volunteers to safely and effectively facilitate visits with individuals at this level. Due to the chosen high school aged volunteer population, it would be most appropriate to focus the volunteer training on early and middle stage dementia to avoid overwhelming volunteers with challenging behaviors and symptoms typically seen in late and end stage dementia. The amount of time and hands-on training necessary to adequately educate the volunteers to successfully interact with individuals living with late and end stage dementia is not feasible for this program.

This program's ability to be person-centered is limited by the supplies in the activity box. The activity box lacks person-centeredness due to the inability to meet with the residents who intended to participate in Heart to Heart. Thus, the activities were not tailored to potential participants' interests. However, the program trains the volunteers to sufficiently modify the activities in the box based on the resident's remaining ability and correlating stage of dementia in order to support the resident's best ability to function. Therefore, the stage-specific activity modifications enable aspects of the program to be person-centered in this unique way.

It is also important to consider that the Heart to Heart volunteer program does not include evaluations that measure the resident's satisfaction with the program. Rather, this program includes evaluation measures focused on the volunteer satisfaction and sentiments pre- and posttraining. Individuals and facilities who wish to implement this program in the future may consider including evaluation tools to measure the resident's changes in engagement and mental 
health as a result of participation in Heart to Heart, as well as overall satisfaction with the program.

Lastly, this program is designed to be facilitated in an in-person setting. Future programs may consider incorporating a virtual component to increase the number of individuals who could access similar experiences and benefit from these visits. 


\section{Implications for Occupational Therapy Practice}

Occupational therapy emphasizes the importance of engagement in meaningful cooccupations and its impact on QOL for all individuals, regardless of physical, cognitive, or emotional ability. The Heart to Heart volunteer program incorporates a person-centered and strengths-based OT perspective to support the unique community in SNFs by targeting interventions at the individual, organizational, and population levels. The OT guides quality communication and engagement for those working with residents with dementia, promoting improved dementia care and intergenerational relationships. Establishment of supportive social environments ultimately prevents social isolation for residents with dementia for improved QOL.

OTs utilize community-based interventions to create supportive social environments. Community-based OT considers the lifestyle of the IwD within their community, including contextual factors, such as culture, social supports, and environmental supports. This is evident through the service provided not only to the residents with dementia living at the SNF, but also the service provided to others within the SNF community, such as the professional caregiving staff and rehabilitation staff, as well as high school volunteer participants. There is a unique community within the SNF, with particular schedules, routines, lifestyles, social and environmental supports that impact the residents' ability to engage in meaningful occupations.

In the Heart to Heart volunteer program, occupational therapy practitioners provide consultation and education at an organizational level to create a community within the SNF that supports occupational engagement for IwD. While the program is implemented at an organizational level, it also provides person-centered intervention for residents with dementia through the use of the client profile in volunteer visits. The client profile combines OT expertise 
in assessments to develop occupational profiles for the residents, and identify the IwD stage of dementia. OTs use the occupational profile to gather critical client information including interests, strengths, and limitations. OTs also use the CDM to identify an individual's strengths and remaining abilities. OTs then match the cognitive demands of tasks with an IwD's remaining abilities for success and safety. Information gathered through the comprehensive assessment process is communicated in the client profile to promote a goodness of fit between the social environment and the resident's best ability to function. The client profile allows the residents to receive individualized interactions.

The client profile also supports the organizational level of the SNF by informing volunteers about the most effective and appropriate communication strategies and activities for successful visits. The multidisciplinary team can also utilize the client profile to provide improved individualized, person-centered care in the SNF. In addition to the client profile, Heart to Heart volunteer program provides volunteers with a variety of tools guided by a holistic, person-centered, strengths-based OT perspective to learn about dementia and develop strategies to socialize with individuals with dementia. Increased volunteer knowledge and skills reduce stigma and enhance social interactions, promoting intergenerational relationships. Intergenerational relationships benefit both the volunteer and residents, as volunteers engage in self-development and residents participate in co-occupations.

Heart to Heart addresses the immediate social needs of the dementia population living in SNFs. Additionally, the virtual platform used for volunteer training supports accessibility and replicability of Heart to Heart.. With establishment of a lasting volunteer program, social isolation can be prevented for future residents. The population of individuals with dementia is rapidly increasing, and OTs provide preventative services to prevent social isolation for 
improved QOL. Heart to Heart is a valuable resource that enhances the QOL for residents with dementia in a SNF community. 


\section{Conclusion}

As the aging population increases in the United States, as does the need for high-quality long-term care in SNFs. Social isolation presents a significant health care challenge for older adults, and residents in SNFs may experience decreased engagement in social occupations (Health Resources \& Services Administration, 2019). Additionally, a resident living with cognitive decline in a SNF faces many challenges that impact their ability to engage in meaningful social co-occupations, increasing the likelihood of social isolation (Ono et al., 2014). Barriers include the resident's decline in cognitive function, the limited availability of the resident's family, existing stigma of $\mathrm{IwD}$, and a lack of comprehensive volunteer and visitor training programs (Alzheimer's Association, 2012; Eggenberger et al., 2012; Hurst et. al., 2019; McCallion et al., 1999; Särkämö et al, 2014; Stites et al., 2018; Van der Ploeg et al., 2014).

Heart to Heart volunteer program aims to prevent social isolation and improve overall QOL for residents with dementia in a SNF, by utilizing a person-centered, occupational therapy perspective to create opportunities for individuals in the community to engage in intergenerational social activities. This program supplies SNFs with resources to recruit volunteers from the local community, as well as to provide the volunteers with sufficient knowledge and tools to utilize appropriate communication techniques, and adapt activities based on the resident's stage of dementia. Increased volunteer competence, confidence, and satisfaction in facilitating individualized activities for residents may increase quality and frequency of visits. The value of OT in program development for residents living in SNFs is essential for high quality, person-centered care, as OTs utilize the occupational profile to gain valuable knowledge about the individual (AOTA, 2014; AOTA, 2017). OTs then incorporate expertise in dementia assessment and care to match the client with activities supporting their 
interests and strengths. Strong implementation feasibility and interest of Heart to Heart supports the value of OT in multidisciplinary, occupation-based, and community-based program development to improve the QOL for residents with dementia in SNFs. 


\section{References}

Allen Cognitive Group. Core Concepts. https://www.allencognitive.com/core-concepts/

Alzheimer's Association. (2012). World Alzheimer Report reveals negative perceptions about people with dementia. https://www.alz.org/news/2012/world-alzheimer-report-revealsnegative-perception

Alzheimer's Association. (2020a). Facts and Figures. https://www.alz.org/alzheimers$\underline{\text { dementia/facts-figures }}$

Alzheimer's Association. (2020b). Residential Care. https://www.alz.org/help$\underline{\text { support/caregiving/care-options/residential-care }}$

Alzheimer's Association (2020c). Stages and Behaviors. https://www.alz.org/help$\underline{\text { support/caregiving/stages-behaviors }}$

Alzheimer's Association. (2020d). Stages of Alzheimer's. https://www.alz.org/alzheimersdementia/stages

Alzheimer's Association. (2020e) What is dementia? https://alz.org/alzheimers-dementia/whatis-dementia

Alzheimer's Society. (2019a). Turning Up the Volume: unheard voices of people with dementia. https://www.alzheimers.org.uk/sites/default/files/migrate/downloads/turning_up the_vol ume_unheard_voices_of_people_with_dementia.pdf

Alzheimer's Society. (2019b). Tackling loneliness in people living with dementia. https://www.alzheimers.org.uk/blog/tackling-loneliness-people-living-dementia 
American Occupational Therapy Association (AOTA). 2020. Ethics AOTA 2020 Occupational Therapy Code of Ethics.

https://www.aota.org/media/Corporate/Files/Practice/Ethics/AOTA-2020-Code-ofEthics.pdf

American Occupational Therapy Association. (2017). Dementia and the Role of Occupational Therapy. https://www.aota.org/About-OccupationalTherapy/Professionals/PA/Facts/Dementia.aspx

American Occupational Therapy Association. (2014). Occupational Therapy Practice Framework, 3rd Ed., Bethesda, MD: AOTA Press.

Brown, C., and Stoffel, V.C. (2011). Occupational Therapy in Mental Health: a vision for participation. Philadelphia, PA: F.A. Davis

Cahill, S., Pierce, M., Werner, P., Darley, A., \& Bobersky, A. (2015). A Systematic Review of the Public's Knowledge and Understanding of Alzheimer's Disease and Dementia. Alzheimer Disease \& Associated Disorders, 29(3), 255-275. https://doi.org/10.1097/wad.0000000000000102

Centers for Disease Control and Prevention. (2019). What is Dementia? https://www.cdc.gov/aging/dementia/index.html

Centers for Medicare and Medicaid Services. (2019). National partnership to improve dementia care in nursing homes. https://www.cms.gov/Medicare/Provider-Enrollment-andCertification/SurveyCertificationGenInfo/National-Partnership-to-Improve-Dementia$\underline{\text { Care-in-Nursing-Homes }}$

Champagne, T. (2006). The ACL battery. OT-Innovations. https://www.otinnovations.com/clinical-practice/cognition-2/the-allen-cognitive-level-battery/ 
Cohen, L. W., Zimmerman, S., Reed, D., Sloane, P. D., Beeber, A. S., Washington, T., Cagle, J. G., \& Gwyther, L. P. (2014). Dementia in relation to family caregiver involvement and burden in long-term care. Journal of applied gerontology: the official journal of the Southern Gerontological Society, 33(5), 522-540. https://doi.org/10.1177/0733464813505701

Cohen-Mansfield, J., Dakheel-Ali, M., Marx, M. S., Thein, K., \& Regier, N. G. (2015). Which unmet needs contribute to behavior problems in persons with advanced dementia?. Psychiatry Research, 228(1), 59-64. https://doi.org/10.1016/j.psychres.2015.03.043

Du Toit, S., \& Van Der Merwe, R. (2013). Promoting person-centred care for people with advanced dementia through environmental adaptations. South African Journal of Occupational Therapy, 43(2), 02-04. http://www.scielo.org.za/scielo.php?script=sci_arttext\&pid=S2310-38332013000200002

Eggenberger, E., Heimerl, K., \& Bennett, M. I. (2012). Communication skills training in dementia care: A systematic review of effectiveness, training content, and didactic methods in different care settings. International Psychogeriatrics, 25(3), 345-358. https://doi.org/10.1017/S1041610212001664

Ensign Therapy. Online Training Modules to Implement the Abilities Care Approach ${ }^{\mathrm{TM}}$. https://ensigntherapy.com/online-training-modules-implement-abilities-care-approach/

Fazio, S., Pace, D., Kallmyer, B., Maslow, K., \& Zimmerman, S. (2018). Alzheimer’s association dementia care practice recommendations. The Gerontologist, 58(S1), S1-S9. 
Foebel, A. D., Onder, G., Finne-Soveri, H., Lukas, A., Denkinger, M. D., Carfi, A., Liperoti, R. (2016). Physical restraint and antipsychotic medication use among nursing home residents with dementia. Journal of the American Medical Directors Association, 17(2), 184.e9-14. https://doi.org/10.1016/j.jamda.2015.11.014

Gilmore-Bykovskyi, A. L., Roberts, T. J., Bowers, B. J., \& Brown, R. L. (2015). Caregiver Person-Centeredness and Behavioral Symptoms in Nursing Home Residents with Dementia: A Timed-Event Sequential Analysis. Gerontologist, 55, s61. Health Resources \& Services Administration. (2019). The "Loneliness Epidemic". https://www.hrsa.gov/enews/past-issues/2019/january-17/loneliness-epidemic

Houser, A. (2007). Nursing homes. AARP Public Policy Institute. https://www.aarp.org/homegarden/livable-communities/info-2007/fs10r_homes.html

Hurst, A., Coyne, E., Kellett, U., \& Needham, J. (2019). Volunteers motivations and involvement in dementia care in hospitals, aged care and resident homes: An integrative review. Geriatric Nursing. https://doi.org/10.1016/j.gerinurse.2019.03.010

Leland, N., \& Wong, C. (2018). Applying the Person-Environment-Occupation model to improve dementia care. American Occupational Therapy Association. https://www.aota.org/ /media/Corporate/Files/Publications/CE-Articles/CE-Article-May$\underline{\text { 8.pdf }}$

Lindman Port, C. (2004). Identifying changeable barriers to family involvement in the nursing home for cognitively impaired residents. Gerontologist, 44(6), 770-778, https://doi.org/10.1093/geront/44.6.770 
Maseda, A., Sánchez, A., Marante, M. P., González-Abraldes, I., de Labra, C., \& Millán-Calenti, J. C. (2014). Multisensory Stimulation on Mood, Behavior, and Biomedical Parameters in People With Dementia: Is it More Effective Than Conventional One-to-One Stimulation? American Journal of Alzheimer's Disease \& Other Dementias, 29(7), 637.

McColl, M. A. (1998). What do we need to know to practice occupational therapy in the community? American Journal of Occupational Therapy, 52(1), 11-18 https://doi.org/10.5014/ajot.52.1.11

McCallion, P., Toseland, R. W., \& Freeman, K. (1999). An evaluation of a family visit education program. Journal of the American Geriatrics Society, 47(2), 203-214. https://doi.org/10.1111/j.1532-5415.1999.tb04579.x

Meyers, S. (2009). Community practice in occupational therapy: A guide to serving the community. (pp. 2-3). Burlington, MA: Jones \& Bartlett Learning.

Ono, K., Kanayama, Y., Iwata, M., \& Yabuwaki, K. (2014). Views on Co-occupation between Elderly Persons with Dementia and Family. Journal of gerontology and geriatric research, 3, https://doi.org/1-6.10.4172/2167-7182.1000185

Padilla, R. (2011). Effectiveness of Interventions Designed to Modify the Activity Demands of the Occupations of Self-Care and Leisure for People With Alzheimer's Disease and Related Dementias. American Journal of Occupational Therapy, 65(5), 523-531. https://doi-org.dominican.idm.oclc.org/10.5014/ajot.2011.002618

Pickens, N. D., \& Pizur-Barnekow, K. (2009). Co-occupation: Extending the dialogue. Journal of Occupational Science, 16, https://doi.org/151-156.0.1080/14427591.2009.9686656 
Piechniczek-Buczek, J., Riordan, M.E., \& Volicer, L. (2007). Family member perception of quality of their visits with relatives with dementia: a pilot study. Journal of the American Medical Directors Association, 8(3), 166-172. https://doi.org/doi:10.1016/j.jamda.2006.09.017.

Redfoot, D., Feinberg, L., \& Houser, A. (2013). The aging of the baby boom and the growing care gap: A look at future declines in the availability of family caregivers. American Association of Retired Persons. http://www.aarp.org/home-family/caregiving/info-082013/the-aging-of-the-baby-boom-and-the-growing-care-gap-AARP-ppi-ltc.html

Särkämö, T., Tervaniemi, M., Laitinen, S., Numminen, A., Kurki, M., Johnson, J. K., \& Rantanen, P. (2014). Cognitive, emotional, and social benefits of regular musical activities in early dementia: Randomized controlled study. The Gerontologist, 54(4), 634650. https://doi.org/10.1093/geront/gnt100

Segal, J., \& Robinson, L. (2019). Volunteering and its surprising benefits. Help Guide. https://www.helpguide.org/articles/healthy-living/volunteering-and-its-surprisingbenefits.htm?pdf=13391

Smit, D., de Lange, J., Willemse, B., Twisk, J., \& Pot, A. M. (2016). Activity involvement and quality of life of people at different stages of dementia in long term care facilities. Aging \& Mental Health, 20(1), 100-109. https://doi.org/10.1080/13607863.2015.1049116

Smith, K., Holmes, K., Haski-Leventhal, D., Cnaan, R. A., Handy, F., \& Brudney, J. L. (2010). Motivations and benefits of student volunteering: Comparing regular, occasional, and non-volunteers in five countries. Canadian Journal of Nonprofit and Social Economy Research, 1(1), 65-81. https://doi.org/10.22230/cjnser.2010v1n1a2 
Stites, S. D., Johnson, R., Harkins, K., Sankar, P., Xie, D., \& Karlawish, J. (2016). Identifiable Characteristics and Potentially Malleable Beliefs Predict Stigmatizing Attributions Toward Persons With Alzheimer's Disease Dementia: Results of a Survey of the U.S. General Public. Health Communication, 33(3), 264-273. https://doi.org/10.1080/10410236.2016.1255847

Stites, S. D., Rubright, J. D., \& Karlawish, J. (2018). What features of stigma do the public most commonly attribute to Alzheimer's disease dementia? Results of a survey of the U.S. general public. Alzheimer's and Dementia, (7), 925-932. https://doi.org/10.1016/j.jalz.2018.01.006

Tina Champagne. (2018). Sensory modulation in dementia care. GB: Jessica Kingsley Publishers. Retrieved from https://ebookcentral.proquest.com/lib/[SITE_ID]/detail.action?docID=5348133

Toye, C., Lester, L., Popescu, A., Mcinerney, F., Andrews, S., \& Robinson, A. L. (2013). Dementia Knowledge Assessment Tool Version Two: Development of a tool to inform preparation for care planning and delivery in families and care staff. Dementia, 13(2), 248-256. https://doi.org/10.1177/1471301212471960

Van der Ploeg, Eva S, Walker, H., \& O'Connor, D. W. (2014). The feasibility of volunteers facilitating personalized activities for nursing home residents with dementia and agitation. Geriatric Nursing, 35(2), 142-146. https://doi.org/10.1016/j.gerinurse.2013.12.003

Yamamoto-Mitani, N., Aneshensel, C. S., \& Levy-Storms, L. (2002). Patterns of family visiting with institutionalized elders: The case of dementia. The Journals of Gerontology. Series B, Psychological Sciences and Social Sciences, 57(4), S234-S246. https://doi.org/10.1093/geronb/57.4.S234 
Appendix A: ACL and Remaining Abilities 


\begin{tabular}{|c|c|c|c|c|c|c|}
\hline $\begin{array}{l}\text { Allen Cognitive } \\
\text { Level (ACL) }\end{array}$ & ACL 1 & ACL 2 & ACL 3 & ACL 4 & ACL 5 & ACL 6 \\
\hline $\begin{array}{l}\text { Performance } \\
\text { Modes/ } \\
\text { Stage of Dementia }\end{array}$ & $\begin{array}{l}\text { Automatic Actions } \\
\text { (Awareness)/End } \\
\text { Stage Dementia }\end{array}$ & $\begin{array}{l}\text { Postural Actions (Gross } \\
\text { Body Movements)/Late } \\
\text { Stage Dementia }\end{array}$ & $\begin{array}{l}\text { Manual Actions/Middle Stage } \\
\text { Dementia }\end{array}$ & $\begin{array}{l}\text { Goal-directed Activity } \\
\text { (Familiar Activity)/Early } \\
\text { Stage Dementia }\end{array}$ & $\begin{array}{l}\text { Exploratory Actions } \\
\text { (Learning New } \\
\text { Activity)/Mild } \\
\text { Cognitive Impairment } \\
\text { (MCI) }\end{array}$ & $\begin{array}{l}\text { Planned Actions } \\
\text { (Conceptual } \\
\text { Ability)/Normal, } \\
\text { healthy aging }\end{array}$ \\
\hline $\begin{array}{l}\text { Developmental } \\
\text { Level }\end{array}$ & Infant & 12-18 Months & 18 months-3 Years & 4 Years-10.5 Years & Teens-Early 20s & $25+$ Years \\
\hline Remaining Abilities & $\begin{array}{l}\text {-Automatic \& } \\
\text { reflexive movements } \\
\text { partial ROM. } \\
\text {-Responds to stimuli } \\
\text { swallows. } \\
\text {-Vocalizes. } \\
\text {-Communicates non- } \\
\text { verbally and with } \\
\text { facial expressions. }\end{array}$ & $\begin{array}{l}\text {-Communicates with } \\
\text { simple verbalizations and } \\
\text { universal gestures. } \\
\text {-Responds to } \\
\text { proprioceptive cues and } \\
\text { maintains upright posture } \\
\text { against gravity. } \\
\text {-Gross motor movements, } \\
\text { including standing and } \\
\text { walking. } \\
\text {-May participate in self } \\
\text { care by eating finger foods, } \\
\text { moving limbs and trunk to } \\
\text { assist with dressing and } \\
\text { bathing, and leaning } \\
\text { forward to swish or spit in } \\
\text { sink during oral care. } \\
\text {-Continence with a toileting } \\
\text { schedule and assistance } \\
\text { visual attention to area } \\
\text { directly in front of person. }\end{array}$ & $\begin{array}{l}\text {-Repetitive motor } \\
\text { actions/manual actions } \\
\text { uses objects. } \\
\text {-Awareness of locations and } \\
\text { supported by routines. } \\
\text {-Follows one step directions } \\
\text { as part of simple and familiar } \\
\text { tasks. } \\
\text {-Completes simple/familiar } \\
\text { tasks and self care routines } \\
\text { with cues to sequence. } \\
\text {-Writes his/her name } \\
\text { can use toilet, may require } \\
\text { reminders. } \\
\text {-Communicates about actions } \\
\text { and objects. } \\
\text {-Able to use a "memory book" } \\
\text { or story board to engage in } \\
\text { meaningful interactions. }\end{array}$ & $\begin{array}{l}\text {-Trial and error problem } \\
\text { solving. } \\
\text {-Relies on old habits/routines } \\
\text { can sequence through steps } \\
\text { of familiar activity } \\
\text { good verbal skills (verbal } \\
\text { skills can mask deficits). } \\
\text {-Benefits from striking visual } \\
\text { cues. } \\
\text {-Learns new } \\
\text { information/skills with } \\
\text { repetition and modified } \\
\text { teaching techniques. } \\
\text {-Participates in familiar ADL } \\
\text { if provided with needed } \\
\text { supplies. } \\
\text {-Unaware of the needs of } \\
\text { others/may not be able to } \\
\text { compromise. }\end{array}$ & $\begin{array}{l}\text {-Independent in daily } \\
\text { care, new learning is } \\
\text { possible with some } \\
\text { repetition. } \\
\text {-Simple problem } \\
\text { solving. } \\
\text {-May need assistance } \\
\text { with finances, decision } \\
\text { making and } \\
\text { organizational skills. } \\
\text {-Limited insight and } \\
\text { judgement (impaired } \\
\text { executive functions). } \\
\text {-Requires increased } \\
\text { time to perform } \\
\text { complex tasks. }\end{array}$ & $\begin{array}{l}\text {-Independent in daily } \\
\text { care, finances and } \\
\text { decision making } \\
\text { skills. } \\
\text {-Can learn new } \\
\text { information, plans } \\
\text { actions, anticipates } \\
\text { effects, perform } \\
\text { complex problem } \\
\text { solving tasks, use } \\
\text { symbols and abstract } \\
\text { ideas. }\end{array}$ \\
\hline
\end{tabular}


Appendix B: Online Module Knowledge Checks 
Module: What is Dementia?

Multiple Choice and Fill in the Blank

- Dementia is part of normal aging.

Answer: False

- Dementia is caused by changes in the

Answer: brain

- Individuals with dementia lose the abilities to do everyday activities like they usually do. Answer: True

\section{Module: Behaviors and Symptoms}

Multiple Response Multiple Choice

- Common behaviors and symptoms an individual with dementia may show are:

Answer: Difficulty with memory, difficulty speaking or understanding, getting lost, difficulty solving problems

- Strategies you can use during challenging times with a resident include:

Answer: Change to another activity, listen to the resident, reassure the resident, provide a short, simple response

\section{Module: Stages of Dementia}

Sorting Activity

ACL 4 - Early Stage

- Speak clearly and have conversations

- Complete familiar and simple activities

- Maintain attention for 20-60 minutes

- Pay attention to people and things within 2-4 feet in front
ACL 3 - Middle Stage

- Pick up, reach for, and let go of objects

- Walk or use their wheelchair

- Complete familiar activities with simple directions and assistance

- Maintain attention for 5-20 minutes

- Pay attention to people and things within 14-18 inches in front

\section{Matching}

- Julie (Early Stage)

Answer: Can independently complete simple and familiar tasks

- Tasha (Middle Stage) Answer: Can complete simple and familiar task with cues throughout the activity

- Mathew (Late Stage) Answer: Responds to touch cues 


\section{Module: Communication Skills and Strategies}

Multiple Choice and Fill in the Blank

- What can you say to best help your resident complete a painting activity? Answer: "Dip the paintbrush in the water"

- Residents may take up to ___ seconds to respond. Answer: 30

- True or False? Residents like to be surprised, so you should approach them from behind. Answer: False

\section{Module: Caring for Residents and Yourself}

- What are some problem-solving strategies?

Answer: ask for help, refer back to your training resources, check the client profile, try something new

\section{Module: Quiz}

It's your first time working with Mary today. You have prepared by checking her client card and talked with the occupational therapist to see how she's doing today. Let's go meet her!

Look at Mary's client profile. What stage of dementia is Mary at?
A. Early Stage
B. Middle Stage
C. Late Stage

Answer: B

You see that Mary's profile says that she is in Allen Cognitive Level 3, or middle stage dementia. She can probably

A. complete familiar activities independently.

B. complete familiar activities with help.

\section{Answer: B}

You see that Mary's profile says that she is in Allen Cognitive Level 3, or middle stage dementia. Some communication strategies you might use include

A. positioning yourself close to Mary (14-18 inches) and using verbal, visual, or touch cues throughout activities.

B. positioning yourself directly in front of Mary (12-18 inches) and using hand-over hand cues to start an activity.

Answer: A 
Look at Mary's client profile. What activity might you start with?
A. Card game
B. Flower arrangement
C. Balloon Toss

\section{Answer: B}

You feel like you have gathered enough information to visit with Mary. Before meeting her, you want to set up the environment. You will...
A. Remove clutter or unnecessary items.
B. Create a playlist with her favorite music and set up lavender essential oils.
C. All of the above.

\section{Answer: C}

You are now prepared to meet Mary. You see her in the activities room. You will
A. approach Mary from the front and say, "Hi Mary! I'm Carrie. Do you want to arrange flowers with me?
B. tap Mary's shoulder from behind and say, "Hi, let's arrange some flowers!"

\section{Answer: A}

You have gained Mary's attention and trust. She is interested in arranging flowers with you. However, she is holding a book and ask her to clean up by saying,

A. "Let's close it and put it away so we can go arrange some flowers."

B. "Mary, can you put the book on the shelf?"

\section{Answer: B}

You are now starting to arrange flowers with Mary. What is the best way to help her?

A. Point to the vase and say, "Put the flower in the vase."

B. Point to the vase and say, "Put it in there."

\section{Answer: A}

You want to have a conversation to build a connection with Mary. You remember some topics of interests from her client profile. You say,
A. "What did you like about Japan?"
B. "Japan has beautiful cherry blossoms!"

\section{Answer: B}


Mary's sitting in her wheelchair looking out the window. She looks agitated and frustrated with something. What will you do next?

A. Listen to her frustration.

B. Tell her to keep arranging flowers.

Answer: A

She tells you she hasn't been able to see her grandson and feels like no one wants to see her anymore. How should you respond?

A. Say, "I'm sorry you feel that way. How about we do some painting?"

B. Ask, "When was the last time your grandson came to visit?"

Answer: A 
Appendix C: Heart to Heart Dementia Volunteer Program Feasibility Evaluation 


\section{Heart to Heart Dementia Volunteer Program Feasibility Evaluation}

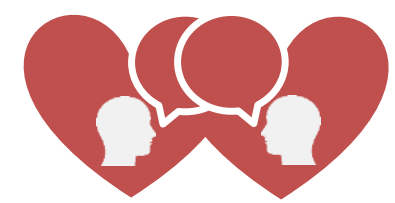

Thank you so much for taking the time to evaluate the materials for our Heart to Heart Dementia Volunteer Program. We appreciate your feedback!

1. Email address

\section{General Thoughts}

What are your overall thoughts about Heart to Heart dementia volunteer program? You will have opportunities to provide feedback specific to each item later.

1. Heart to Heart is designed to promote engagement in social occupations for individuals with dementia (IwD) in SNFs through volunteer training for communication strategies and appropriate activities optimal for the remaining abilities at the various stages of dementia. This program also aims to increase visiting frequency and IwD's QOL as a result of the volunteers' increased competency and confidence in engaging with the residents with dementia. Do the materials support the program's purpose? Dementia occurs because of changes in the brain.
$\square 1$
$\square 2$
$\square 3$
$\square 4$
$\square 5$

Strongly disagree

Strongly agree

2. Does Heart to Heart positively impact social isolation in individuals with dementia?
$\square 1$
$\square 2$
$\square 3$
$\square 4$
$\square 5$

Strongly disagree

Strongly agree 
3. What were some strengths you observed from reviewing the Heart to Heart Dementia Volunteer Program?

4. You will have opportunities to provide feedback for specific training materials later on. Do you have any overall suggestions for the Heart to Heart Dementia Volunteer Program?

\section{Rise Online Modules}

What are your thoughts about the Rise online modules? Volunteers will complete an online course before completing a hands-on, in-person training. The online course will provide education regarding dementia, dementia stages, and communication strategies. It will also provide an introduction to our activity box.

5. RISE ONLINE MODULES: Were the modules easy or intuitive to navigate?
$\square 1$
$\square 2$
$\square 3$
$\square 4$
$\square 5$

Strongly disagree

Strongly agree

6. RISE ONLINE MODULES: Is the content delivered effectively through various mediums, such as visuals, multi-modal learning, or knowledge checks?
$\square 1$
$\square 2$
$\square 3$
$\square 4$
$\square 5$

Strongly disagree

Strongly agree 
7. RISE ONLINE MODULES: Do the sections flow well?
$\square 1$
$\square 2$
$\square 3$
$\square 4$
$\square 5$

Strongly disagree

Strongly agree

8. RISE ONLINE MODULES: Is the provided information accurate?
$\square 1$
$\square 2$
$\square 3$
$\square 4$
$\square 5$

Strongly disagree

Strongly agree

9. RISE ONLINE MODULES: Is the language appropriate for juniors and seniors in high school?
$\square 1$
$\square 2$
$\square 3$
$\square 4$
$\square 5$

Strongly disagree

Strongly agree

10. RISE ONLINE MODULES: Do you have any suggestions for improvement?

\section{Volunteer Handbook}

What are your thoughts about the Volunteer Handbook? The handbook is an extra resource for volunteers to use during their training or visits.

11. VOLUNTEER HANDBOOK: Is the content delivered effectively through various mediums, such as visuals and text?
$\square 1$
$\square 2$
$\square 3$
$\square 4$
$\square 5$

Strongly disagree

Strongly agree

12. VOLUNTEER HANDBOOK: Is the language appropriate for juniors and seniors in high school?
$\square 1$
$\square 2$
$\square 3$
$\square 4$
$\square 5$

Strongly disagree

Strongly agree 
13. VOLUNTEER HANDBOOK: Does the Volunteer Handbook provide an effective summary to supplement the Rise Modules?
$\square 1$
$\square 2$
$\square 3$
$\square 4$
$\square 5$

Strongly disagree

Strongly agree

14. VOLUNTEER HANDBOOK: Do you have any suggestions for improvement?

\section{Activity Box Instructions for Volunteers}

What are your thoughts about the Activity Box Instructions? The Activity Box Instructions will be provided in Activity Boxes to guide volunteers in their facilitation of activities during their visits.

15. ACTIVITY BOX INSTRUCTIONS: Is the content delivered effectively through various mediums, such as visuals and text?
$\square 1$
$\square 2$
$\square 3$
$\square 4$
$\square 5$

Strongly disagree

Strongly agree

16. ACTIVITY BOX INSTRUCTIONS: Is the language appropriate for juniors and seniors in high school?
$\square 1$
$\square 2$
$\square 3$
$\square 4$
$\square 5$

Strongly disagree

Strongly agree

17. ACTIVITY BOX INSTRUCTIONS: Do you understand what the activities are?
$\square 1$
$\square 2$
$\square 3$
$\square 4$
$\square 5$

Strongly disagree

Strongly agree 
18. ACTIVITY BOX INSTRUCTIONS: Do you understand how to adapt activities to various stages of dementia?
$\square 1$
$\square 2$
$\square 3$
$\square 4$
$\square 5$

Strongly disagree

Strongly agree

19. ACTIVITY BOX INSTRUCTIONS: Do you have any suggestions for improvement?

\section{User Manual for OT Students}

What are your thoughts about the User Manual? A future capstone group of OT students will refer to the User Manual to guide implementation of Heart to Heart.

20. USER MANUAL: Is the content delivered effectively through various mediums, such as visuals and text?
$\square 1$
$\square 2$
$\square 3$
$\square 4$
$\square 5$

Strongly disagree

Strongly agree

21. USER MANUAL: Is the language appropriate for graduate occupational therapy students or professionals in other disciplines?
$\square 1$
$\square 2$
$\square 3$
$\square 4$
$\square 5$

Strongly disagree

Strongly agree

22. USER MANUAL: Do the sections flow well?
$\square 1$
$\square 2$
$\square 3$
$\square 4$
$\square 5$

Strongly disagree

Strongly agree

23. USER MANUAL: Do you understand how to run the program?
$\square 1$
$\square 2$
ㄴ 3
$\square 4$
$\square 5$

Strongly disagree

Strongly agree 
24. USER MANUAL: Do you have any suggestions for improvement?

\section{Thank you for your time and feedback!}


Appendix D: Implementation Guide 



\section{HEART TO HEART VOLUNTEER PROGRAM \\ IMPLEMENTATION GUIDE}

CREATED BY NHAT HOANG OTS, KIYOMI KURODA OTS, VICTORIA RAMIA OTS, \& KELSY WALLACE OTS

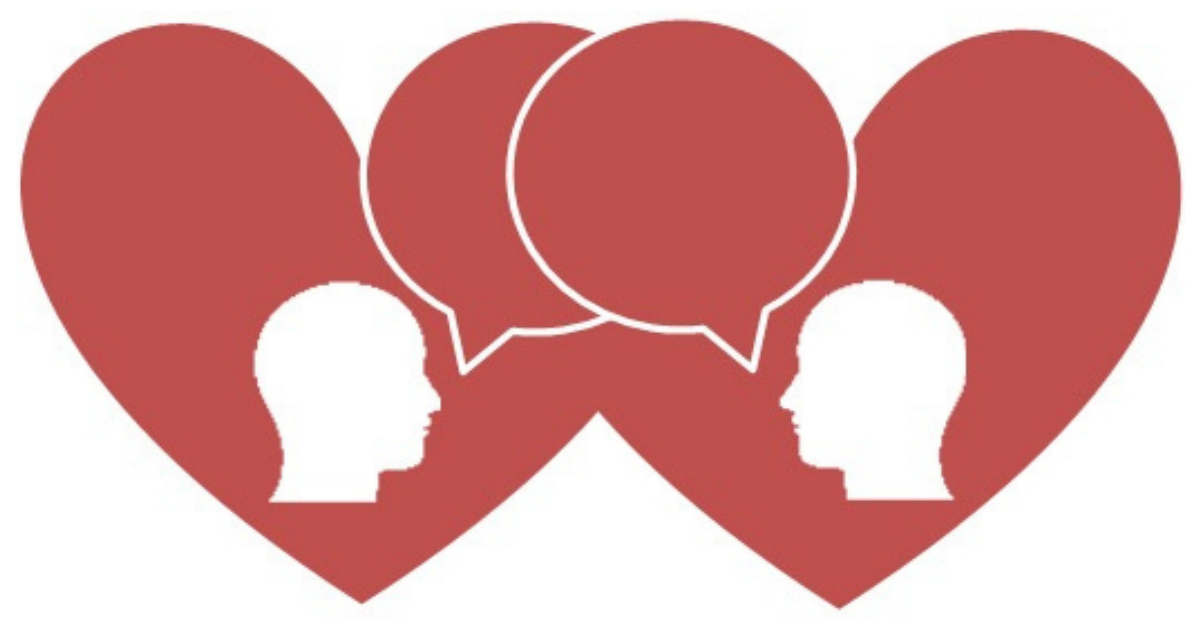

Copyright (c) 2020 by Nhat Hoang, Kiyomi Kuroda, Victoria Ramia, and Kelsy Wallace

All rights reserved. No part of this training manual may be reproduced or used in any manner without written permission of the training manual owners.

Dominican University of California

MSOT Graduate Program 


\section{ACKNOWLEDGEMENTS\& CONSIDERATIONS}

CREATED BY NHAT HOANG OTS, KIYOMI KURODA OTS, VICTORIA RAMIA OTS, \& KELSY WALLACE OTS

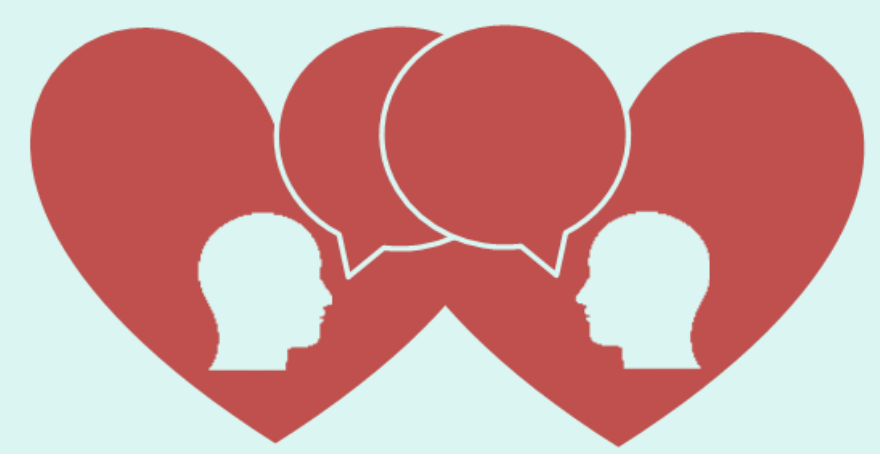

We would like to extend an immense gratitude to Dr. Gina Tucker-Roghi for guiding us through the creation of this program. We could not have done this without your constant support!

We would like to acknowledge JB Chua, Cason Bush, and all the staff at Summerfield Healthcare Center in Santa Rosa, CA for their willingness to collaborate with us, and for making possible the creation of Heart to Heart volunteer program.

Thank you to Dr. Susan Morris for providing invaluable support in the early stages of our project. We would also like to thank Tina Hand and Amanda Grace for evaluating our program for feasibility. Lastly, we would like to thank California Foundation of Occupational Therapy (CFOT) and Ensign Services, Inc. (a network of affiliated facilities who provide post-acute rehabilitation services) for selecting our project for seed grant

money that made possible the development and funding of this program.

We would not have been able to do any of this without your amazing supports!

\section{Dominican University of California MSOT Graduate Program}




\section{WELCOME TO HEART TO HEART VOLUNTEER PROGRAM}

IMPLEMENTATION GUIDE

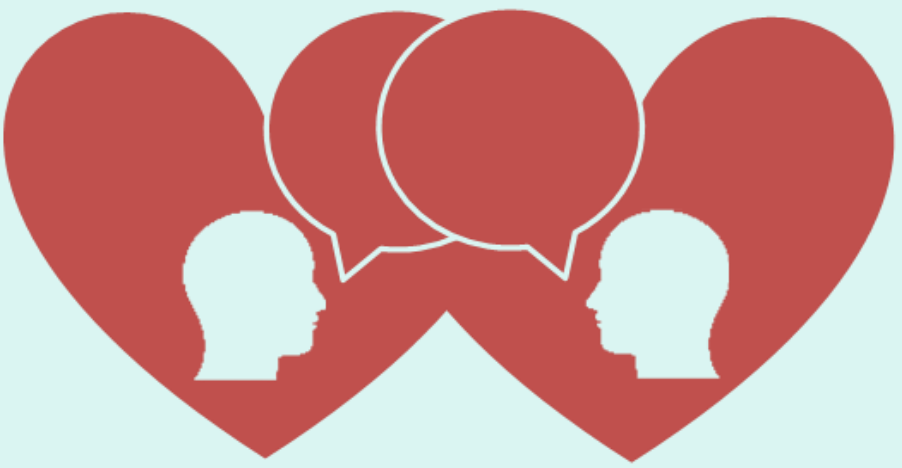

Thank you for embarking on the journey of implementing this exciting program!

In these pages you will find descriptions of each component of the program, followed by tools to support the actualization of each step along the way.

Dominican University of California MSOT Graduate Program 


\section{TABLE OF CONTENTS}

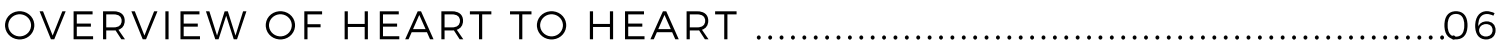

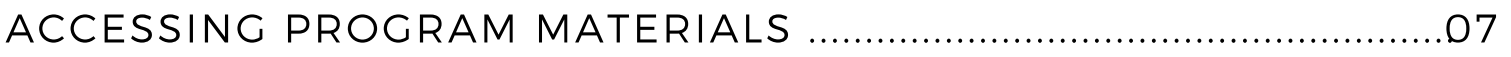

SEQUENCE OF PROGRAM COORDINATION ....................................

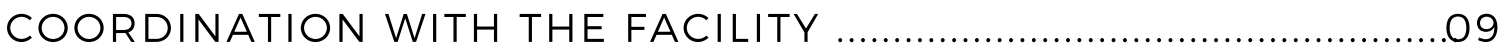

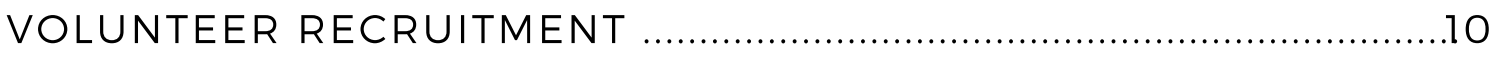

VOLUNTEER RECRUITMENT MATERIALS ....................................11-16

VOLUNTEER CONTACT FORM .....................................................

VOLUNTEER CONSENT FORM ................................................

VOLUNTEER CHECKLIST OVERVIEW \& FORM ..................................19-20

OVERVIEW OF TRAINING SCHEDULE ........................................21

IN PERSON TRAINING DAY ONE OVERVIEW ...................................22

ONLINE TRAINING MODULES: OVERVIEW .....................................23

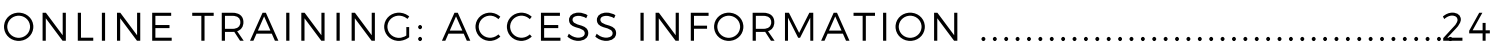

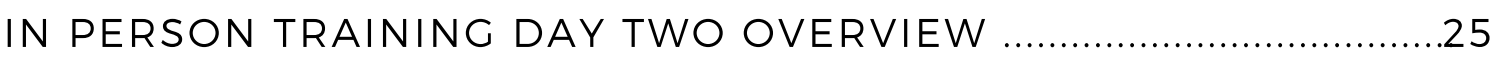

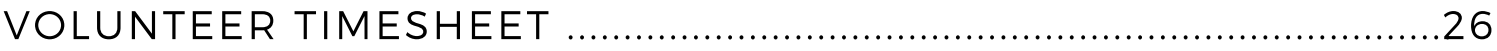

IN PERSON TRAINING PRESENTATION ..............................................

TOOLS FOR VOLUNTEERS:

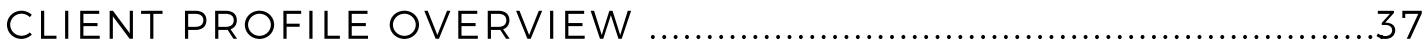

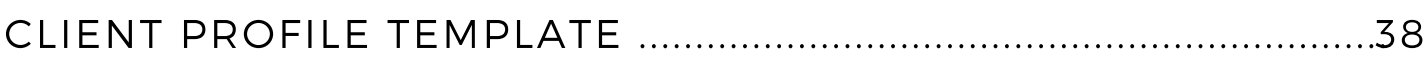

TOOLS FOR VOLUNTEERS:

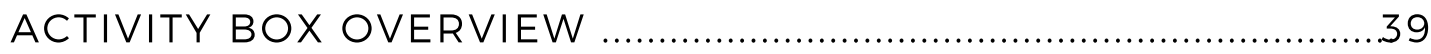

ACTIVITY BOX CONTENTS ...............................................40

ACTIVITY BOX PHOTO ...........................................................41

ACTIVITY BOX INSTRUCTIONS …...........................................42

TOOLS FOR VOLUNTEERS:

VOLUNTEER HANDBOOK OVERVIEW.......................................43

VOLUNTEER HANDBOOK......................................................44-50

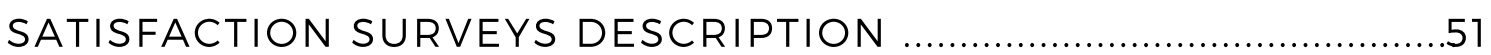

PRE \& POST VOLUNTEER SATISFACTION SURVEY ....................52-63

SATISFACTION SURVEYS: SCORING OVERVIEW ..............................64

SATISFACTION SURVEYS: SCORING SHEET ............................65-66

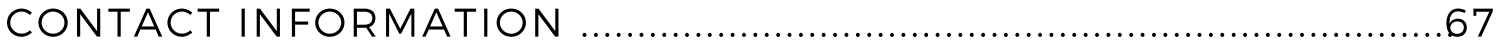




\section{OVERVIEW OF HEART TO HEART}

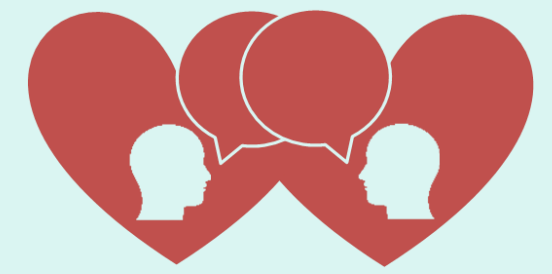

The Heart to Heart volunteer program is designed to provide volunteers with foundational knowledge about behaviors, general abilities, and communication skills of individuals with dementia. The aim of this program is to promote comfort and confidence in volunteers in order for them to facilitate meaningful activities and interactions with residents with dementia.

This program is designed to consider the residents' abilities based on their specific stage of dementia in order to promote residents' optimal engagement in activities.

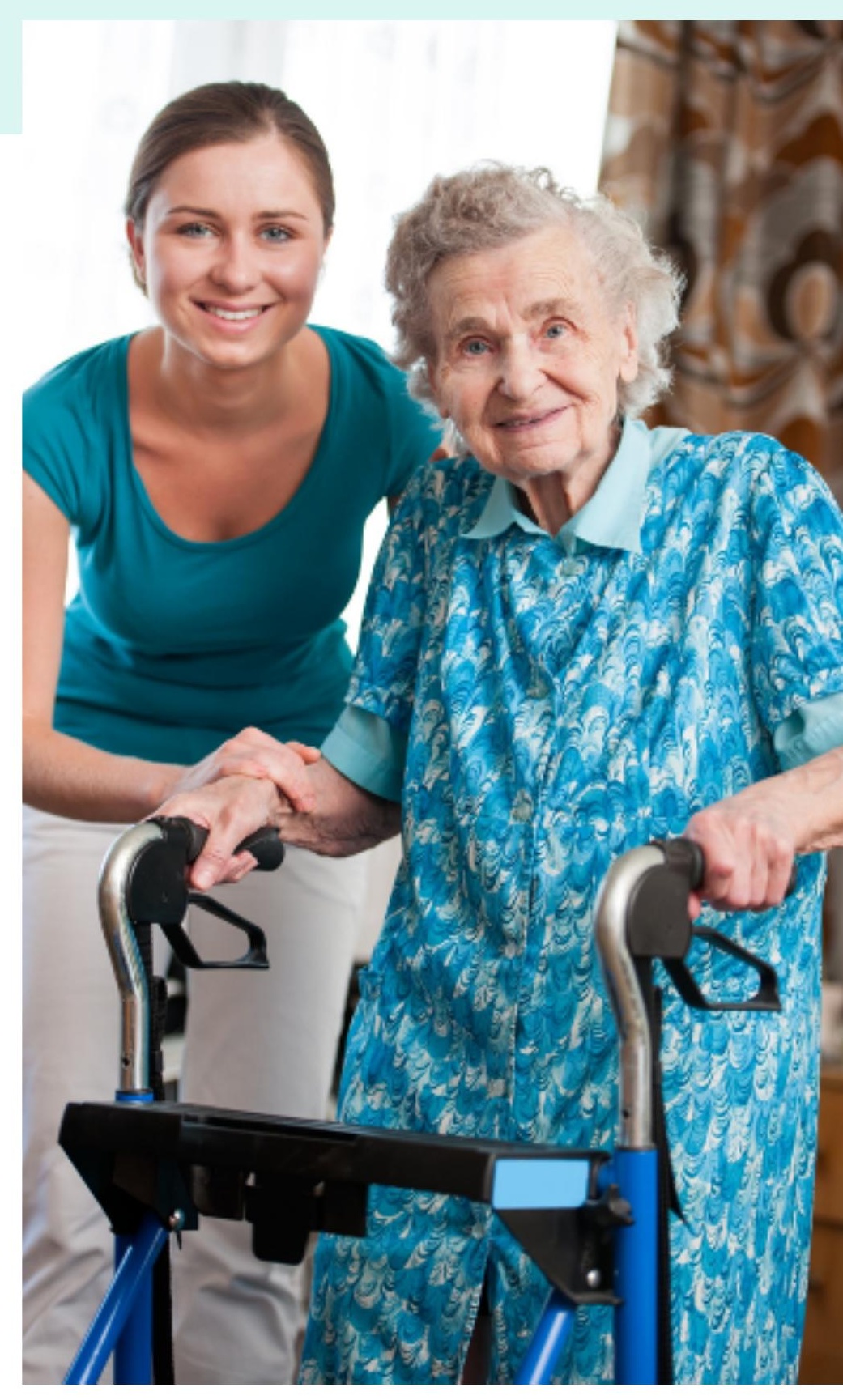

By tailoring each volunteer and resident interaction based on the resident's remaining abilities, this program focuses on establishing and enhancing client-centeredness at the heart of each visit. The clientcentered relationship allows for a more meaningful interaction, and greater engagement for the resident. 


\section{ACCESSING HEART TO HEART VOLUNTEER PROGRAM MATERIALS}

In order to access all the training materials, please use the following URL:

https://www.dominican.edu/academics/schools/schoolhealth-and-natural-sciences/healthy-aging

Click on the link available under "OT Services for Individuals Living in Long Term Care Communities" This will provide access to a Google Site with all program materials, including the online training modules.

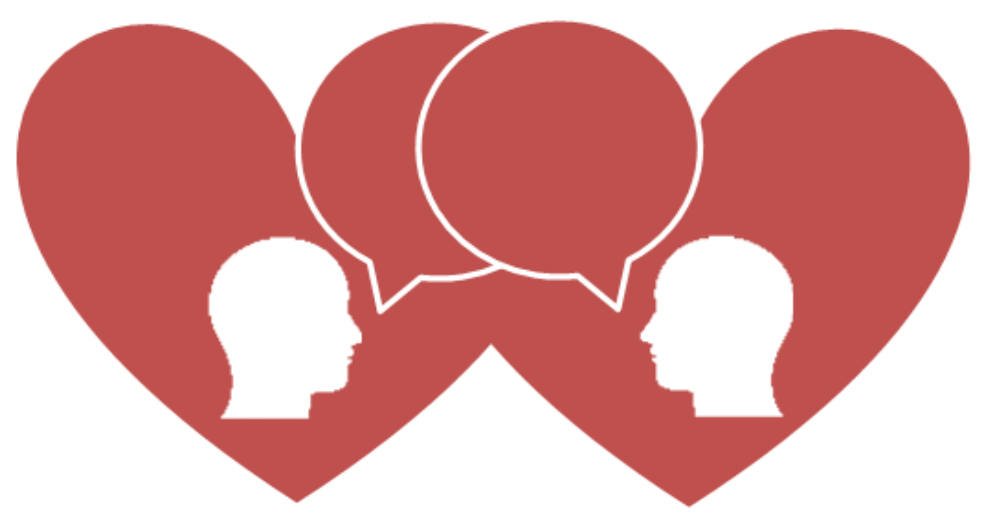




\section{SEQUENCE OF PROGRAM COORDINATION: OVERVIEW}

1. Request approval for Heart to Heart volunteer program implementation with skilled nursing facility:

a. Contact and coordinate with Summerfield Healthcare Facility.

2. Recruitment of volunteers:

a. Contact high schools and coordinate informational sessions.

b. Present recruitment powerpoint, and provide volunteer forms during this time.

3. In-person training Day 7:

a. Schedule and complete one hour facility tour \& day one in-person training with skilled nursing facility. Student volunteers will receive a physical handout of the presurvey evaluation to complete before in-person training day 2.

4. Online course:

a. Student volunteers complete three hour online training.

5. In-person training day 2:

a. Students attend one hour in-person training day 2.

6. Volunteer visitations with residents:

a. Begin program sessions.

b. Program to be completed after 8 weeks.

7. Commencement celebration:

a. Host program commencement celebration with volunteers.

b. Provide volunteers with post-survey evaluation. 


\section{COORDINATION WITH THE FACILITY}

\section{To begin...}

First establish a program facilitator, such as the Activity Director at the skilled nursing facility. Then identify the requirements of conducting volunteer program from the facility, including HIPAA acknowledgements, and volunteer consent forms.

\section{Create a timeline that includes:}

- Program information sessions at high schools for volunteer recruitment

- Program training days

- Program start and end dates

- Hours of the day and days of the week which the volunteers will be at the facility 


\section{VOLUNTEER \\ RECRUITMENT}

\section{Who is the target volunteer population?}

High school juniors and seniors interested in volunteer opportunities.

\section{Who to contact for recruitment?}

Local high school career counselors.

\section{Presentation/Info session for volunteers}

- Host a 15-minute Powerpoint informational session to the high school students, including an overview of the Heart to Heart volunteer program (see page \#).

- Provide students with a flyer about the program. Allow interested students to sign up for the program and complete a student contact form prior to leaving the informational session.

- Distribute a consent form for students to take home to complete for collection at the first inperson training session. 


\section{Heart to Heart}

Volunteer

Training Program

\section{Presented by:}

[Name of Presenter; Name of Skilled Nursing Facility]
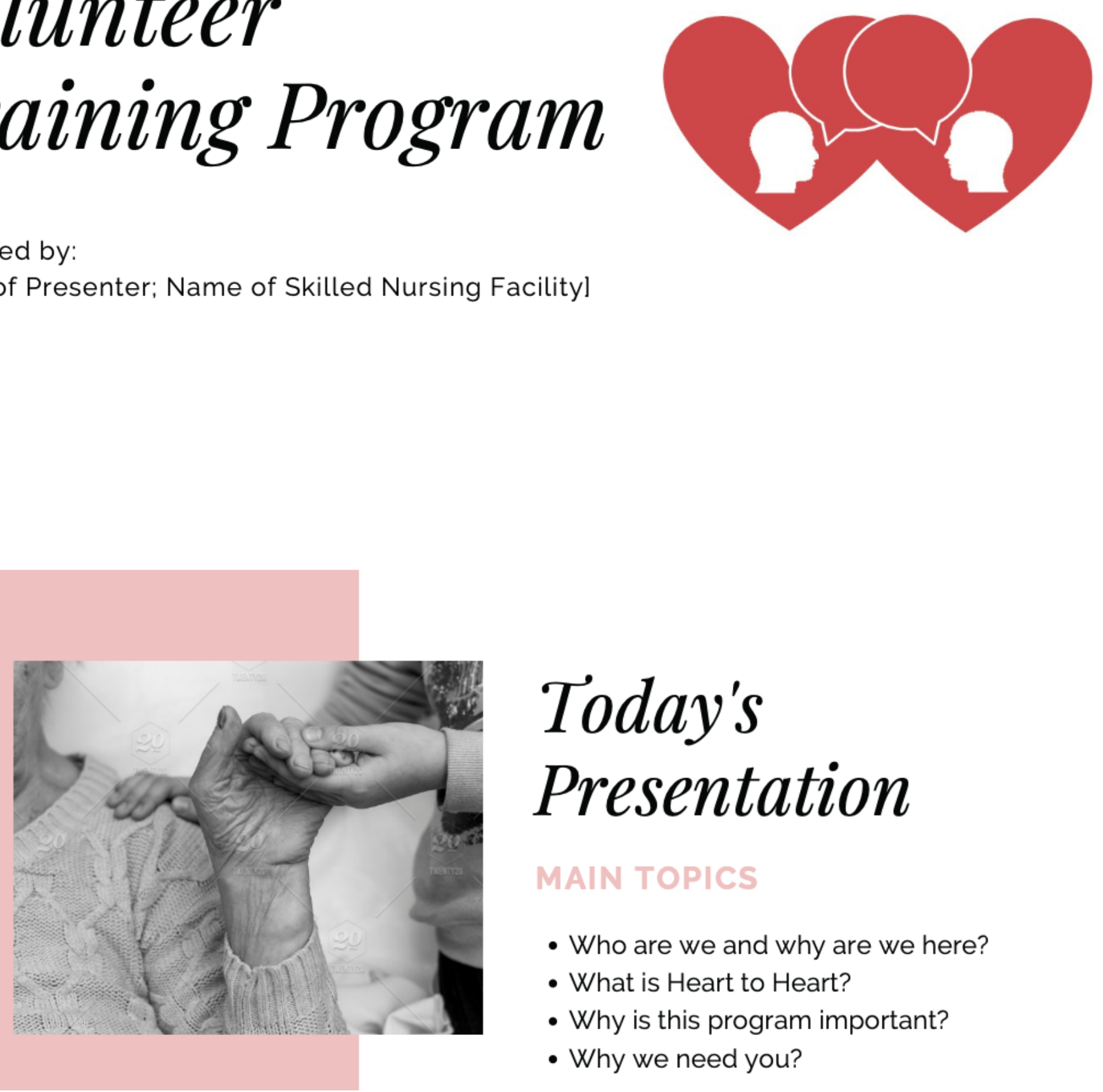

\section{Today's} Presentation

\section{MAIN TOPICS}

-Who are we and why are we here?

- What is Heart to Heart?

-Why is this program important?

- Why we need you? 


\section{Heart to Heart \\ Training Program}

OVERVIEW OF DETAILS

Education \& Training Face to Face Interactions Shadowing Opportunities

- 2 in-person training sessions with our team at

- 1 hour sessions each week for

- Occupational therapists the duration of the program $\quad$ - Physical therapists with residents with dementia. $\quad-\quad$ RNs \& CNAs

Summerfield Healthcare.

- Online training modules to be completed at home.

- Activities director

\section{Why We Need You!}

\section{BREAK THE STIGMA}

The more people are able to learn about dementia, the less stigma there will be about this population.

\section{CREATIVITY}

Creativity and willingness to try new activities with the residents truly enhance the experience for both the resident and the volunteer!

\section{INTERGENERATIONAL}

There is so much value in developing an intergenerational relationship for both the young person and the older person!

\section{KNOWLEDGE \& CONFIDENCE!}

We will equip you with the knowledge needed to create successful visits! Your confidence is key here in your experience with the residents. 


\section{Why is This Important?}

\section{Aging Population}

As the population changes, there is a need for assistance with the aging adults. The older adult population will outnumber the rest of the population.

\section{Quality of Life}

Often, individuals with dementia do not receive regular visits from family members or volunteers, and experience loneliness. Social interaction is a meaningful way for individuals with dementia to experience a greater quality of life.

\section{Prevalence of Dementia}

As the older adult community increases, the number of incidences of dementia will increase as well. Often, individuals with dementia live in care facilities.

\section{Stigma}

Negative and inaccurate societal beliefs about dementia impact the desire of community members to volunteer with this population.

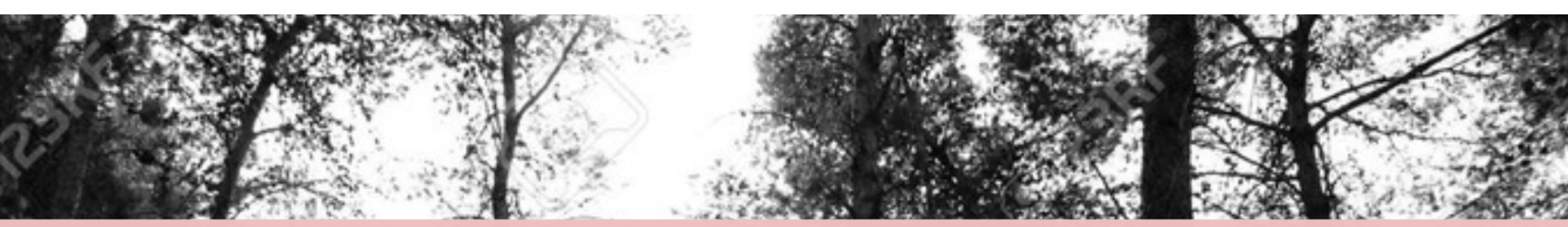

\section{Thank you!}

Any questions?
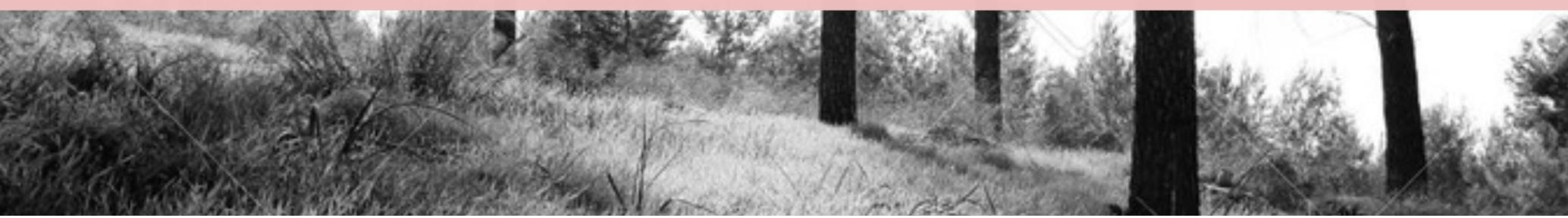


\section{Are You Interested?}

\section{CONTACT US!}

heart2heartprogram2020@gmail.com 


\section{Heart to Heart Volunteer Contact Form}

Name of Volunteer Today's Date

Home Address

Telephone Number

Email

In the event of an emergency, please list the names and contact information of the individuals you would like us to contact.

Emergency Contact \#1

Name of Emergency Contact

Relationship

Home Address

Telephone Number

Emergency Contact \#2

Name of Emergency Contact

Relationship

Home Address

Telephone Number 


\section{Heart to Heart Volunteer Consent Form}

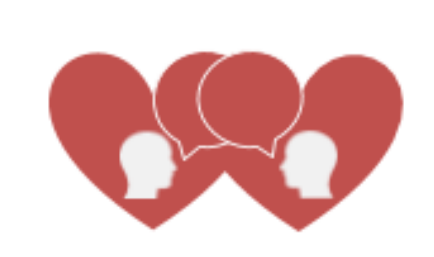

By signing this consent form, I acknowledge that I am volunteering my time, in order to participate in the Heart to Heart Program at [Name of Site Here].

I understand my participation is completely voluntary, without pay, compensation, or benefits. I understand that I may stop volunteering at any time.

I understand I am volunteering with residents with dementia, who may exhibit challenging behaviors, including but not limited to, forgetfulness, confusion, agitation, or aggression.

I understand my volunteer duties include one-on-one visits that may require me to provide physical assistance during activities, but not for mobility, when working with a resident with dementia

I understand that information about the residents at this facility, families of the residents, and/or employees shall be held confidential and never discussed with anyone outside or inside the facility.

I certify that I am at least eighteen (18) years of age or I have had this document reviewed and signed by my parent or guardian.

I have carefully read this agreement and fully understand its contents. I consent to all terms of this agreement.

Volunteer Printed Name Volunteer Date of Birth

Volunteer Signature Date

\section{Parental/Guardian Consent}

If the individual is a minor (under 18 years of age), the following must be signed by a parent or legal guardian.

By signing below, I acknowledge that I am the parent or legal guardian of the minor named above. I have reviewed the above agreement with my child. I consent and agree to the terms above. I authorize my child to volunteer at [Name of Site Here]..

\section{Parent/Guardian Printed Name}

Parent/Guardian Signature Date 


\section{VOLUNTEER CHECKLIST: OVERVIEW}

The following form is to be completed by the volunteer prior to beginning their in-person visits with participating residents with dementia at the skilled nursing facility.

The volunteer should return these forms indicated on the volunteer checklist to the Activities Director at the skilled nursing facility once all items have been completed. 


\section{Heart to Heart Volunteer Checklist}

Thank you so much for participating with the Heart to Heart dementia volunteer program!

Before starting your visits, please complete the following:

$\square$ Volunteer Consent Form

$\square$ Volunteer Contact Form

$\square$ Day 1 of In-Person Training

$\square$ Pre-Volunteer Survey

$\square$ Online Course (on Rise)

$\square$ Day 2 of In-Person Training

Please submit your completed forms to the Activities Director.

Thank you and we hope you enjoy your time volunteering with Heart to Heart! 


\section{OVERVIEW OF TRAINING SCHEDULE}

1. One hour In-Person Training Day 1

2. Volunteers Complete Online Training Modules

3. One hour In-Person Training Day 2

Once trainings have been completed, it is time to begin volunteer sessions! 


\section{IN PERSON TRAINING DAY ONE (OF TWO).}

This in-person training will include introductions of the program, facility, and staff,

gather information about volunteer experience, and provide a tour of the facility

\section{Agenda for In-Person Training Day 1}

Introduce program

Introduce staff

Discuss expectations and requirements of volunteers

Sharing of any previous experience

Think pair share

Tour of facility

Final Questions

Provide student volunteers a physical handout of the presurvey evaluation to complete before in-person training day 2 . 


\section{ONLINE TRAINING MODULES: OVERVIEW}

Online training will include modules educating the learners about dementia, dementia stages and $A C L$, communication strategies, and the activities box. Supplemental information about dementia and general communication skills will be adapted from $A C A \otimes$ training materials.

Each module includes a variety of knowledge interactive assessments, such as quizzes, matching, flashcards, and case studies. Modules will also include photos and audio to provide a variety of learning experiences. 


\section{ONLINE TRAINING MODULES: ACCESS INSTRUCTIONS}

In order to access this online training resource, please use the following URL:

https:/www.dominican.edu/academics/schools/sc hool-health-and-natural-sciences/healthy-aging

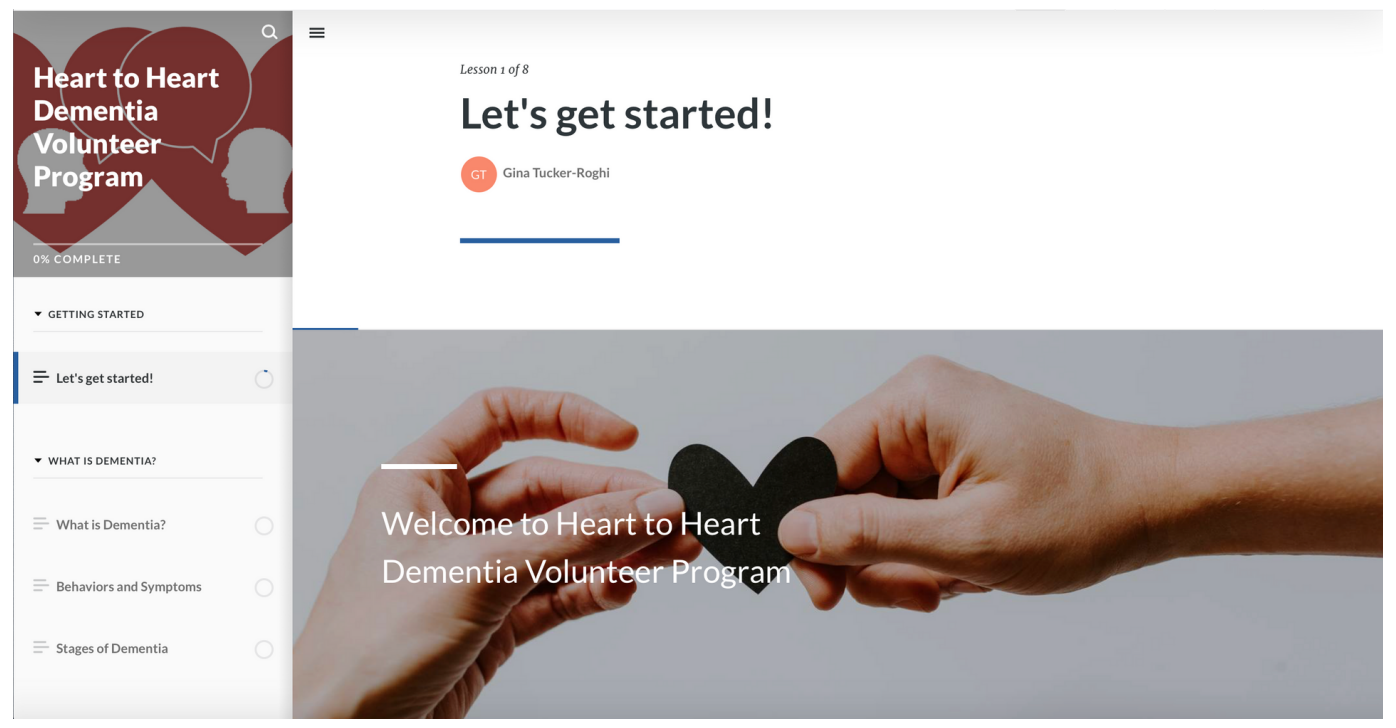




\section{IN PERSON TRAINING DAY TWO (OF TWO).}

After completing the online module, the volunteers will return to the facility to complete their last in-person training.

During this time, they will work together to role-play scenarios they may encounter during their visits with residents and become familiar with the activities box. They will also receive information on how to log their hours.

\section{Agenda for In-Person Training Day 2}

Reflection of the online modules

Explanation of activity box and client cards

$$
\text { Group activity }
$$

Logging hours (see form on page 27)

Closing and questions 


\section{Heart to Heart Volunteer Hours}

Name:

\begin{tabular}{|c|c|c|c|}
\hline Date & Time In & Time Out & Initials \\
\hline & & & \\
\hline & & & \\
\hline & & & \\
\hline & & & \\
\hline & & & \\
\hline & & & \\
\hline & & & \\
\hline & & & \\
\hline & & & \\
\hline & & & \\
\hline & & & \\
\hline & & & \\
\hline & & & \\
\hline & & & \\
\hline & & & \\
\hline & & & \\
\hline & & & \\
\hline & & & \\
\hline
\end{tabular}




\section{HEART TO HEART IN-PERSON TRAINING DAY 1}

Presented by: [Name of Presenter Here; Name of Associated Site]

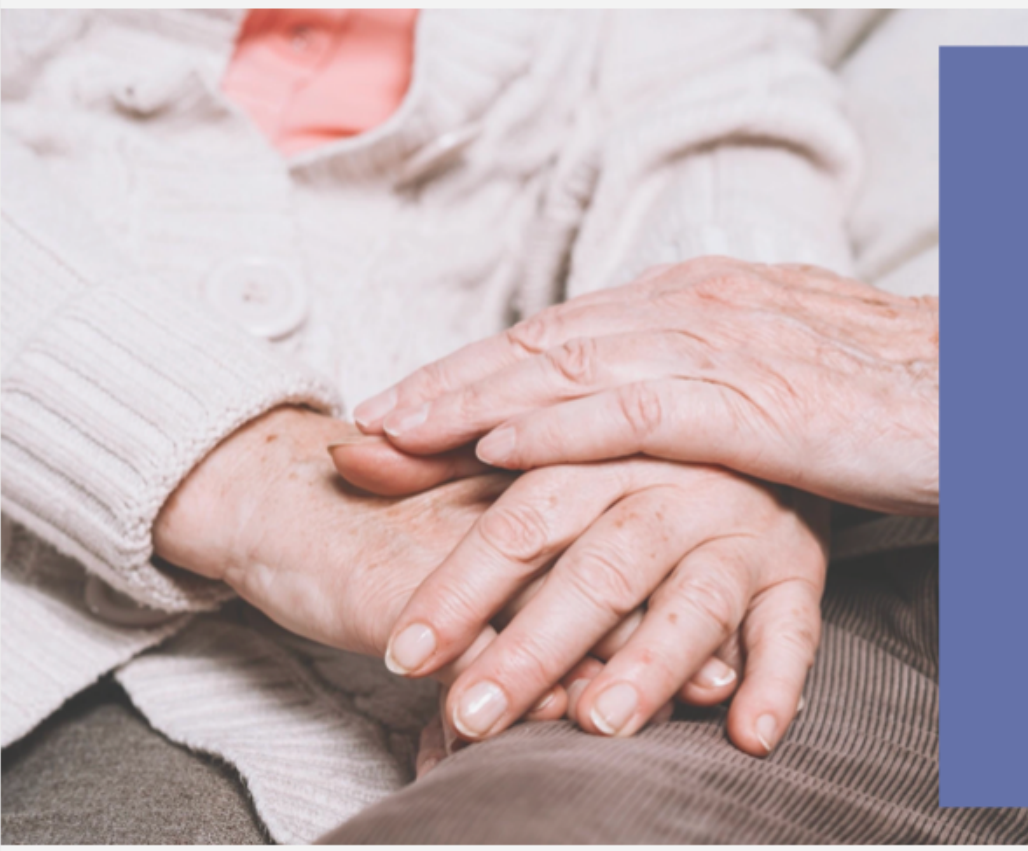

\section{Agenda for Day 1}

- Introduce program

- Introduce staff

- Discuss expectations and requirements of volunteers

- Sharing of any previous experience

- Think pair share

- Tour of facility

- Explanation of activity box and client profiles 


\section{Objectives and Goals Day 1}

In-Person Training

- Understand procedure for logging volunteer hours

- Locate facility reception desk, nursing station, activity room, and resident rooms.

- Identify key facility staff to address questions and issues that may arise, and best methods of contact.

- Define dementia, and understand various strengths in early and middle stage dementia.

What is Heart to Heart?
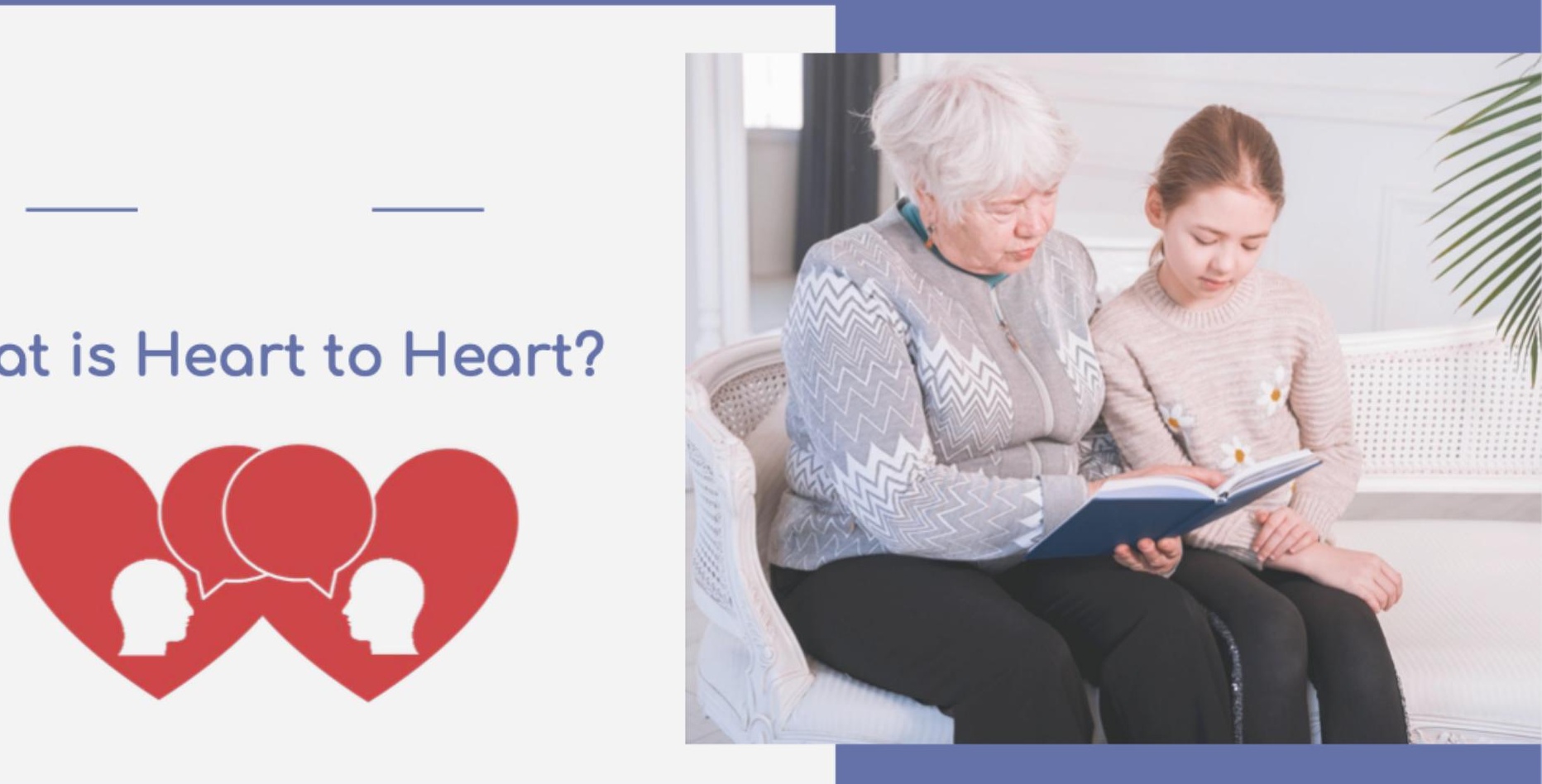


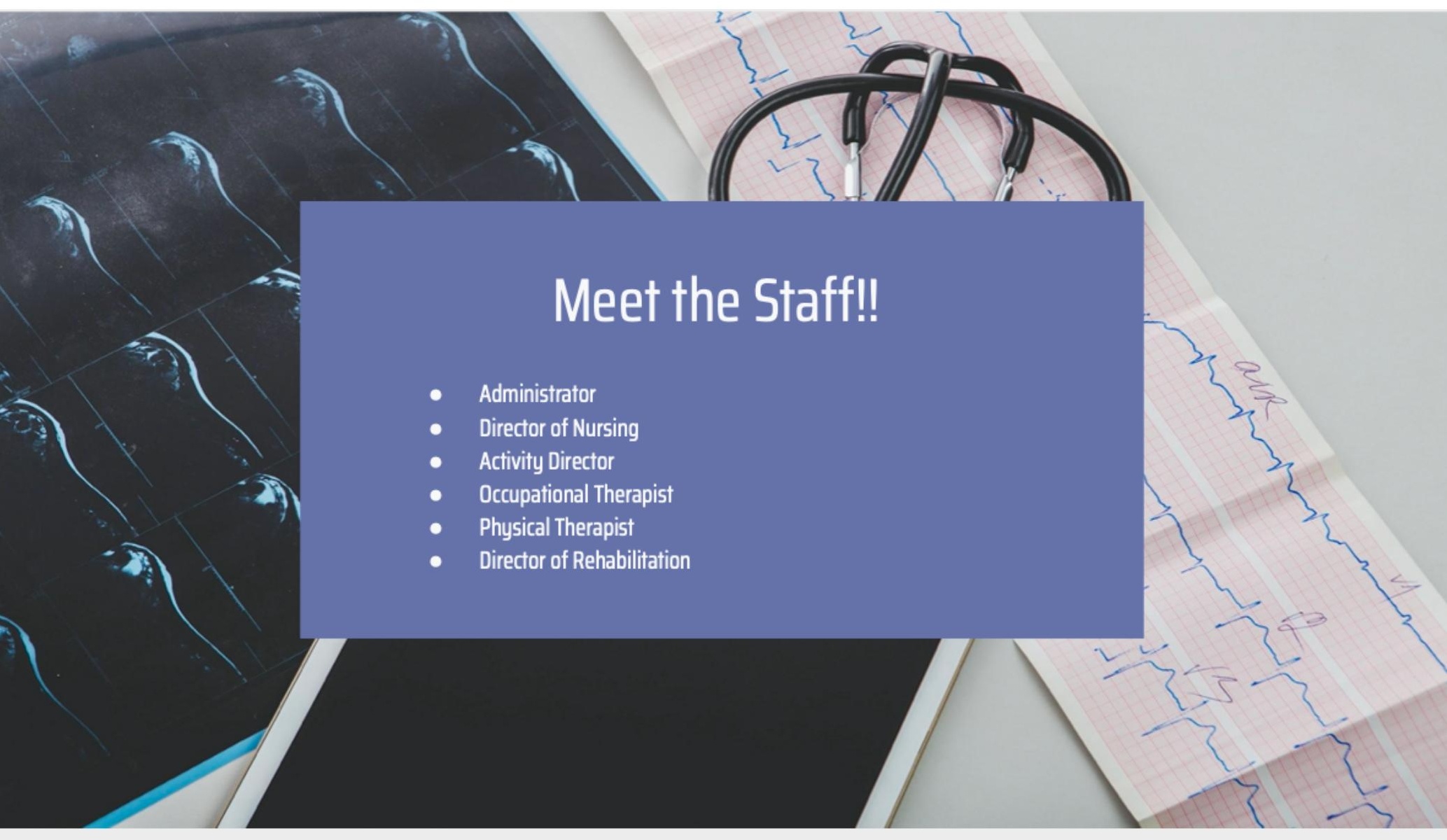

\section{Expectations}

\&

Requirements

\section{For}

Volunteers
- Be on time to trainings and scheduled visits.

- Come with a good attitude.

- Respect the residents, other volunteers, and staff at site.

- Communicate concerns and questions when they come up.

- Sign in and out each day. 


\section{THINK PAIR SHARE}

When you

hear the

word

dementia,

what words

come to

Talk with the person next to you

Come up to the board and write the words down

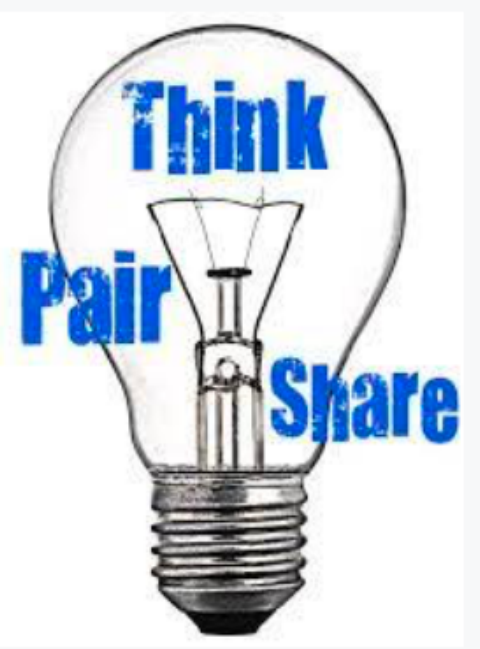
mind?

\section{Group discussion:}

Share any experience you have had in this setting, and/or experience you hope to gain during your time participating in Heart to Heart. 


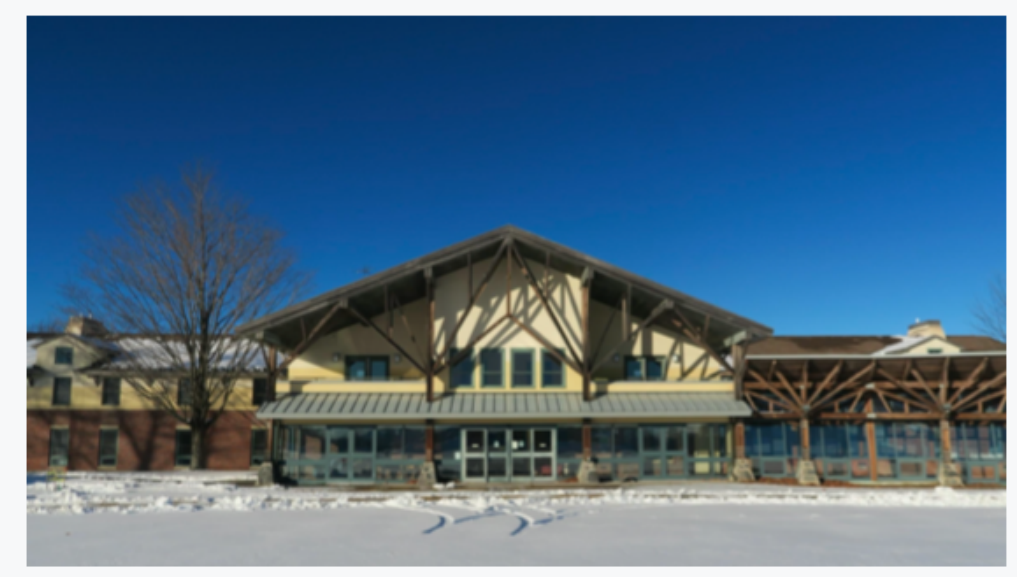

\section{Let's Get Up \& Tour the Facility!}

\section{Assignment: Online Learning Modules}

Please complete the Online Learning Modules prior to coming to the second in-person training!

Thank you for your commitment! We look forward to working with roty you! 


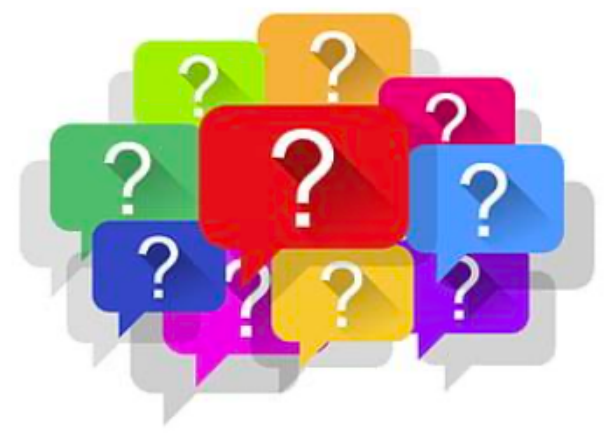

Any

Questions?

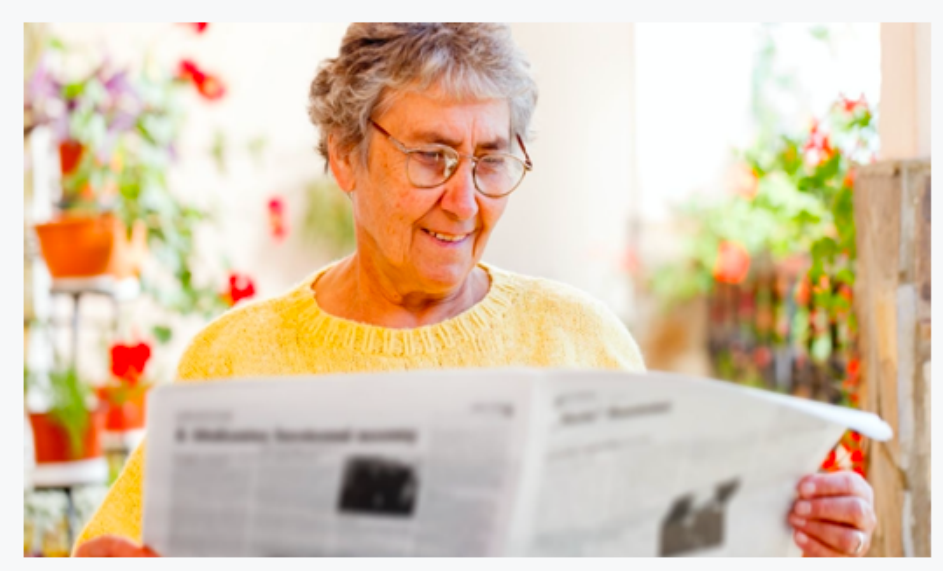

\section{HEART TO HEART IN-PERSON TRAINING DAY 2}

Presented by: [Name of Presenter Here; Name of Associated Site]

Created by: Nhat Hoang, 0T5, Kiyomi Kuroda, OT5, Victoria Ramia, OT5, Kelsy Wallace, Dominican University of California 


\section{AGENDA FOR THE DAY}

- Reflection on the online modules.

- Explanation of activity box and client profiles.

- Group activity.

- Logging hours.

- Questions and closing.

\section{Objectives and Goals for Day 2}

1. Feel confident in using the activity box to create meaningful interactions

2. Be able to select an appropriate activity for a resident based on their stage of dementia, and client profile.

3. Be able to demonstrate the activities to a resident using appropriate strategies.

4. Be able to to log hours correctly for each session. 


\section{Online Module Reflection and Questions}

This is the time to clarify any questions you may have from

completing the online modules with us!

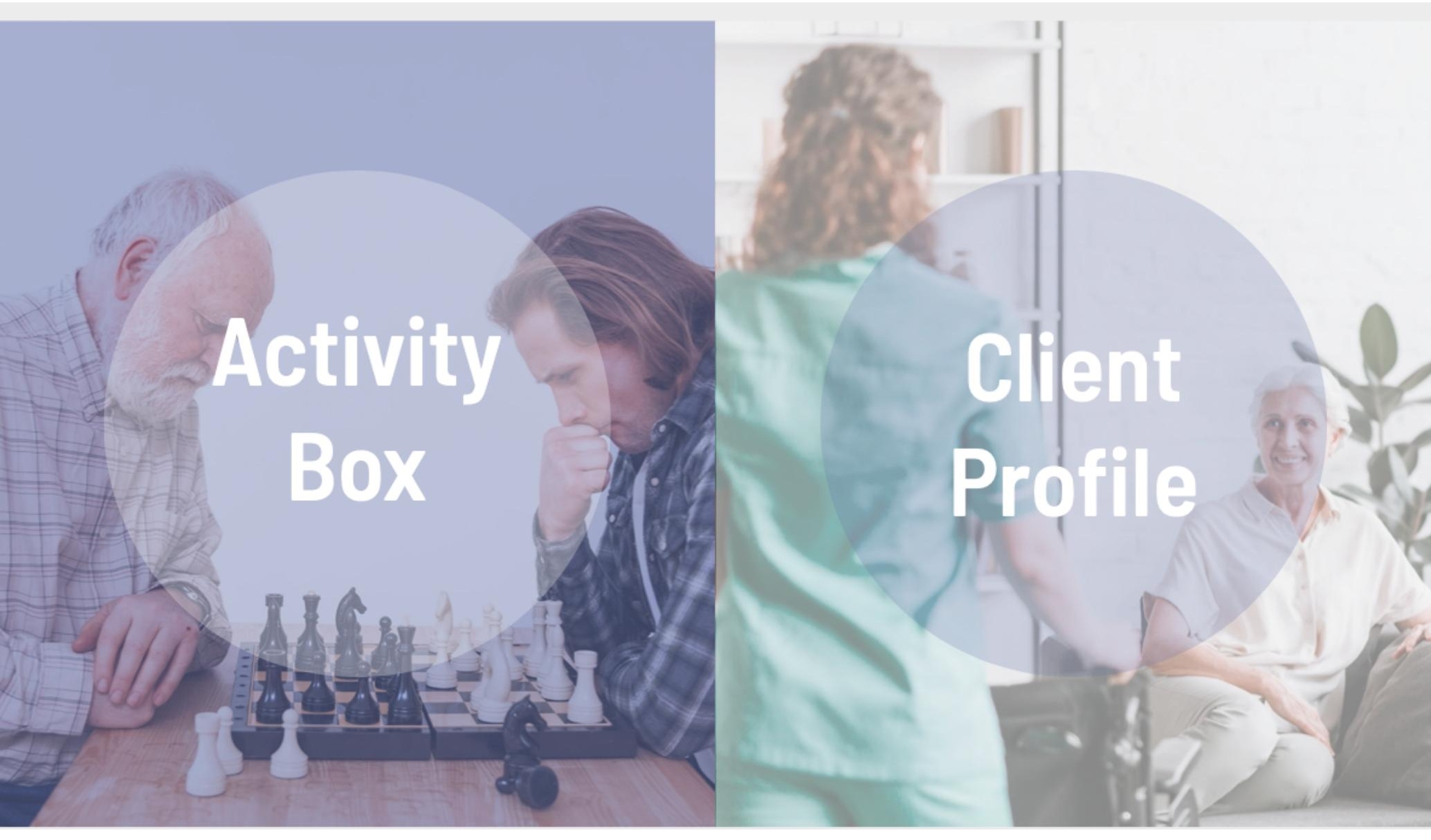




\section{Let's Practice!}

\section{GROUP Activity}

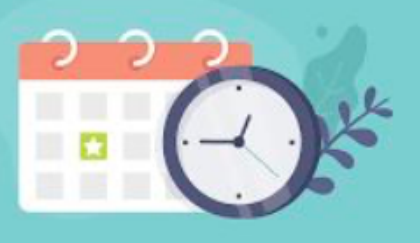

Clocking in and out / Logging Volunteer Hours 


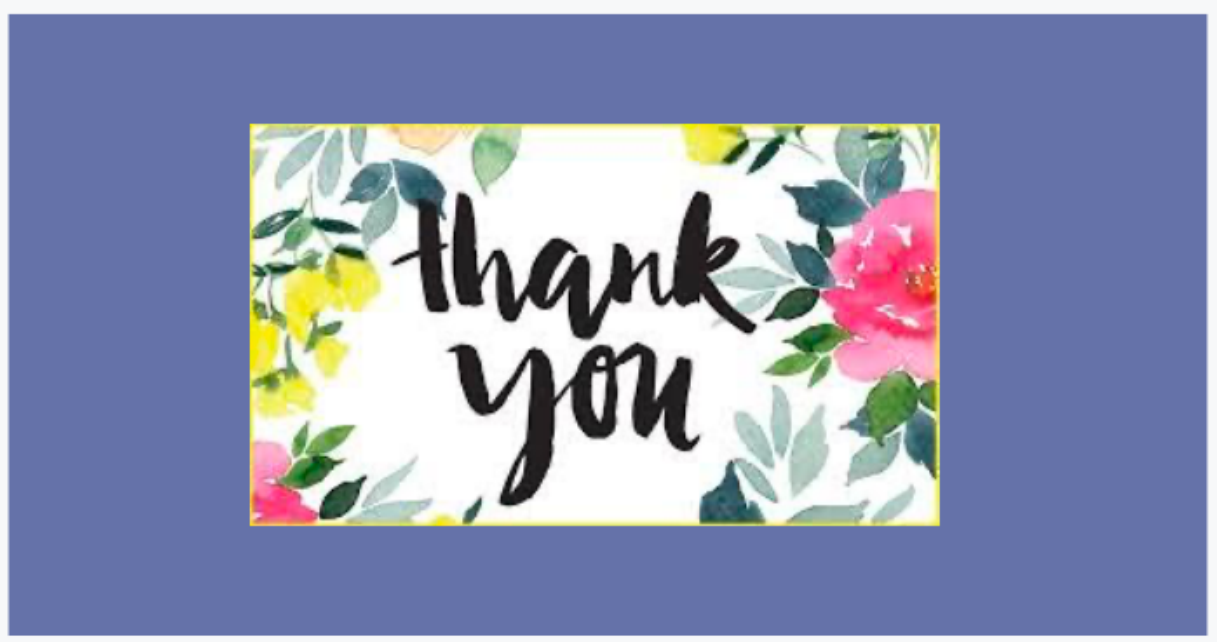

PAGE 36 


\section{TOOLS FOR VOLUNTEERS: CLIENT PROFILE OVERVIEW}

The licensed occupational therapist at the skilled nursing facility will use information about the resident with dementia gathered from the occupational profile, assessments completed with the resident, and activity prescriptions to guide the creation of the client profile card.

The client profile card identifies important resident information, such as the resident's stage of dementia, sensory likes and dislikes, supportive strategies, strengths, challenges, recommended conversation topics, recommended activities, and favorite songs.

The volunteer can use the client profile for their visits with residents with dementia, as this information allows the volunteer to understand the resident on a more personal level and facilitate more meaningful visits 


\section{Heart to Heart Volunteer Client Profile}

Initials:

Room \#

Preferred Name:

Stage of Dementia (ACL and stage):

Responds well to:

口 Sight:

口 Touch:

口 Sound:

口 Smell:

To complete activities, client may benefit from:
- Verbal instructions
口 Text (list, labels)
$\square$ Gestures
$\square$ Modeling
口 Physical help

$\square$ Other:

Strengths:

Challenges:

Conversation topics of interest:

Activities of interest:

Completed by:

Date: 


\section{TOOLS FOR VOLUNTEERS: ACTIVITY BOX OVERVIEW}

The activity boxes are designed to provide the volunteers with tools and structure to

facilitate activities and meaningful communication for residents with dementia.

The activity boxes will contain various games, activities, objects, as well as instructions for suggested use of contents

based on the resident's abilities and interests. The aim of providing these organized activity boxes to volunteers during their visits with IwD is to increase the volunteer's confidence in engaging with IwD, and to promote meaningful interactions during the visits. All of the contents of the activity box will be made accessible and replicable in order to create multiple boxes, and for continued use by the activities director in skilled nursing facilities. 


\title{
ACTIVITY BOX CONTENTS
}

\author{
Balloons \\ Deck of Cards \\ Jigsaw Puzzle \\ Flameless Candles \\ Essential Oil Diffuser \\ Lavender Essential Oil \\ Jewelry Making (Cord \& Beads) \\ Water Paint Book \& Paint Brushes \\ Artificial Flower Bouquet \& Plastic Vases
}




\section{ACTIVITY BOX CONTENTS: PHOTO}

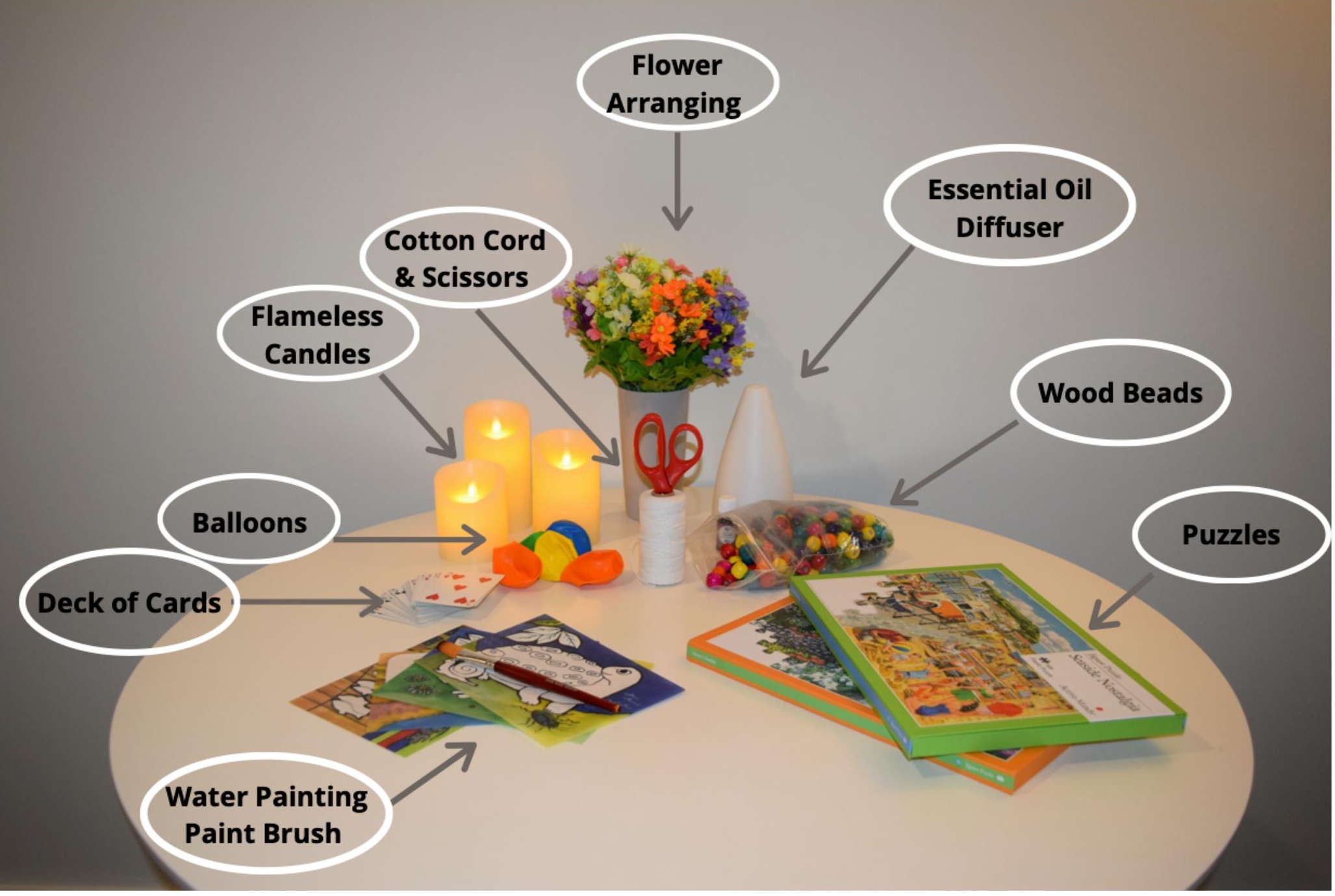




\section{$\because \because 0$

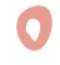 \\ $0: 0$}
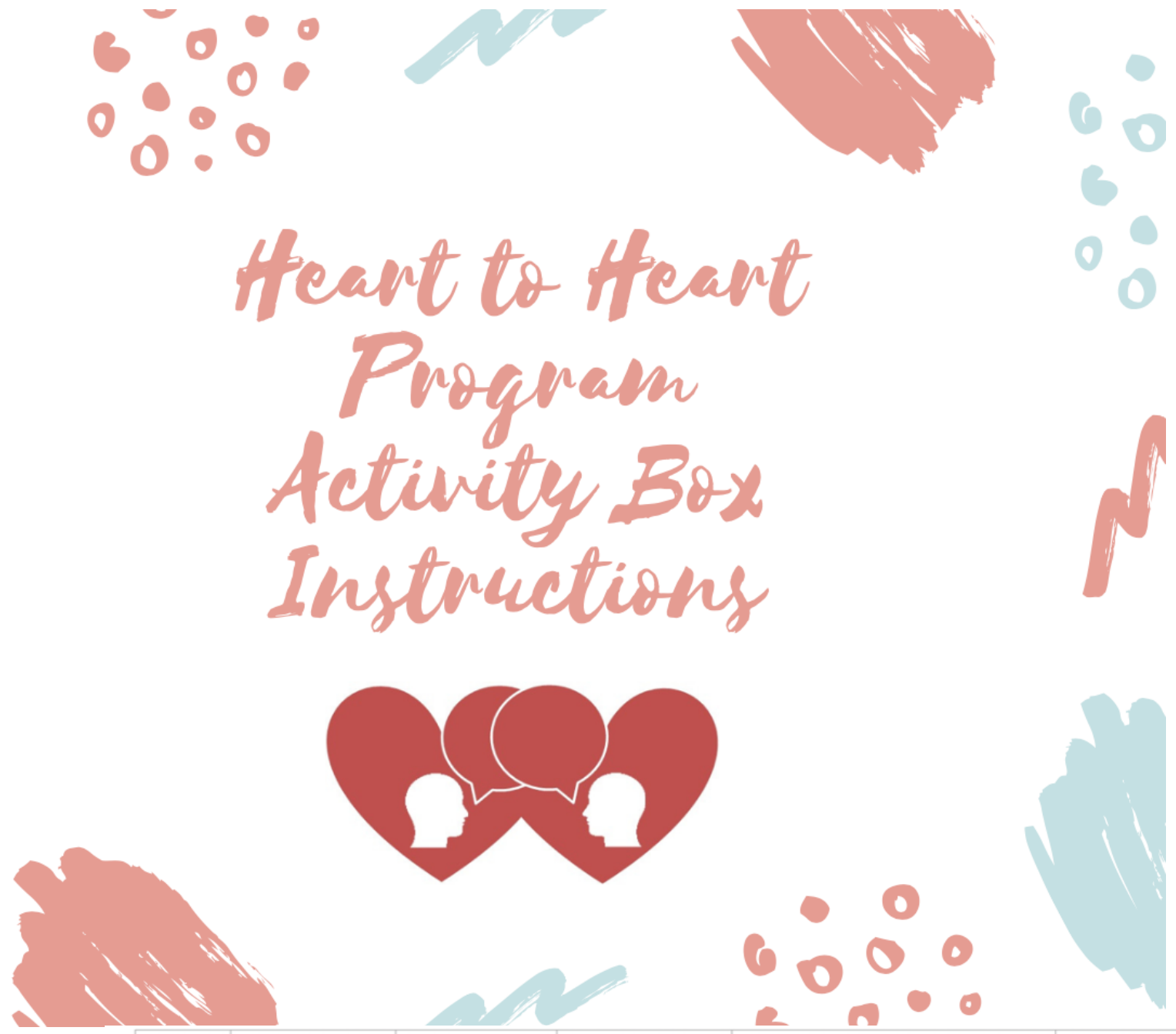

\begin{tabular}{|c|c|c|c|c|}
\hline & Activity & Materials & Description & Modifications for Early Stage \\
\hline Number One & Flower Arranging & $\begin{array}{l}\text { Artificial flowers and } 2 \\
\text { vases (one for resident, one } \\
\text { for volunteer). }\end{array}$ & $\begin{array}{l}\text { The resident will make flower } \\
\text { arrangements using artificial } \\
\text { flowers and vases for } \\
\text { themselves or for other close } \\
\text { friends. }\end{array}$ & $\begin{array}{l}\text { - Lay out flowers and vase on table in front of } \\
\text { resident. } \\
\text { Give resident up to } 3 \text { step instructions for } \\
\text { engaging in activity. } \\
\text { - Example of using } 3 \text { step instructions: "Grab the } \\
\text { gray cup, pick out the flowers you like, and put } \\
\text { the flowers in the cup." }\end{array}$ \\
\hline Number Two & Jewelry Making & $\begin{array}{l}\text { Cotton string, wooden } \\
\text { beads, and scissors }\end{array}$ & $\begin{array}{l}\text { The resident will make a piece } \\
\text { of jewelry of their choosing } \\
\text { using beads and string. }\end{array}$ & $\begin{array}{l}\text { Set up materials on table in front of resident. } \\
\text { Give clear, } 1-3 \text { step instructions for engaging in } \\
\text { the activity. } \\
\text { Example of using } 1 \text { step instructions at a time: } \\
\text { "Pick out } 3 \text { beads you like." (Resident follows } \\
\text { direction). } \\
\text { Example of next instruction: "Now pick out a long } \\
\text { string, or a short string." }\end{array}$ \\
\hline Number Three & Balloon Toss & Balloons & $\begin{array}{l}\text { The volunteer will blow up the } \\
\text { balloon and tie it The resident } \\
\text { and volunter will pass the } \\
\text { balloon back and forth without } \\
\text { letting it touch the ground. } \\
\text { Keep track or how many times } \\
\text { you pass it back and forth each } \\
\text { round. }\end{array}$ & $\begin{array}{l}\text { If activity is very easy for resident, volunteer can add in } \\
\text { more balloons, increasing the complexity of the activity. }\end{array}$ \\
\hline Number Four & Puzzles & Puzzle pieces & $\begin{array}{l}\text { The volunteer and the resident } \\
\text { will put the puzzle together. }\end{array}$ & $\begin{array}{l}\text { Separate the purzle into colors and sections and only work } \\
\text { on one section at a time. }\end{array}$ \\
\hline Number Five & Card Games & Deck of Cards & $\begin{array}{l}\text { The volunteer and the resident } \\
\text { will play simple and familiar } \\
\text { card games (ie: go fish, war, } \\
\text { gin rummy). }\end{array}$ & $\begin{array}{l}\text { Volunteer can utilize simplified instructions to describe } \\
\text { rules of card game. }\end{array}$ \\
\hline Number Six & $\begin{array}{l}\text { Painting Pictures using } \\
\text { Water Brush }\end{array}$ & $\begin{array}{l}\text { Paper cup, water, painting } \\
\text { picture and brush from kit }\end{array}$ & $\begin{array}{l}\text { The volunteer and resident will } \\
\text { use a wet paint brush to paint } \\
\text { the preferered water painting } \\
\text { card (Each card is reusable, } \\
\text { and only requiries watet to } \\
\text { make the colorful picture } \\
\text { appear). }\end{array}$ & $\begin{array}{l}\text { - Volunteer can verbally instruct resident how to } \\
\text { paint the picture using using } 1.3 \text { step instructions. } \\
\text { - Example of using } 3 \text { step instructions: "Pick out the } \\
\text { picture you would like to paint, pick out a paint } \\
\text { brushh then dip the paint brush in the water to start } \\
\text { painting." }\end{array}$ \\
\hline $\begin{array}{l}\text { Number Seven } \\
\text { Part A }\end{array}$ & Flameless Candles & Flameless candles & $\begin{array}{l}\text { Use of flameless candles } \\
\text { during visiting sessions to } \\
\text { provide an enhanced sensory } \\
\text { experience. }\end{array}$ & $\begin{array}{l}\text { Volunteer can verbally instruct resident how to } \\
\text { turn on and off flameless candle using } 1-3 \text { step } \\
\text { directions. } \\
\text { Resident can be in charge of turning on and off the } \\
\text { candles for each session, if they desire. }\end{array}$ \\
\hline $\begin{array}{l}\text { Number Seven } \\
\text { Part B }\end{array}$ & Essential On Diffuser & $\begin{array}{l}\text { Essential oil diffuser and } \\
\text { essential oil }\end{array}$ & $\begin{array}{l}\text { Use of essential oil diffuser } \\
\text { during visiting sessions to } \\
\text { provide an enhanced sensory } \\
\text { experience. }\end{array}$ & $\begin{array}{l}\text { - Volunteer demonstrate how to set up the diffuse } \\
\text { before allowing resident to participate. } \\
\text { Resident can be in charge of adding water and } \\
\text { essential oil to diffuser, and turning on and off the } \\
\text { diffuser for each session, if desired. }\end{array}$ \\
\hline
\end{tabular}

for Middle Stage

- Position self and flowers $14-18$ inches in front of
resident

- Create a display of the flower arrangement.

able in front of

resident.
Use 1 step instructions at a time.

Example of using 1 step directions: "Pick a
flower." (Once resident has picked a flower, give next

step).
Example of next instruction: "Put flower in Example of nex
vase." (Repeat).

- Only give the resident $1-2$ of beads at a time resident to pick up the beads they want for their mecklase or bracele, then volunteer can instruct

Have resident place the balloon into your ha Volunteer can simply hit the balloon in the air to keep

- Separate the puzzle into sections and only work on Directly hand 2 or more puzzle pieces to the resident
that will fit together, and have the resident put the

Wlunteer sits 14-18 inches in front of resident, and utilize I ep directions, and other cues to help resident understand

Help resident by demonstrating how to paint the

Volunter use 1 step directions at a time.

Volunteer demonstrate visually how to turn on and of using 1 step verbal directions to describe steps. Resident can turn on the candles for use during
session, and turn off at the end of the session.

Volunteer demonstrates visually how to add water
and essential oil to the diffuser, while using 1 step directions to describe each step.
Volunteer demonstrates visually how to turn on and action.
Resident can turn on the candles for use during 


\section{TOOLS FOR VOLUNTEERS: VOLUNTEER HANDBOOK OVERVIEW}

The Heart to Heart Dementia Volunteer Program Handbook is designed to be an easy and accessible tool for volunteers to utilize. Within the handbook are helpful, concise tips for communication with individuals with dementia, broken down by the specific stages.

This handbook was created thoughtfully to enhance the volunteer's confidence when they need additional support during sessions with volunteers. The content outlines stage-specific strengths and challenges, as well as tips for meaningful communication and activities with the resident. 


\title{
Heart to Heart
}

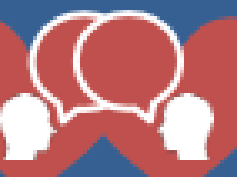 \\ DEMENTIA \\ VOLUNTEER PROGRAM \\ HANDBOOK
}




\section{TABLE OF CONTENTS}

TIPS TO COMMUNICATE WITH IWD.

2

WAYS TO HELP YOUR RESIDENT COMPLETE ACTIVITIES

EARLY STAGE DEMENTIA STRENGTHS, CHALLENGES, TIPS

EARLY STAGE DEMENTIA ACTIVITY ADAPTATION EXAMPLE

MIDDLE STAGE DEMENTIA STRENGTHS, CHALLENGES, TIPS.

MIDDLE STAGE DEMENTIA ACTIVITY ADAPTATION EXAMPLE 


\section{WAYS TO HELP YOUR RESIDENT COMPLETEACTIVITIES}

\section{VERBAL CUES}

\begin{tabular}{|c|c|}
\hline Direct & Indirect \\
\hline $\begin{array}{c}\text { Provide simple instructions for resident to } \\
\text { complete an activity. } \\
\text { "Put the flower in the vase." }\end{array}$ & $\begin{array}{c}\text { Ask questions or provide simple choices to allow } \\
\text { the resident to problem solve through an activity. } \\
\text { "Does the flower go in the vase or in the cup?" }\end{array}$ \\
\hline
\end{tabular}

\section{VISUAL CUES}

\begin{tabular}{|c|c|c|}
\hline Environmental & Gestural & Demonstration \\
\hline $\begin{array}{c}\text { Use pictures, labels, lists, } \\
\text { checklists, or visible objects to } \\
\text { help the resident understand } \\
\text { what to do and locate items. }\end{array}$ & $\begin{array}{c}\text { Point or gesture to help the } \\
\text { resident locate objects or a } \\
\text { destination. }\end{array}$ & $\begin{array}{c}\text { Model how to complete a task } \\
\text { by doing it, for the resident to } \\
\text { imitate. }\end{array}$ \\
\hline
\end{tabular}

\section{PHYSICAL CUES}

\begin{tabular}{|c|c|c|}
\hline Touch Body Part & Hand Over/Under Hand & Guiding \\
\hline $\begin{array}{c}\text { Touch a body part to gain the } \\
\text { resident's attention. }\end{array}$ & $\begin{array}{l}\text { Place your hand over the } \\
\text { resident's hand to guide } \\
\text { movement or provide } \\
\text { comforting touch. }\end{array}$ & $\begin{array}{l}\text { Move the resident's body to } \\
\text { help them complete a task. }\end{array}$ \\
\hline
\end{tabular}

\section{CONTEXTUAL-Sensory Bridging}

Complete activities in familiar environments and the same environment across visits 


\section{EARLY STAGE DEMENTIA - ACL 4 Strengths, Challenges, and Tips}

\section{STRENGTHS - EARLY STAGE}

Individuals at early stage dementia may:

- speak clearly and have conversations

- complete familiar and simple activities with supplies in sight and a model

- function well with routine and old habits

- maintain attention for 20-60 minutes

- pay attention to people and things within 3-4 feet in front of them

- learn new information with rebetition

\section{CHALLENGES - EARLY STAGE}

Individuals at early stage dementia may have difficulty with:

- solving problems

- demonstrating safety

- compromising

- recalling short-term memory

- making appropriate judgement

- learning new skills

- completing complex activities

\section{TIPS FOR FACILITATING ACTIVITIES AT EARLY STAGE}

- Use familiar objects and activities

- Provide instructions 1-3 steps at a time

- Demonstrate or provide a model or sample for activities

- Repeat activities to allow for learning of new skills

- Reminisce about favorite conversation

\section{SUGGESTED ACTIVITIES AT EARLY STAGE}
Bingo
Painting
Sewing
Crosswords
Gardening

\author{
Basic card games \\ Coloring \\ Knitting \\ Word finds \\ Balloon volleyball
}

\author{
Crafts \\ Drawing \\ Crocheting \\ Puzzles
}

See the next page for an example of an adapted craft activity! 


\section{EARLY STAGE DEMENTIA - ACL 4 Activity Adaptation Example for Jewelry Making}

In the Heart to Heart Activity Box, you will find materials and instructions to facilitate jewelry making.

Materials include:

- Cotton string

- Wooden beads

- Scissors

Tips to set up, adapt, and facilitate jewelry making for early stage dementia:

- Set up the materials on the table in front of the resident.

- Provide clear instructions 1-3 steps at a time. For example.

- Say. "Pick out 3 beads."

- Say. "Pick up the string."

- Say, "Cut the string this long," while providing a gestural cue.

- Demonstrate how to string the bead.

- Provide a model of a completed jewelry piece.

- Talk about a conversation topic from the resident's client profile.

- Repeat the activity across several visits to encourage the resident's learning. 


\section{MIDDLE STAGE DEMENTIA - ACL 3 Strengths, Challenges, and Tips}

\section{STRENGTHS - MIDDLE STAGE}

Individuals at middle stage dementia may:

- pick up, reach for, and let go of objects

- walk or move their wheelchair

- complete familiar activities with cues for what to do next and assistance (verbal, visual, or touch)

- maintain attention for 5-20 minutes

- pay attention to people and things within 14-18 inches in front of them

\section{CHALLENGES - MIDDLE STAGE}

Individuals at middle stage dementia may have difficulty with:

- knowing what to do with objects

- recognizing mistakes, problem solving, or asking for help

- remembering

- learning new things

- feeling confused or fearful

- knowing what to do next

- communicating their wants and needs

- understanding what to do next

\section{TIPS FOR FACILITATING ACTIVITIES AT MIDDLE STAGE}

- Position self and objects $14-18$ inches in front of the resident

- Use familiar objects and activities

- Provide instructions 1 step at a time

- Provide verbal, visual, or touch cues to help the resident complete activities

- Gain the resident's attention with a variety of stimulating sights, sounds, touch, or smells

- Reduce distractions in the environment

\section{SUGGESTED ACTIVITIES AT MIDDLE STAGE}
Music
Wiping/polishing
Sorting objects in/out of containers
Large puzzles
Clay/dough kneading
Singing
Balloon toss
Basic Crafts
Coloring

Playing instruments
Sanding
Building blocks
Painting
Sewing cards

See the next page for an example of an adapted puzzle activity! 


\section{MIDDLE STAGE DEMENTIA - ACL 3 Activity Adaptation Example for Puzzles}

In the Heart to Heart Activity Box, you will find materials and instructions to facilitate puzzles.

\section{Materials include:}

- Puzzle pieces

Tips to set up, adapt, and facilitate puzzles for middle stage dementia:

- Set up the materials on the table in front of the resident.

- Removeall unnecessary items or distractions in the environment, if possible.

- Gain the resident's attention by touching their body part and speaking about $14-18$ inches in front.

- Separate the puzzles into sections and only work on one section at a time.

- Provide clear instructions 1 step at a time. For example.

- Say, "Pick up this piece," while pointing at the piece.

- Say, "Put the piece here," while supporting the resident's elbow and moving the resident's hand toward the piece.

- Directly hand the resident two pieces that will fit together.

- Play preferred music from the resident's client profile, if applicable.

- Diffuse preferred essential oils from the resident's profile, if applicable. 


\section{SATISFACTION SURVEYS: DESCRIPTION}

To evaluate the effectiveness of Heart to Heart, volunteers will complete a questionnaire with Likert Scale questions, as well as questions regarding knowledge and beliefs about dementia before completing their volunteer training (in-person and online). The volunteers will complete the same survey at the commencement of their final visit with the residents in Heart to Heart. The scale will evaluate volunteer satisfaction, comfort, confidence, and knowledge of dementia. Scores from pre-and post-training will be compared to determine the effectiveness of the program on improving volunteer knowledge, ease, and competency in engaging with residents with dementia.

The questionnaire addresses knowledge of dementia and attitudes towards dementia. Nine questions in a Likert Scale will determine the volunteer's knowledge of dementia.

Surveys can be accessed online, or the program facilitator may wish to provide physical copies to the volunteers.

Link for the online version of survey to be administered before volunteers complete training:

https://forms.gle/533MMGj8cxUNpdaX7

Link for the online version of survey to be administered after their final visit of the program:

https://forms.gle/8oH5NeABCPCKOSES9 


\section{Heart to Heart Program Survey}

Thank you for participating in the Heart to Heart volunteer program!

Heart to Heart is a program designed to provide volunteers with sufficient knowledge about dementia in order to promote effective communication strategies and meaningful interactions between volunteers and individuals with dementia. The primary aim of this program is to facilitate feelings of confidence in volunteers to promote frequency of visits, thus enhancing the quality of life and decreasing social isolation for IwD.

Heart to Heart has been created by four occupational therapy students at Dominican University of California with the guidance of Dr. Gina Tucker-Roghi, OTD, OTR/L.

The survey should not take longer than 15 minutes.

Information gathered from this survey is solely used for the purpose of improving Heart to Heart volunteer program. We wish to better understand our volunteers, in terms of their knowledge about dementia and their attitude towards individuals with dementia, in order to provide meaningful support throughout the program.

If you have any questions or needs assistance, please contact at: heart2heartprogram2020@gmail.com 


\section{Heart to Heart Program Survey}

\section{Dementia Knowledge}

Here are some statements about dementia.

Please read each statement carefully and select one to show if you agree or disagree with the statement, or if you do not know. Please fill out every section.

Adapted from: Toye, C., Lester, L., Popescu, A., Mcinerney, F., Andrews, S., \& Robinson, A. L. (2013). Dementia Knowledge Assessment Tool Version Two: Development of a tool to inform preparation for care planning and delivery in families and care staff. Dementia, 13(2), 248-256. doi: 10.1177/1471301212471960

Dementia occurs because of changes in the brain.

$\square$ Yes $\square$ No $\square$ I don't know

Brain changes causing dementia are often progressive.

$\square$ Yes $\square$ No $\square$ I don't know

Confusion in an older person is almost always due to dementia.

$\square$ Yes $\square$ No $\square$ I don't know

Only older adults develop dementia.

$\square$ Yes $\square$ No $\square$ I don't know

Dementia is likely to limit life expectancy.

$\square$ Yes $\square$ No $\square$ I don't know

Uncharacteristic distressing behaviors may occur in people who have dementia (e.g., aggressive behavior in a gentle person).

$\square$ Yes $\square$ No $\square$ I don't know

Changing the environment (e.g., putting on a $C D$, opening or closing the blinds) will make no difference to a person who has dementia.

$\square$ Yes $\square$ No $\square$ I don't know

When a person who has dementia is distressed, it may help to talk to them about their feelings.

$\square$ Yes $\square$ No $\square$ I don't know

It is important to always correct a person who has dementia when they are confused.

$\square$ Yes $\square$ No $\square$ I don't know 


\section{Heart to Heart Program Survey}

\section{Attitude towards Dementia}

Please rate each statement according to how much you agree or disagree with it. Mark 1 , $2,3,4$, or 5 , according to how you feel in each case. Please be honest. There are no right or wrong answers.

Adapted from: O'Connor, M. L. \& McFadden, S.H. (2010). Development and Psychometric Validation of the Dementia Attitudes Scale. International Journal of Alzheimer's Disease, 2010, 1-10.https://doi.org/10.4061/2010/454218

I feel confident around individuals with dementia.
$\square 1$
$\square 2$
$\square 3$
$\square 4$
$\square 5$

Strongly disagree

Strongly agree

I am comfortable touching individuals with dementia.
$\square 1$
$\square 2$
$\square 3$
$\square 4$
$\square 5$

Strongly disagree

Strongly agree

I feel uncomfortable being around individuals with dementia.
$\square 1$
$\square 2$
$\square 3$
$\square 4$
$\square 5$
Strongly disagree
Strongly agree

I am not very familiar with individuals with dementia.
$\square 1$
$\square 2$
$\square 3$
$\square 4$
$\square 5$

Strongly disagree

Strongly agree

I would avoid an agitated individual with dementia.
$\square 1$
$\square 2$
$\square 3$
$\square 4$
$\square 5$

Strongly disagree

Strongly agree

I feel relaxed around individuals with dementia.
$\square 1$
$\square 2$
$\square 3$
$\square 4$
$\square 5$
Strongly disagree
Strongly agree

I feel frustrated because I don't know how to help an individual with dementia.
$\square 1$
$\square 2$
$\square 3$
$\square 4$
$\square 5$
Strongly disagree
Strongly agree 


\section{Heart to Heart Program Survey}

It is rewarding to work with individuals with dementia.
$\square 1$
$\square 2$
$\square 3$
$\square 4$
$\square 5$

Strongly disagree

Strongly agree

I cannot imagine caring for someone with dementia.
$\square 1$
$\square 2$
$\square 3$
$\square 4$
$\square 5$

Strongly disagree

Strongly agree

I am afraid of individuals with dementia.
$\square 1$
$\square 2$
$\square 3$
$\square 4$
$\square 5$

Strongly disagree

Strongly agree

Individuals with dementia can be creative.
$\square 1$
$\square 2$
$\square 3$
$\square 4$
$\square 5$

Strongly disagree

Strongly agree

Every person with dementia has different needs.
$\square 1$
$\square 2$
$\square 3$
$\square 4$
$\square 5$

Strongly disagree

Strongly agree

Individuals with dementia like having familiar things nearby.
$\square 1$
$\square 2$
$\square 3$
$\square 4$
$\square 5$
Strongly disagree
Strongly agree

It is important to know the past history of the individuals with dementia.
$\square 1$
$\square 2$
$\square 3$
$\square 4$
$\square 5$
Strongly disagree
Strongly agree

It is possible to enjoy interacting with individuals with dementia.
$\square 1$
$\square 2$
$\square 3$
$\square 4$
$\square 5$
Strongly disagree
Strongly agree

Individuals with dementia can enjoy life.
$\square 1$
$\square 2$
$\square 3$
$\square 4$
$\square 5$
Strongly disagree
Strongly agree 


\section{Heart to Heart Program Survey}

Individuals with dementia can feel when others are kind to them.
$\square 1$
$\square 2$
$\square 3$
$\square 4$
$\square 5$

Strongly disagree

Strongly agree

We can do a lot now to improve the lives of individuals with dementia.
$\square 1$
$\square 2$
$\square 3$
$\square 4$
$\square 5$
Strongly disagree
Strongly agree

I admire the coping skills of individuals with dementia.
$\square 1$
$\square 2$
$\square 3$
$\square 4$
$\square 5$
Strongly disagree
Strongly agree

Difficult behaviors may be a form of communication for individuals with dementia.
$\square 1$
$\square 2$
$\square 3$
$\square 4$
$\square 5$
Strongly disagree
Strongly agree 


\section{Heart to Heart Program Survey}

Thank you for participating in the Heart to Heart volunteer program!

Heart to Heart is a program designed to provide volunteers with sufficient knowledge about dementia in order to promote effective communication strategies and meaningful interactions between volunteers and individuals with dementia. The primary aim of this program is to facilitate feelings of confidence in volunteers to promote frequency of visits, thus enhancing the quality of life and decreasing social isolation for IwD.

Heart to Heart has been created by four occupational therapy students at Dominican University of California with the guidance of Dr. Gina Tucker-Roghi, OTD, OTR/L.

The survey should not take longer than 25 minutes.

Information gathered from this survey is solely used for the purpose of improving Heart to Heart volunteer program. We wish to better understand our volunteers, in terms of their knowledge about dementia and their attitude towards individuals with dementia, in order to provide meaningful support throughout the program.

If you have any questions or needs assistance, please contact at:

heart2heartprogram2020@gmail.com 


\section{Heart to Heart Program Survey}

\section{Dementia Knowledge}

Here are some statements about dementia.

Please read each statement carefully and select one to show if you agree or disagree with the statement, or if you do not know. Please fill out every section.

Adapted from: Toye, C., Lester, L., Popescu, A., Mcinerney, F., Andrews, S., \& Robinson, A. L. (2013). Dementia Knowledge Assessment Tool Version Two: Development of a tool to inform preparation for care planning and delivery in families and care staff. Dementia, 13(2), 248-256. doi: 10.1177/1471301212471960

Dementia occurs because of changes in the brain.

$\square$ Yes $\square$ No $\square$ I don't know

Brain changes causing dementia are often progressive.

$\square$ Yes $\square$ No $\square$ I don't know

Confusion in an older person is almost always due to dementia.

$\square$ Yes $\square$ No $\square$ I don't know

Only older adults develop dementia.

$\square$ Yes $\square$ No $\square$ I don't know

Dementia is likely to limit life expectancy.

$\square$ Yes $\square$ No $\square$ I don't know

Uncharacteristic distressing behaviors may occur in people who have dementia (e.g., aggressive behavior in a gentle person).

$\square$ Yes $\square$ No $\square$ I don't know

Changing the environment (e.g., putting on a $C D$, opening or closing the blinds) will make no difference to a person who has dementia.

$\square$ Yes $\square$ No $\square$ I don't know

When a person who has dementia is distressed, it may help to talk to them about their feelings.

$\square$ Yes $\square$ No $\square$ I don't know

It is important to always correct a person who has dementia when they are confused.

$\square$ Yes $\square$ No $\square$ I don't know 


\section{Heart to Heart Program Survey}

\section{Attitude towards Dementia}

Please rate each statement according to how much you agree or disagree with it. Mark 1, $2,3,4$, or 5 , according to how you feel in each case. Please be honest. There are no right or wrong answers.

Adapted from: O'Connor, M. L. \& McFadden, S.H. (2010). Development and Psychometric Validation of the Dementia Attitudes Scale. International Journal of Alzheimer's Disease, 2010, 1-10._https://doi.org/10.4061/2010/454218

I feel confident around individuals with dementia.
$\square 1$
$\square 2$
$\square 3$
$\square 4$
$\square 5$

Strongly disagree $\quad$ Strongly agree

I am comfortable touching individuals with dementia.
$\square 1$
$\square 2$
$\square 3$
$\square 4$
$\square 5$

Strongly disagree

Strongly agree

I feel uncomfortable being around individuals with dementia.
$\square 1$
$\square 2$
$\square 3$
$\square 4$
$\square 5$
Strongly disagree
Strongly agree

I am not very familiar with individuals with dementia.
$\square 1$
$\square 2$
$\square 3$
$\square 4$
$\square 5$

$\begin{array}{ll}\text { Strongly disagree } & \text { Strongly agree }\end{array}$

I would avoid an agitated individual with dementia.
$\square 1$
$\square 2$
$\square 3$
$\square 4$
$\square 5$

Strongly disagree

Strongly agree

I feel relaxed around individuals with dementia.
$\square 1$
$\square 2$
$\square 3$
$\square 4$
$\square 5$
Strongly disagree
Strongly agree

I feel frustrated because I don't know how to help an individual with dementia.
$\square 1$
$\square 2$
$\square 3$
$\square 4$
$\square 5$
Strongly disagree
Strongly agree 


\section{Heart to Heart Program Survey}

It is rewarding to work with individuals with dementia.
$\square 1$
$\square 2$
$\square 3$
$\square 4$
$\square 5$

Strongly disagree

Strongly agree

I cannot imagine caring for someone with dementia.
$\square 1$
$\square 2$
$\square 3$
$\square 4$
$\square 5$

Strongly disagree

Strongly agree

I am afraid of individuals with dementia.
$\square 1$
$\square 2$
$\square 3$
$\square 4$
$\square 5$

Strongly disagree

Strongly agree

Individuals with dementia can be creative.
$\square 1$
$\square 2$
$\square 3$
$\square 4$
$\square 5$

Strongly disagree

Strongly agree

Every person with dementia has different needs.
$\square 1$
$\square 2$
$\square 3$
$\square 4$
$\square 5$
Strongly disagree
Strongly agree

Individuals with dementia like having familiar things nearby.
$\square 1$
$\square 2$
$\square 3$
$\square 4$
$\square 5$
Strongly disagree
Strongly agree

It is important to know the past history of the individuals with dementia.
$\square 1$
$\square 2$
$\square 3$
$\square 4$
$\square 5$
Strongly disagree
Strongly agree

It is possible to enjoy interacting with individuals with dementia.
$\square 1$
$\square 2$
$\square 3$
$\square 4$
$\square 5$
Strongly disagree
Strongly agree

Individuals with dementia can enjoy life.
$\square 1$
$\square 2$
口 3
$\square 4$
$\square 5$
Strongly disagree
Strongly agree 


\section{Heart to Heart Program Survey}

Individuals with dementia can feel when others are kind to them.
$\square 1$
$\square 2$
$\square 3$
$\square 4$
$\square 5$

Strongly disagree

Strongly agree

We can do a lot now to improve the lives of individuals with dementia.
$\square 1$
$\square 2$
$\square 3$
$\square 4$
$\square 5$

Strongly disagree

Strongly agree

I admire the coping skills of individuals with dementia.
$\square 1$
$\square 2$
$\square 3$
$\square 4$
$\square 5$
Strongly disagree
Strongly agree

Difficult behaviors may be a form of communication for individuals with dementia.
$\square 1$
$\square 2$
3
$\square 4$
$\square 5$
Strongly disagree
Strongly agree 


\section{Heart to Heart Program Survey}

\section{Volunteer Satisfaction}

Please rate each statement according to how much you agree or disagree with it. Mark 1 , $2,3,4$, or 5 , according to how you feel in each case. Please be honest. There are no right or wrong answers.

Overall, I am satisfied with the Heart to Heart volunteer program at Summerfield.
1
$\square 2$
3
$\square 4$
5

Strongly disagree

Strongly agree

I received the information I needed regarding my volunteer role.
1
$\square 2$
$\square 3$
$\square 4$
$\square 5$
Strongly disagree
Strongly agree

My volunteer job description accurately reflects what I am asked to do.
1
$\square 2$
3
$\square 4$
5
Strongly disagree
Strongly agree

I received the training I needed to perform my volunteer job duties.
$\square 1 \quad \square 2$
$\square 3$
$\square 4$
5
Strongly disagree
Strongly agree

I felt comfortable interacting with the resident when utilizing the activity box.
$\square 1$
$\square 2$
$\square 3$
$\square 4$
$\square 5$
Strongly disagree
Strongly agree

I know more about dementia after participating in the volunteer program.
$\square 1$
$\square 2$
3
$\square 4$
$\square 5$
Strongly disagree
Strongly agree

I feel more comfortable interacting with individuals with dementia after participation in the volunteer program.
1
$\square 2$
3
$\square 4$
$\square 5$

Strongly disagree

Strongly agree

I will recommend others to participate in the Heart to Heart volunteer program.
1
$\square 2$
口 3
$\square 4$
$\square 5$

Strongly disagree

Strongly agree 


\section{Heart to Heart Program Survey}

\section{Your input helps us!}

We want to know your experience while volunteering with Heart to Heart.

Please feel free to leave feedback to help improve this program for future volunteers.

What are things you enjoyed about the Heart to Heart program?

Are there any suggestions you have for improvements to the Heart to Heart program for future volunteers? 


\section{SATISFACTION SURVEYS: SCORING}

Scores from pre- and post-volunteer surveys should be compared to determine the program's impact on volunteer knowledge, ease, and competency in engaging with residents with dementia.

Instructions for survey scoring sheets can be found within the scoring document. 


\section{Heart to Heart Survey: Scoring sheet}

\section{Dementia Knowledge}

Adapted from: Toye, C., Lester, L., Popescu, A., Mcinerney, F., Andrews, S., \& Robinson, A. L. (2013). Dementia Knowledge Assessment Tool Version Two: Development of a tool to inform preparation for care planning and delivery in families and care staff. Dementia, 13(2), 248-256. doi: $10.1177 / 1471301212471960$

1. Dementia occurs because of changes in the brain.

2. Brain changes causing dementia are often progressive.

3. Confusion in an older person is almost always due to dementia."

4. Only older adults develop dementia.*

5. Dementia is likely to limit life expectancy.

6. Uncharacteristic distressing behaviors may occur in people who have dementia (e.g., aggressive behavior in a gentle person).

7. Changing the environment (e.g., putting on a $\mathrm{CD}$, opening or closing the blinds) will make no difference to a person who has dementia.*

8. When a person who has dementia is distressed, it may help to talk to them about their feelings.

9. It is important to always correct a person who has dementia when they are confused.* Note:* Statement is incorrect, therefore reverse scored.

For this tool, 'Don't know' responses are coded as incorrect. The total number of correct responses are summed to provide an indication of 'foundation level' knowledge of dementia. When providing education sessions, the specific items/ areas addressed by the education are clearly the ones that you would expect to be answered correctly by more people after the education than before.

\section{Attitude towards Dementia}

Adapted from: O'Connor, M. L. \& McFadden, S.H. (2010). Development and Psychometric Validation of the Dementia Attitudes Scale. International Journal of Alzheimer's Disease, 2010, 1-10. https://doi.org/10,4061/2010/454218

1. I feel confident around individuals with dementia.

2. I am comfortable touching individuals with dementia

3. I feel uncomfortable being around individuals with dementia.*

4. I am not very familiar with individuals with dementia.*

5. I would avoid an agitated individual with dementia."

6. I feel relaxed around individuals with dementia.

7. I feel frustrated because I don't know how to help an individual with dementia.*

8 . It is rewarding to work with individuals with dementia.

9. I cannot imagine caring for someone with dementia.* 
10. I am afraid of individuals with dementia.*

11. Individuals with dementia can be creative.

12. Every person with dementia has different needs.

13. Individuals with dementia like having familiar things nearby.

14. It is important to know the past history of the individuals with dementia.

15. It is possible to enjoy interacting with individuals with dementia.

16. Individuals with dementia can enjoy life.

17. Individuals with dementia can feel when others are kind to them.

18. We can do a lot now to improve the lives of individuals with dementia.

19. I admire the coping skills of individuals with dementia.

20. Difficult behaviors may be a form of communication for individuals with dementia.

Note: *Statements are reverse scored.

To arrive at a total score, add up all the items and calculate the average.

\section{Volunteer Satisfaction}

To arrive at a total score, add up all the items and calculate the average.

Open-ended question utilized to gain qualitative reports from the participants 


\section{CONTACT INFORMATION FOR QUESTIONS ABOUT PROGRAM}

For questions regarding the program, please contact Dr. Gina Tucker-Roghi OTD, OTR/L gina.tucker-roghi@dominican.edu 


\section{REFERENCES}

Alzheimer's Association. (2020). Stages of Alzheimer's. Retrieved from https://www.alz.org/alzheimers-dementia/stages

Alzheimer's Association. (2020). Residential Care. Retrieved from https://www.alz.org/help-support/caregiving/care-options/residential-care

Alzheimer's Society. (2019). Tackling loneliness in people living with dementia. Retrieved from alzheimers.org.uk/blog/tackling-loneliness-people-living-dementia |

American Occupational Therapy Association (AOTA). (2014). Occupational Therapy Practice Framework, 3rd Ed., Bethesda, MD: AOTA Press.

Brown, C., and Stoffel, V.C. (2011). Occupational Therapy in Mental Health: a vision for participation. Philadelphia, PA: F.A. Davis

Champagne, T. (2006). The ACL battery. Retrieved from https://www.ot-innovations.com/clinical-practice/cognition-2/the-allen-cognitive-level-ba $\underline{\text { ttery/ }}$

Fazio, S., Pace, D., Kallmyer, B., Maslow, K., \& Zimmerman, S. (2018). Alzheimer's association dementia care practice recommendations. The Gerontologist, 58(S1), S1-S9.

Foebel, A. D., Onder, G., Finne-Soveri, H., Lukas, A., Denkinger, M. D., Carfi, A., . . Liperoti, R. (2016). Physical restraint and antipsychotic medication use among nursing home residents with dementia. Journal of the American Medical Directors Association, 17(2), 184.e9-14. doi:10.1016/j.jamda.2015.11.014

Hurst, A., Coyne, E., Kellett, U., \& Needham, J. (2019). Volunteers motivations and involvement in dementia care in hospitals, aged care and resident homes: An integrative review. Geriatric Nursing. https://doi-org.dominican.idm.oclc.org/10.1016/j.gerinurse.2019.03.010 
Lindman Port, C. (2004). Identifying changeable barriers to family involvement in the nursing home for cognitively impaired residents. Gerontologist, 44(6), 770-778, https://doi.org/10.1093/geront/44.6.770

Ono, K., Kanayama, Y., Iwata, M., \& Yabuwaki, K. (2014). Views on Co-occupation between Elderly Persons with Dementia and Family. Journal of gerontology and geriatric research, 3, 1-6.

Segal, J., \& Robinson, L. (2019). Volunteering and its surprising benefits. Retrieved from https://www.helpguide.org/articles/healthy-living/volunteering-and-its-surprising-benefits .htm?pdf=13391

Stites, S. D., Johnson, R., Harkins, K., Sankar, P., Xie, D., \& Karlawish, J. (2016). Identifiable Characteristics and Potentially Malleable Beliefs Predict Stigmatizing Attributions Toward Persons With Alzheimer's Disease Dementia: Results of a Survey of the U.S. General Public. Health Communication, 33(3), 264-273. doi:

$10.1080 / 10410236.2016 .1255847$

Tina Champagne. (2018). Sensory modulation in dementia care. GB: Jessica Kingsley Publishers. Retrieved from https://ebookcentral.proquest.com/lib/[SITE_ID]/detail.action?docID=5348133 